\title{
Protein Adsorption and Transport in Novel Chromatographic Anion Exchange and Multimodal Resins
}

\author{
A Dissertation \\ Presented to \\ the faculty of the School of Engineering and Applied Science \\ University of Virginia
}

\author{
in partial fulfillment \\ of the requirements for the degree \\ Doctor of Philosophy
}

by

Mimi Zhu

May 2017 


\title{
APPROVAL SHEET
}

\author{
This Dissertation \\ is submitted in partial fulfillment of the requirements \\ for the degree of \\ Doctor of Philosophy
}

Author Signature: Mrven

This Dissertation has been read and approved by the examining committee:

Advisor: Giorgio Carta

Committee Member: Geoffrey Geise

Committee Member: B.Jill Venton

Committee Member: David Green

Committee Member: Steven Caliari

Committee Member:

Accepted for the School of Engineering and Applied Science:

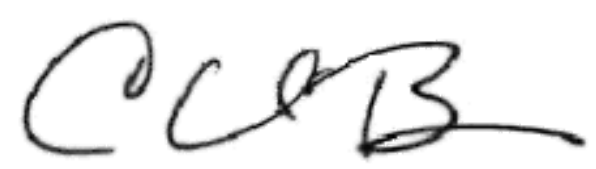

Craig H. Benson, School of Engineering and Applied Science

May 2017 


\begin{abstract}
Understanding the mechanism of protein adsorption and transport and the effects of the stationary phase architecture are critical for the optimum design of chromatographic processes. This work studies the properties of novel stationary phases that are based on a rigid macroporous backbone matrix synthesized with hydrophilic polymers (UNOsphere), which can be functionalized with a variety of ligands. Cationic ligands introduced with a range of grafted polymeric surface extenders as well as multimodal anionic ligands are considered. Both macroscopic and microscopic studies of particle properties, as well as orthogonal measurements of protein adsorption isotherms and kinetics, are used to understand these materials.

Characterizations of anion exchangers with no polymer grafts (UNO Q), moderate graft content (Nuvia HR Q), and high graft content (Nuvia Q) show the pore volume accessible by neutral macromolecules decreases greatly with the grafts content. Higher binding capacities are found for BSA and PEGylated BSA (with $10 \mathrm{kD}$ and $30 \mathrm{kD}$ PEG chain) in polymer grafted adsorbents. The adsorption kinetics of these proteins are also faster in Nuvia HR Q and Nuvia Q, apparently as a result of a solid diffusion mechanism. However, this enhancement in adsorption kinetics depends on the relative size of protein and grafted polymer as well as ionic strength. The adsorption of thyroglobulin on Nuvia HR Q is found to be highly hindered at low ionic strength, but faster kinetics are observed at higher ionic strength.
\end{abstract}

Two resins with multimodal ligands are also studied: Nuvia cPrime, based on the UNOsphere matrix, and Capto MMC, based on an agarose matrix. The two resins have similar multimodal ligand but the pore structures are distinctly different. Equilibrium binding capacities for lysozyme and $(\mathrm{mAb})$ are similar for both resins at comparable $\mathrm{pH}$ and salt concentration, although Capto MMC shows a weaker dependence on salt concentration as a result of its more 
hydrophobic character. The main difference is the binding kinetics of the mAb. The rate of mass transfer is much smaller in Capto MMC at $\mathrm{pH}$ values of 5 or 6 , as a result of the smaller pores and much smaller column dynamic binding capacities are obtained for this resin. 


\section{Acknowledgements}

First and foremost, I would like to express my sincere gratitude to my advisor, Prof. Carta, for his encouragement, guidance, and support throughout my Ph. D study. Thank you for always been so kind and patient.

I would also like to thank my advisory committee members: Prof. Geise, Prof. Venton, Prof. Green and Prof. Caliari, for their helpful inputs and inspiring discussions.

Thanks to Bio-Rad Laboratories for supporting this work and thanks to the following members: Mark Snyder, Jiali Liao and Xuemei He, for their valuable insights relevant to this study.

I also want to thank all past and present members of Carta lab, especially Ernie, Tarl, Yige, Shaojie, Jing, Arch, Jason, Yiran, Andreas, and Preston. Thank you for the help and the great companionship. I had a wonderful time in the lab with you all.

Thanks to Prof. Peri in Keck Center for the help in operating confocal microscopy and thanks to Prof. Guillot in school of medicine for the help in preparing TEM samples.

Finally, I would like to thank my family. To my parents, Xiaoyan Zhu and Feiling Zhang, thank you for loving me all the time, trusting me and letting me pursuing my dream abroad. To my sister, Weiwei Zhu, and to my brother, Zuxin Zhu, thanks for your encouragements. To my wonderful husband, Cheng Yang, thank you for been in my life and going through all these years with me. I love you and I could never have it done without you. 


\section{Table of Contents}

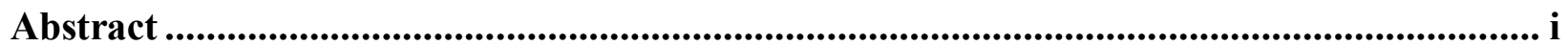

Acknowledgements................................................................................................................................. iii

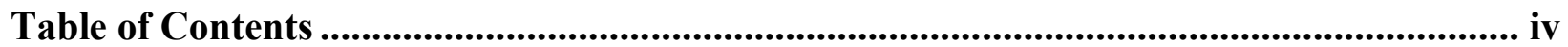

List of Figures............................................................................................................................. vii

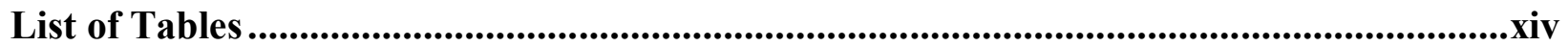

Chapter 1 Motivation and Background .........................................................................................1

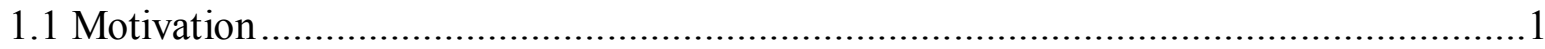

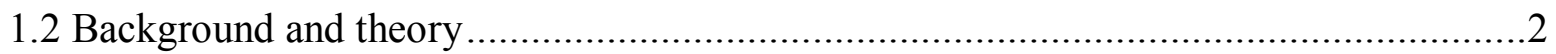

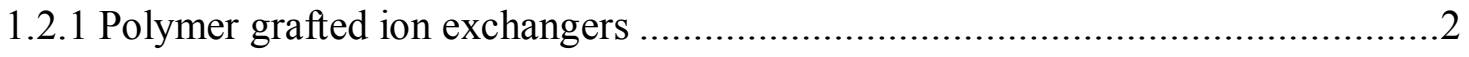

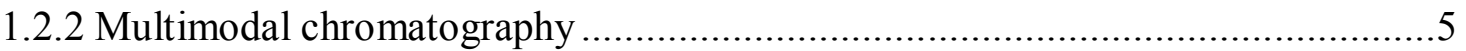

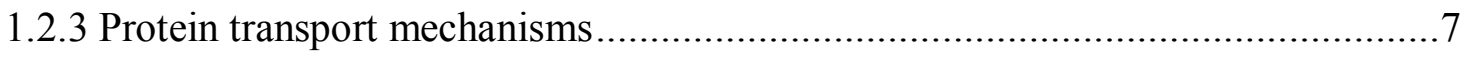

1.3 Specific research goals and objectives ..................................................................

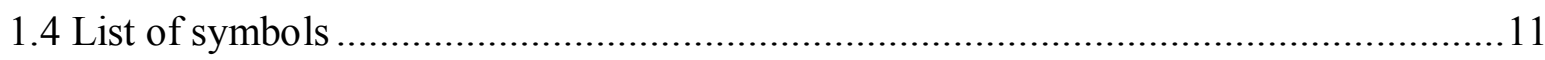

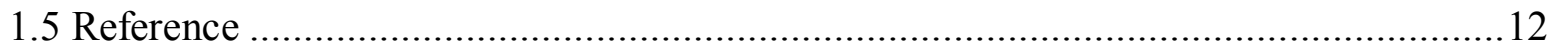

Chapter 2 Structure Characterization of Anion Exchangers with Varying Length of

Polymer Grafting ............................................................................................................................18

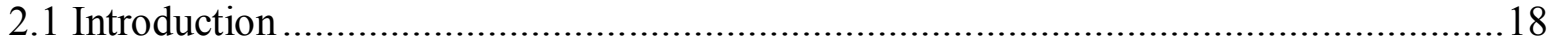

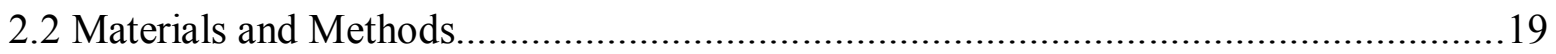

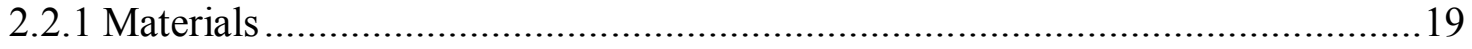

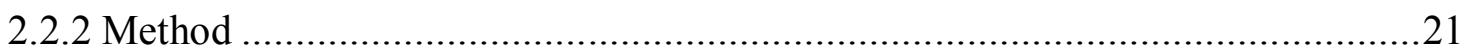

2.2.2.1 Transmission electron microscopy (TEM) ….....................................21

2.2.2.2 Inverse size exclusion chromatography (iSEC) .......................................21 


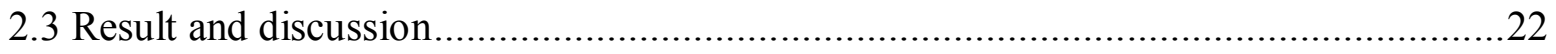

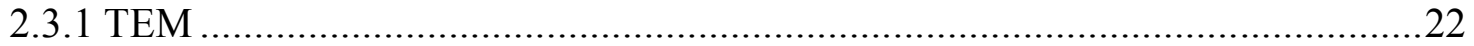

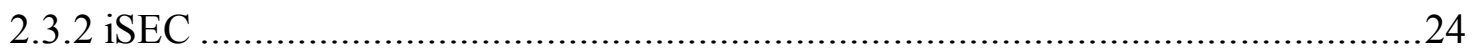

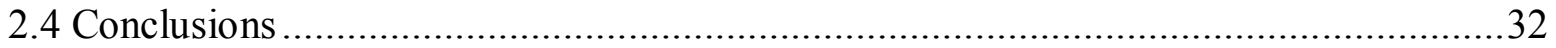

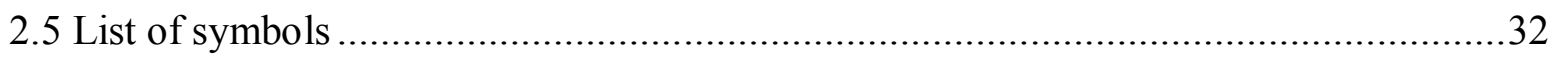

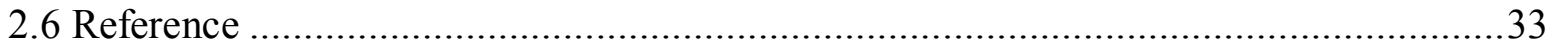

\section{Chapter 3 Adsorption Equilibrium and Transport of Native and PEGylated BSA on Anion}

Exchange Resins with Varying of Polymer Grafting ..................................................................36

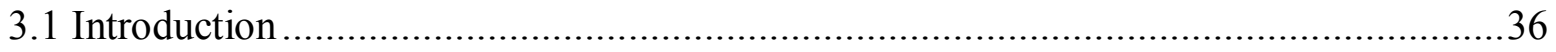

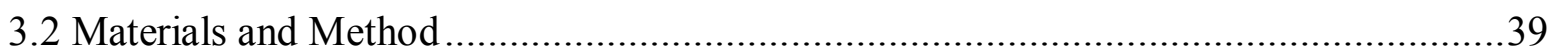

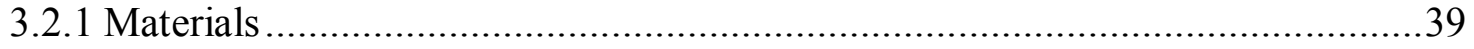

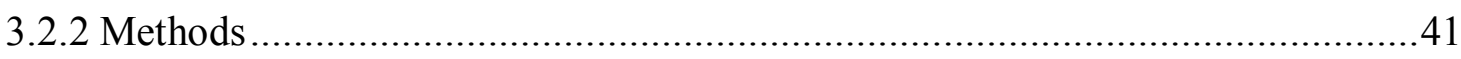

3.2.2.1 PEGylation reactions ........................................................ 41

3.2.2.2 Linear gradient elution........................................................ 41

3.2.2.3 Adsorption isotherms and batch adsorption kinetics..........................42

3.2.2.4 Confocal microscopy .......................................................... 43

3.3 Results and Discussion ...........................................................................4 46

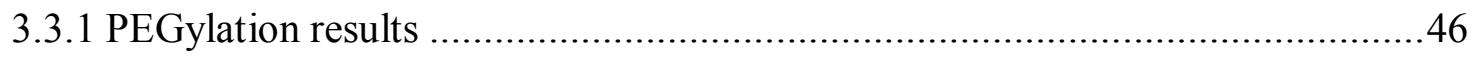

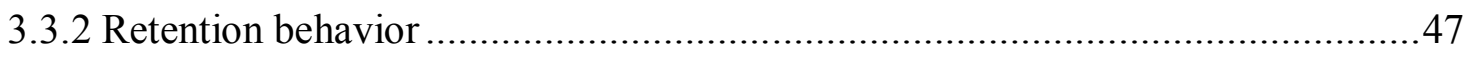

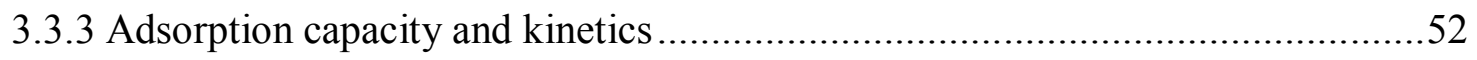

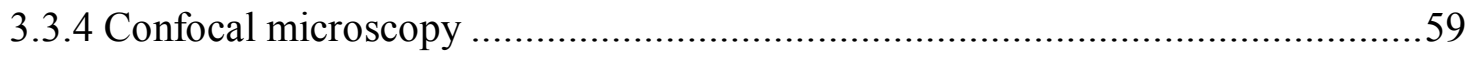

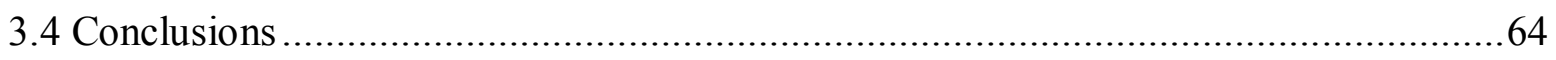

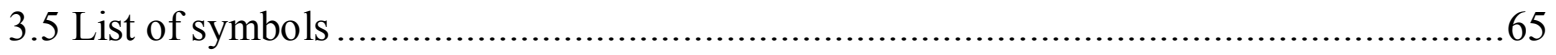


3.6 Reference

\section{Chapter 4 Thyroglobulin Adsorption on Anion Exchange Resins with Varying Grafted}

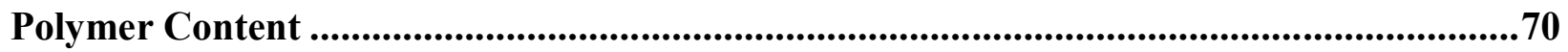

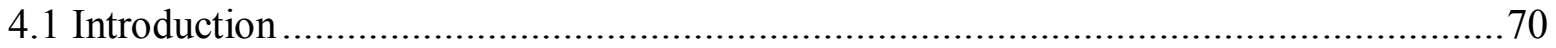

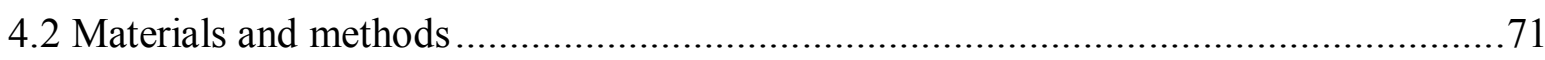

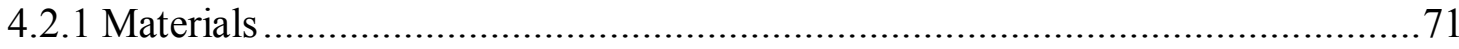

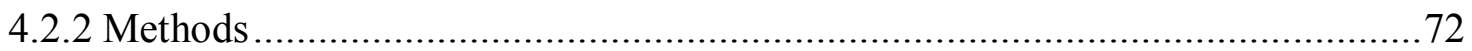

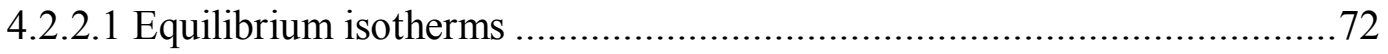

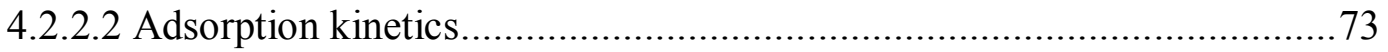

4.2.2.3 Chromatographic analysis for non-binding conditions ............................74

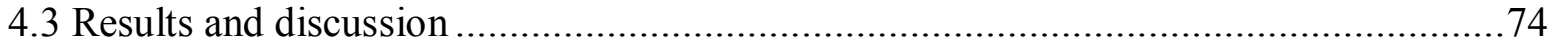

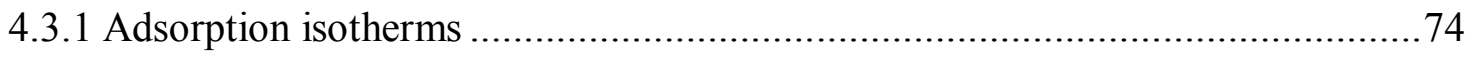

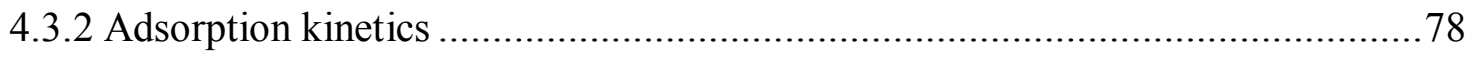

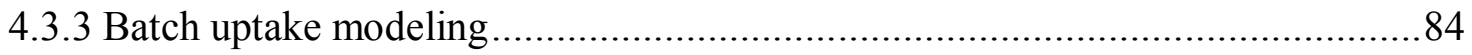

4.3.2 Mass transfer kinetics for non-binding conditions.......................................... 87

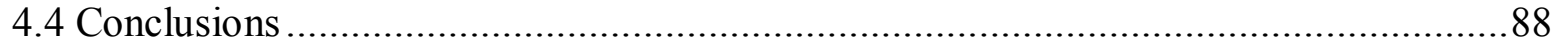

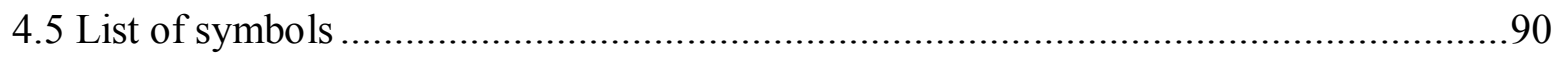

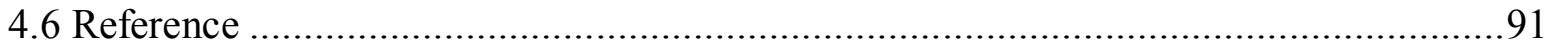

Chapter 5 Protein Adsorption Equilibrium and Kinetics in Multimodal Cation Exchange

Resins

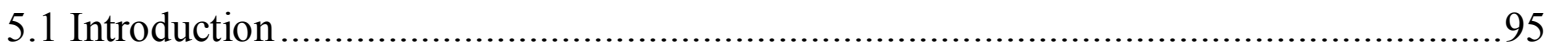

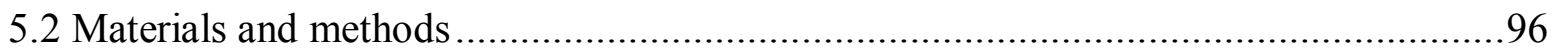

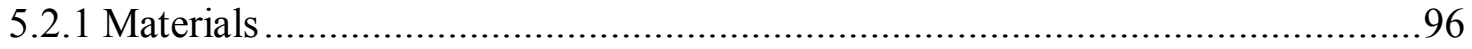


5.2.2 Methods

5.2.2.1 Resin physical and chemical properties...............................................97

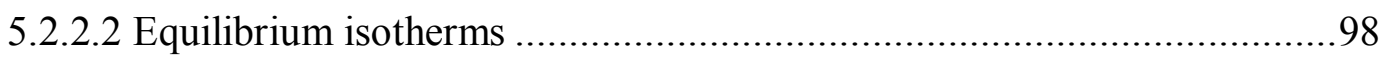

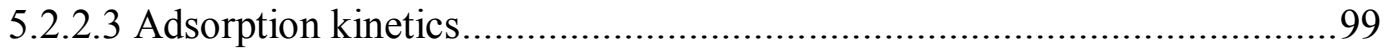

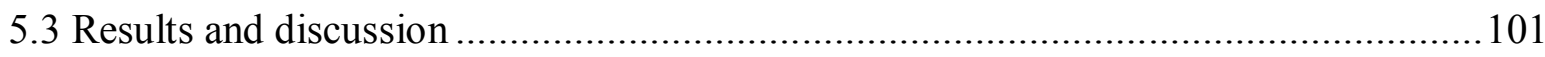

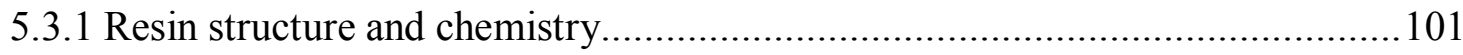

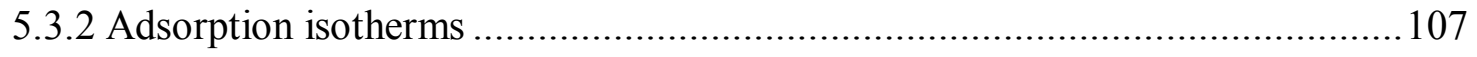

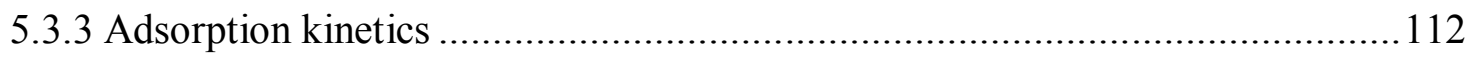

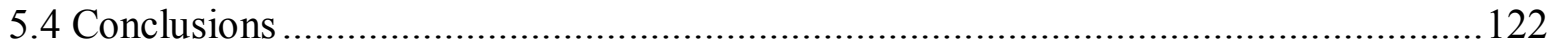

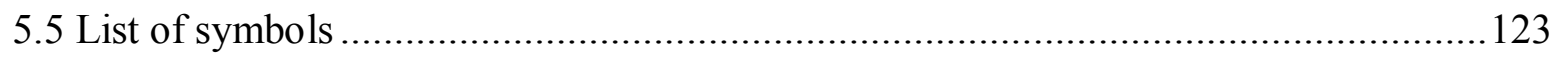

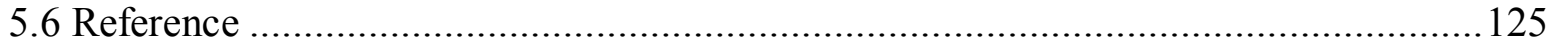

Chapter 6 Concluding Remarks ..................................................................................................128

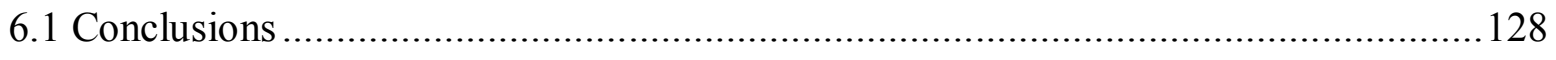

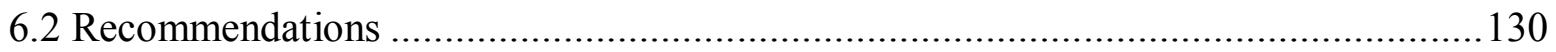

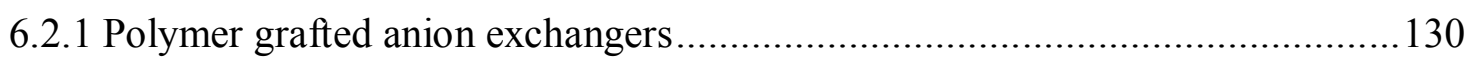

6.2.2 Multimodal cation exchanger ...................................................................131 


\section{List of Figures}

Fig. 2.1 Representative micrographs for and particle size distribution for UNO Q (a,d), Nuvia

HR Q (b,e), and Nuvia Q (c,f). .20

Fig. 2.2 TEM images of BSA-free and BSA-saturated resin samples at $10 \mathrm{~K}$ magnification for UNO (a,d), Nuvia HR Q (b,e), and Nuvia Q (c,f). .23

Fig. 2.3 iSEC results for UNO Q in pH 7 buffer containing (a) $0 \mathrm{M}$, (b) $0.15 \mathrm{M}$ and (c) $1 \mathrm{M}$ $\mathrm{NaCl}$. The vertical dash line indicates the estimated extraparticle porosity, $\varepsilon$, obtained from column pressure drop. .25

Fig. 2.4 iSEC results for Nuvia HR Q in pH 7 buffer containing (a) $0 \mathrm{M}$, (b) $0.15 \mathrm{M}$ and (c) $1 \mathrm{M}$ $\mathrm{NaCl}$. The vertical dash line indicates the estimated extraparticle porosity, $\varepsilon$, obtained from column pressure drop. .26

Fig. 2.5 iSEC results for Nuvia Q in pH 7 buffer containing (a) $0 \mathrm{M}$, (b) $0.15 \mathrm{M}$ and (c) $1 \mathrm{M}$ $\mathrm{NaCl}$. The vertical dash line indicates the estimated extraparticle porosity, $\varepsilon$, obtained from 2000 $\mathrm{kD}$ dextran retention. .27

Fig. 2.6 Distribution coefficient $K_{D}$ for glucose, 4, 10, 40, 70, 80, 270 and $2000 \mathrm{kD}$ dextran standards plotted as a function of their hydrodynamic radius for UNO Q (a), Nuvia HR Q (b) and Nuvia Q (c) in pH 7 buffer containing 20 mM BTP-HCl and $0(\bullet), 0.15$ ( $)$ and $1 \mathrm{M}$

$(\bullet) \mathrm{NaCl}$. The lines are calculated from Eq. 2.3 using the parameters in Table 2.1. 31

Fig. 3.1. SEC analysis of Rhodamine Red labeled BSA on a Superdex 200 column (GE

Healthcare, Piscataway, NJ, USA). The labeling ratio was 0.18 . .44

Fig. 3.2. LGE analysis of Rhodamine Red labeled BSA on a $0.5 \times 10 \mathrm{~cm}$ UNO Q column (a) and $0.5 \times 10 \mathrm{~cm}$ Nuvia Q column (b). The labeling ratio was 0.18. Buffer A: $20 \mathrm{mM} \mathrm{BTP-HCl,} \mathrm{pH} \mathrm{7,}$ 
Buffer B: 1 M NaCl, 20 mM BTP-HCl, pH 7, Flowrate: 1 mL/min, Sample: 2 mg/mL, $200 \mu \mathrm{L}$ injection, Wash $2 \mathrm{CV}$, Gradient: 0-30\% Buffer B in $10 \mathrm{CV}$.

Fig. 3.3. Preparative separation of BSA and $10 \mathrm{kD}$ PEG-BSA by step elution with a $10 \times 100 \mathrm{~mm}$ Source 15Q column. Inset shows the SEC analyses of the PEGylation mixture and of the fractions indicated conducted with a Superdex 200 SEC column 47

Fig. 3.4. LGE chromatograms of BSA, 10 kD PEG-BSA, and 30 kD PEG-BSA on UNO Q (a), Nuvia HR Q (b) and Nuvia Q (c) using $20 \mathrm{CV}, 0-400 \mathrm{mM} \mathrm{NaCl}$ gradients in $20 \mathrm{mM}$ BTP-HCl pH 7 buffer at flowrate equivalent to 2 minute residence time. The short dashed lines show the UV trace obtained by injecting a mixture of the three components.

Fig. 3.5. Plot of normalized gradient slope vs. chloride concentration at elution for BSA (a), 10 kD PEG-BSA (b) and 30 kDa PEG-BSA (c). Lines are calculated from Eq. 3.2 with parameters

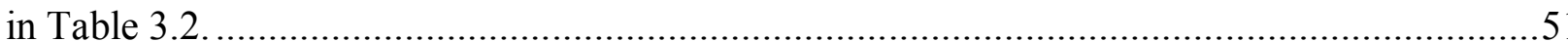

Fig. 3.6 Adsorption isotherms of BSA (a), 10 kD PEG-BSA (b) and 30 kD PEG-BSA (c) obtained for $24 \mathrm{~h}$ contact time in $20 \mathrm{mM} \mathrm{BTP}-\mathrm{HCl} \mathrm{pH} 7$ buffer. Lines are calculated from Eq. 3.3 with parameters in Table 3.3. $q$ and $C$ values are in mg of BSA per mL excluding the mass of conjugated PEG. Note the different y-axis. .53

Fig. 3.7. Batch adsorption kinetics of $1 \mathrm{mg} / \mathrm{mL}$ BSA (a), $10 \mathrm{kD}$ PEG-BSA(b) and 30 kD PEGBSA (c) in $20 \mathrm{mM} \mathrm{BTP-HCl} \mathrm{pH} 7$ buffer on UNO Q, Nuvia HR Q and Nuvia Q. Lines are calculated from the pore diffusion model accounting for particle size distribution and assuming a rectangular isotherm. Note that $q$ values are in mg of BSA per mL excluding the mass of conjugated PEG. .56 
Fig. 3.8 Reduced HETP vs. reduced velocity obtained from pulse injection at $1 \mathrm{M} \mathrm{NaCl}$ for BSA, 10 kD PEG-BSA, and 30 kD PEG-BSA on UNO Q (filled), Nuvia HR Q (open) and Nuvia Q (half-filled).

Fig. 3.9. CLSM images of one component adsorption on UNO Q, Nuvia HR Q and Nuvia Q for $1 \mathrm{mg} / \mathrm{mL}$ BSA (top row) and $30 \mathrm{kD}$ PEG-BSA (bottom row) in $20 \mathrm{mM} \mathrm{BTP-HCl} \mathrm{pH} 7$ buffer. Actual diameters of the particle shown are about 70, 50 and $80 \mu \mathrm{m}$ for UNO Q, Nuvia HR Q and Nuvia Q, respectively. Laser intensities were kept constant for each time series. .60

Fig. 3.10. CLSM images of two-component sequential adsorption on UNO Q and Nuvia Q of 1 $\mathrm{mg} / \mathrm{mL}$ BSA (middle row) on beads pre-saturated with10 kD PEG-BSA (top row) in $20 \mathrm{mM}$ BTP-HCl pH 7 buffer. The bottom row shows a composite of red and green images. Actual diameters for the particles shown are about 70 and $80 \mu \mathrm{m}$ for UNO Q and Nuvia Q, respectively.

Fig. 3.11. CLSM images of two-component co-adsorption on UNO Q, Nuvia HR Q and Nuvia Q of $1 \mathrm{mg} / \mathrm{mL}$ each of BSA (middle row) and $10 \mathrm{kD}$ PEG-BSA (top row) in $20 \mathrm{mM} \mathrm{BTP-HCl} \mathrm{pH} 7$ buffer. The bottom row shows a composite of the red and green images. Actual diameters of particles shown are about 70, 50 and $80 \mu \mathrm{m}$ for UNO Q, Nuvia HR Q, and Nuvia Q, respectively. 63

Fig. 4.1. Adsorption isotherms of BSA in $20 \mathrm{mM} \mathrm{BTP-HCl} \mathrm{pH} 7$ buffer containing (a) $0 \mathrm{mM}$ and (b) $50 \mathrm{mM} \mathrm{NaCl}$, obtained for $24 \mathrm{~h}$ contact time. Lines are the Langmuir isotherm model with parameters in Table 4.2 . .75

Fig. 4.2. Adsorption isotherms of $\mathrm{Tg}$ in $20 \mathrm{mM} \mathrm{BTP-HCl} \mathrm{pH} 7$ buffer containing (a) $0 \mathrm{mM}$ and (b) $50 \mathrm{mM} \mathrm{NaCl}$, obtained for $24 \mathrm{~h}$ contact time. Lines are the Langmuir isotherm model with parameters in Table 4.2 . .76 
Fig. 4.3. CLSM images of $1 \mathrm{mg} / \mathrm{mL}$ BSA adsorption on UNO Q, Nuvia HR Q and Nuvia Q in 20 mM BTP-HCl pH 7 buffer containing $0 \mathrm{mM} \mathrm{NaCl}$. Actual particle diameters are about 70, 50 and $80 \mu \mathrm{m}$ for UNO Q, Nuvia HR Q, and Nuvia Q, respectively. Laser intensities were kept constant for each time series.

Fig. 4.4. CLSM images of $1 \mathrm{mg} / \mathrm{mL}$ Tg adsorption on UNO Q, Nuvia HR Q and Nuvia Q in 20 mM BTP-HCl pH 7 buffer containing (a) $0 \mathrm{mM}$ and (b) $50 \mathrm{mM} \mathrm{NaCl}$. Actual particle diameters are about 70, 50 and $80 \mu \mathrm{m}$ for UNO Q, Nuvia HR Q and Nuvia Q, respectively. Laser intensities were kept constant for each time series. .80 Fig. 4.5. Batch adsorption kinetics of $1 \mathrm{mg} / \mathrm{mL}$ BSA in $20 \mathrm{mM}$ BTP-HCl pH 7 buffer containing $0 \mathrm{mM} \mathrm{NaCl}$ on UNO Q, Nuvia HR Q, and Nuvia Q. Lines are calculated from the pore diffusion model for UNO Q and from the solid diffusion model for Nuvia HR Q and Nuvia Q using parameters in Table 4.3 .

Fig. 4.6. Batch adsorption kinetics of $1 \mathrm{mg} / \mathrm{mL}$ Tg in $20 \mathrm{mM} \mathrm{BTP-HCl} \mathrm{pH} 7$ buffer containing (a) $0 \mathrm{mM}$ and (b) $50 \mathrm{mM} \mathrm{NaCl}$ on UNO Q, Nuvia HR Q, and Nuvia Q. Lines are calculated from the pore diffusion model for UNO Q and from the solid diffusion model for Nuvia HR Q

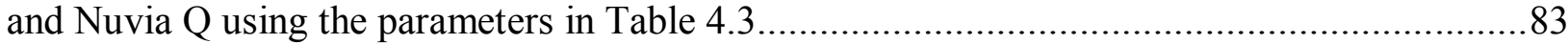

Fig. 4.7. Transport mechanism of small and large protein in anion exchanger with varying length of polymer grafting under strong binding condition.

Fig. 5.1. Multimodal ligands in (a) Nuvia cPrime and (b) Capto MMC according to the respective manufacturer. .96 Fig. 5.2. TEM images of (a) Nuvia cPrime at 10k magnification, (b) Capto MMC at 20k magnification and (c) UNO Q at 10k magnification. Note the different scales for (b). 102 
Fig. 5.3. iSEC results showing each probe $K_{D}$-values vs. its hydrodynamic radius. Lines are based on Eq. 12 for Capto MMC and Eq. 8 for Nuvia cPrime using the parameters in Table 5.1.

Fig. 5.4. Potentiometric titrations of (a) Nuvia cPrime and (b) Capto MMC with different concentrations of $\mathrm{NaCl}$. Lines are calculated from Eq. 5.3 with parameters in Table 5.1..........106 Fig. 5.5. Adsorption isotherms for lysozyme as a function of $\mathrm{pH}$ and $\mathrm{NaCl}$ concentration in buffers containing $20 \mathrm{mM} \mathrm{Na}^{+}$. $\mathrm{NaCl}$ concentration are: $0(\bullet), 200(\bigcirc)$, and $400 \mathrm{mM}(\bullet)$. Lines are the Langmuir isotherm model with parameters in Table 5.2...........................................109 Fig. 5.6. Adsorption isotherms for the $\mathrm{mAb}$ as a function of $\mathrm{pH}$ and $\mathrm{NaCl}$ concentration in buffers containing $20 \mathrm{mM} \mathrm{Na}^{+}$. $\mathrm{NaCl}$ concentration are: $0(\bullet), 100(\triangle) 200(\bigcirc)$, and $400 \mathrm{mM}$ $(\bullet)$. Lines are the Langmuir isotherm model with parameters in Table 5.3.

Fig. 5.7. Batch uptake curves for (a) lysozyme and (b) the mAb in buffers containing $20 \mathrm{mM}$ $\mathrm{Na}^{+}$. Lines are the pore diffusion model with $D_{e}$-values in Table 5. Note the different time scales in the two graphs. The initial protein concentration in solution was $1 \mathrm{mg} / \mathrm{mL}$ in all cases. 114 Fig. 5.8. CLSM images of $1 \mathrm{mg} / \mathrm{mL} \mathrm{mAb}$ adsorption on Nuvia cPrime particles in buffers containing $20 \mathrm{mM} \mathrm{Na}^{+}$at (a) $\mathrm{pH} 5$ and (b) $\mathrm{pH}$ 6. Actual particle diameters for the particles shown are $68 \pm 1 \mu \mathrm{m}$ 116 Fig. 5.9. CLSM images of $1 \mathrm{mg} / \mathrm{mL} \mathrm{mAb}$ adsorption on Capto MMC particles in buffers containing $20 \mathrm{mM} \mathrm{Na}^{+}$at (a) $\mathrm{pH} 5$ and (b) $\mathrm{pH}$ 6. Actual particle diameters for the particles shown are $84 \pm 1 \mu \mathrm{m}$. 117

Fig. 5.10. Plots of dimensionless position of the adsorption front vs. reduced time based CLSM images for the adsorption of $1 \mathrm{mg} / \mathrm{mL} \mathrm{mAb}$ on (a) Nuvia cPrime and (b) Capto MMC particles in 
buffers containing $20 \mathrm{mM} \mathrm{Na}^{+}$. Note the different $\mathrm{x}$-axis scales in the two plots. Lines are

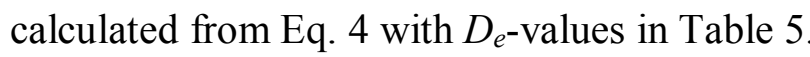

Fig. 5.11. CLSM images of $1 \mathrm{mg} / \mathrm{mL}$ mAb adsorption on Capto MMC particles in buffers containing $20 \mathrm{mM} \mathrm{Na}^{+}$at (a) $\mathrm{pH} 5$ and (b) $\mathrm{pH}$ 6, illustrating different adsorption rates for different particles in the same experiment. Actual particle diameters for the particles shown are $100 \pm 1 \mu \mathrm{m}$ (a) and $66 \pm 1 \mu \mathrm{m}$ in (b).

Fig. 5.12. Breakthrough curves for (a) lysozyme at 1 min residence and (b) the mAb at $2 \mathrm{~min}$ residence time at $\mathrm{pH} 5$ in $20 \mathrm{mM}$ sodium acetate. The protein feed concentration was $C_{F}=$ $1.9 \pm 0.1 \mathrm{mg} / \mathrm{mL}$. Actual column lengths were $5.8 \mathrm{~cm}$ for Nuvia cPrime and $5.3 \mathrm{~cm}$ for Capto MMC. Flow rates were 1 and $0.5 \mathrm{~mL} / \mathrm{min}$ for lysozyme and the $\mathrm{mAb}$, respectively. Lines are the pore diffusion model with $D_{e}$-values in Table 5 


\section{List of Tables}

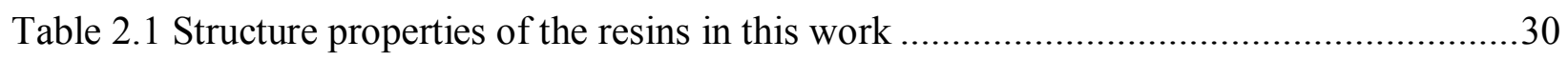

Table 3.1 Diffusivity and hydrodynamic radius of purified BSA and PEGylated BSA.............46

Table 3.2 Retention parameters based on LGE results. ..............................................52

Table 3.3 Equilibrium isotherm parameters. ............................................................54

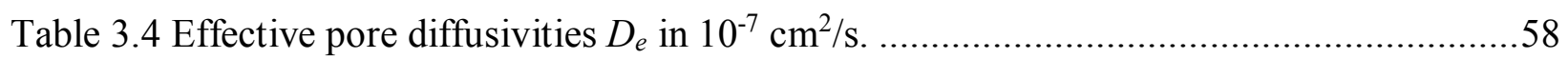

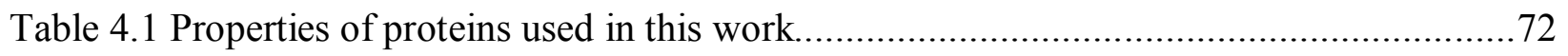

Table 4.2 Langmuir isotherm parameters for BSA and Thyroglobulin ( $\mathrm{Tg}$ ) in buffers containing

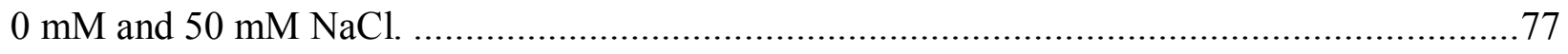

Table 4.3 Diffusivity values determined from batch uptake curves. De are based on Eqs. 4.2 and

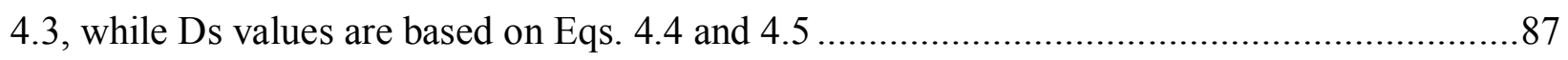

Table 4.4 Effective diffusivity values determined from pulse response under nonbinding

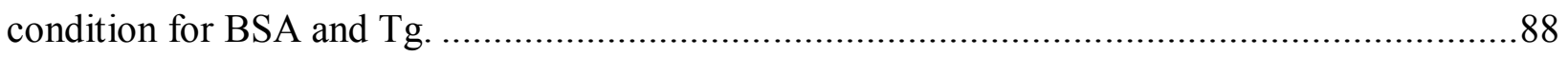

Table 5.1 Physical and chemical properties of the resins used in this work.........................105

Table 5.2. Langmuir isotherm parameters for lysozyme in buffers containing $20 \mathrm{mM} \mathrm{Na}{ }^{+} \ldots . .110$

Table 5.3 Langmuir isotherm parameters for the $\mathrm{mAb}$ in buffers containing $20 \mathrm{mM} \mathrm{Na}{ }^{+} \ldots \ldots \ldots 112$

Table 5.4 Effective pore diffusivities $D_{e}$ in $10^{-7} \mathrm{~cm}^{2} / \mathrm{s}$ in buffers containing $20 \mathrm{mM} \mathrm{Na}^{+} \ldots \ldots \ldots 115$ 


\section{Chapter 1}

\section{Motivation and Background}

\subsection{Motivation}

Bioseparation processes have always been critical steps in the manufacturing of highpurity biopharmaceutical products and the biopharmaceutical industry has never stopped seeking more efficient bioseparation process. As one of the most widely used bioseparation techniques, chromatography is crucial to the production of therapeutic proteins, such as monoclonal antibodies [1,2]. However, economic limitations and technological factors often challenge the implementation of chromatography at large scale, including high costs, low throughput, and complexity of scale-up [1]. Those challenges call for better stationary phases with high binding capacity, high selectivity, fast adsorption kinetics and high mechanic strength [1-3].

The base matrices used to synthesize stationary phases for biochramotograhy fall into three main categories: natural carbohydrate polymers, synthetic polymers, and inorganic materials. Generally, higher binding capacity is achieved for natural carbohydrate polymers, such as agarose and dextran. These polymers are usually easy to functionalize and have low nonspecific binding. However, the mechanical strength is relatively low and the pore size is often small which results in slow transport rates. Synthetic polymer matrices have relatively high rigidity, larger pore size and some of them exhibit low non-specific binding. However, their large pore size often leads to small surface areas and hence, low binding capacity [4]. Yet after some modification, hydrophilic synthetic polymer matrices, such as polymethacrylates or polyacrylamide, seems to have the potential to meet the requirements of high capacity, high selectivity, fast adsorption and high mechanic strength. 
A promising modification of open-pore matrix is to graft charged polymer that acts as "surface extenders" to the pore surface [3,5]. Such grafted stationary phases are often found to have high binding capacity resulting from the interaction of the protein with the grafted polymer while maintaining the mechanical strength of the support matrices. Another promising modification is to functionalize the matrix with multimodal ligands [6,7]. By utilizing multiple interactions to adsorb and separate protein, multimodal chromatography has shown to have better selectivity over conventional single mode chromatography $[6,8,9]$.

However, the development of process-scale chromatography of these two novel stationary phase is hampered by the complexity of the systems, especially for large proteins when the molecule size approaches the characteristic length scale of the grafted polymers and the underlying support matrices [10-14]. Hence, understanding of the stationary phase properties, as well as protein adsorption and transport mechanisms on them, is critical. The overall objective of this work is thus to investigate newly developed chromatographic resins that embody such functionalization, including polymer-grafted anion exchangers that have a range of polymer and pore sizes, and two multimodal cation exchangers. Protein with a wide range of size and surface charge properties will be studied, including small protein like lysozyme and large protein such as PEGylated BSA and thyroglobulin.

\subsection{Background and theory}

\subsubsection{Polymer grafted ion exchangers}

Proteins can be separated chromatographically from impurities based on differences in various properties such as charge, size, hydrophobicity or bio-affinity. Ion exchange chromatography (IEC) utilizes charge differences to separate proteins. For example, because of their higher charge, dimers and other higher order aggregates are often found to be more strongly 
bound than monomers. Additionally, protein unfolding of protein conjugation to hydrophilic polymers can affect the strength of binding since both can affect the distribution of surface charge on the modified molecules and, thus, chromatographic retention. IEC is one of the most widely used chromatography mode in biopharmaceutical manufacturing which is involved in about $70 \%$ of protein purification protocols [15]. Advantages of IEC include relatively low cost, a broad range of available stationary phases and buffer systems, high binding capacity, high resolution and most importantly the ability to preserve the biological activity of the product [16].

Composite matrices which incorporate grafted polymers into a rigid porous support structure have attracted considerable interest as a mean of combining high capacity, high transport rate, and high mechanical strength $[3,5,17]$. Based on the structural difference of the polymers incorporated, these composite matrices can be classified into three classes: (1) "gel-ina-shell" media, in which the pores are filled with a crosslinked polymeric gel; (2) adsorbents in which polymers are covalently attached to the support matrix with multi-point attachment per chain; and (3) adsorbents in which polymers are covalently attached to the support matrix with single point of attachment per chain [17]. In all three cases, these polymers are functionalized with protein interacting ligands often resulting in higher binding capacities than non-polymer grafted media $[3,5,17-19]$. The higher binding capacity is generally attributed to multi-layer or three-dimensional adsorption inside a gel-like structure formed inside the pore by the grafted polymers $[3,5,18]$. In some cases, protein transport rate is also found to be enhanced in these adsorbents. [3,5,17-18,20]. For example, Almodovar et al. [21-23] have investigated protein adsorption and transport in cation exchangers based on UNOsphere matrix with and without grafted polymers using lysozyme and $\operatorname{IgG}$ as model proteins. The binding capacity was found to be about three times greater for the grafted materials while adsorption rates were found to be 
about 2 times higher. Several theories have been proposed to explain the faster transport rate in polymer grafted ion exchanger: the solid or homogeneous diffusion [24], electrostatic coupling of diffusion fluxes [20], "bucket brigade" effect or "chain delivery" effect (protein passed from one polymer chain to the next) $[25,26]$ and "partitioning" mechanism $[3,23]$. No matter what the actual mechanism is, the enhancement can significantly depend on a combination of (1) the physical properties of the adsorbents (grafting density, chain length, and pore size), (2) protein characteristics (size and surface charge distribution), and (3) buffer ionic strength.

Various studies have been conducted to understand the effects of the factors mentioned above for protein adsorption on polymer grafted ion exchangers. The influence of grafting density on protein adsorption in polymer-grafted exchanger has been studied by both experimental methods and simulation. For example, Yu et al. [25] and Wang et al. [27] studied BSA adsorption on a series of polymer-grafted IEC adsorbents based on Sepharose FF agarose matrices using poly(ethylenimine) and glycidyl methacrylate as grafts respectively. In both cases, a critical ionic capacity and corresponding graft density were shown to exist above which protein adsorption and transport behaviors change dramatically. Basconi et al. [28] studied protein adsorption into polymer-grafted IEC adsorbents by multiscale modeling. The simulation results showed that increased ligand density leads to higher capacity but also to the partial exclusion of protein from the pore under weak binding condition. Hence the grafting density should be carefully selected.

The effects of buffer ionic strength and protein properties have also been studied by various researchers. Yu and Sun [29], for example, found the adsorption capacity decrease on PEI-grafted IEC adsorbents was less sensitive to ionic strength compared to conventional IEC adsorbents at low grafting density. While at high grafting density, both capacity and diffusivity 
on PEI-grafted IEC adsorbents were found to first increase and then decrease with ionic strength. Stone et al. [28] studied the effect of ionic strength on adsorption and transport of lysozyme, BSA, and IgG in agarose based cation exchanger with dextran grafts. Different effects of ionic strength on adsorption kinetics were found for the different proteins. For lysozyme, the diffusivity decreased with ionic strength dramatically while for IgG an optimized ionic strength was found to exist which maximized the fastest kinetics.

Most of the studies on polymer grafted ion exchangers, however, have been about cation exchangers. Much less is known about the behavior of anion exchangers.

\subsubsection{Multimodal chromatography}

Multimodal or mixed mode chromatography (MMC) utilizes stationary phases that are functionalized with ligands containing multiple chemical moieties providing complementary interactions to adsorb and separate proteins [6-8,30]. Most commonly, MMC media involves an ion exchange group, which provides electrostatic interactions, and a hydrophobic group, which

provides binding via van der Waals' forces [7,31]. Combining these interactions has been shown to provide higher selectivity for various separations [11,32] as well strong binding even at relatively high salt concentrations or "salt-tolerance" allowing the use of MMC to capture proteins from a high salt feedstock without having to dilute or buffer exchange the feed [33].

As noted by several authors [11-14], the combined interactions make MMC dependent in a complex way on several process variables including $\mathrm{pH}$, salt concentration, temperature, and the presence of mobile phase additives, such as arginine [13,30,34]. As a result, developing processes based on MMC usually requires extensive experimentation [14,35]. A better understanding of both protein-ligand interactions and of the transport mechanism in MMC is thus desirable in order to develop more rational approaches to process development. 
Protein interactions with ligand have been studied for proteins of relatively small molar mass (e.g. ubiquitin, lysozyme, and BSA) $[12,32,36,38]$ by NMR, isothermal titration calorimetry, and simulation. For example, Adsorption isotherm models taking salt concentration and $\mathrm{pH}$ into account have also been proposed both based on the Langmuir isotherm by Gao et al. [36] and based on a thermodynamic framework by Nfor et al. [7]. The latter also extended further for modeling the protein retentions in mixed-mode chromatography for isocratic and gradient elution in a wide range of $\mathrm{pH}$ and salt concentration [38]. Elution method based on $\mathrm{pH}$ gradient or $\mathrm{pH}$ step changes has also been proposed to increase the elution efficiency and selectivity [39-40]. While both the understanding of protein interaction with ligand and the control of $\mathrm{pH}$ gradient elution requires a precise description of the ligand response to $\mathrm{pH}$, works regarding the determination of resin pKa and ionization model is lacked.

Protein adsorption kinetics on MMC resins has also been studied for model proteins in cationic MMC resins. Zhao et al. [41] obtained the effective diffusivity of BSA in experimental resins and reported that the diffusivity decreased with salt concentration. Gao et al. [42] reported instead that, for a different experimental resin, the effective diffusivity had a maximum at a moderate salt concentration. Yu et al. [18] studied the uptake rate of $\gamma$-globulin on dextran-grafted resins functionalized either with a cationic ligand or with a cationic mixed-mode ligand. While intraparticle protein transport was high for the cationic ligand, presumably because of surface diffusion contribution to transport, slower rates were observed for the MMC ligand, indicating the protein transport is hindered by the stronger binding that results from multiple interactions. Until now, the research regarding transport kinetics is limited to the cationic multimodal resin and mainly focused on multimodal media based on agarose matrix. In addition, the relationship 
between matrix properties and adsorption kinetics is not clearly discussed. A more intuitive method showing the transport process is also needed.

\subsubsection{Protein transport mechanisms}

Column performance is generally determined by both equilibrium factors, such as adsorption equilibrium and ionic dissociation, and dispersive or rate factors, such as mobile phase dispersion, mass transfer resistance, and kinetics resistance to binding. In general, equilibrium factors define the best achievable separation and dispersive factors determine how far the real performance is away from the ideal case. Because of the relatively large size of protein molecules, mass transfer resistances often dominate overall dispersion in protein chromatography using porous particles. In general, mass transfer resistances include: (1) external mass transfer in the fluid surrounding the particle; (2) diffusion within the particles; and (3) kinetic resistance to binding. The external resistance is usually negligible for the relatively large particles used in protein application. Hence, intra-particle diffusion is always the main concern.

Two distinct mechanisms of intraparticle transport can be observed - pore diffusion and solid diffusion. Pore diffusion occurs in pores that are sufficiently large to permit the protein molecules to diffuse without interacting with resin's ligands [16]. The rate of pore diffusion depends on the protein effective pore diffusivity, $D_{e}$, which is commonly written as:

$$
D_{e}=\frac{\varepsilon_{p} D_{0}}{\tau_{p}} \psi_{p}
$$

where $D_{0}$ is the protein free solution diffusivity, $\varepsilon_{p}$ is the intraparticle porosity, $\tau_{p}$ is the tortuosity factor, and $\psi_{p}$ is the hindrance factor. The latter describes restricted diffusion in the 
pores and is substantially less than one when the ratio $\lambda=r_{\text {protein }} / r_{\text {pore }}$ of molecular radius and pore radius is greater than 0.1 [4]. The mass transfer flux is then written as:

$$
J=-D_{e} \nabla c
$$

where $\nabla c$ is the protein concentration gradient in the pore liquid. Typically, the value of $D_{e}$ is much smaller than $D_{0}$, because of the relatively large size of the protein molecule, the tortuosity of the pore structure, and diffusion hindrance effects.

Solid diffusion can occur through a polymer gel, that is either crosslinked or defined by polymers grafted in a support matrix when the gel mesh size is small enough that the protein molecules diffuse while interacting with the resin's functional ligands, but not too small that diffusional mobility is prevented [16]. The driving force for solid diffusion is best expressed in terms of the adsorbed protein concentration gradient $\nabla q$. The mass transfer flux is then given by:

$$
J=-D_{s} \nabla q
$$

where $D_{s}$ is the diffusivity of the protein in the gel. Although $D_{s}$ is expected to be very small, since $\nabla q$ can be much larger than $\nabla c$ when the binding is highly favorable, actual solid diffusion rates can be higher than those observed for pore diffusion [16,23]. In this case, an apparent effective pore diffusivity can be defined as [26]:

$$
D_{e, a p p}=\frac{q}{C} D_{s}
$$

where $D_{e, a p p}$ is the pore diffusivity that would give approximately the same transport flux as that observed for solid diffusion [16]. When the isotherm is rectangular, $q \sim q_{m}=$ constant. In this case, if $D_{s}$ is also constant, $D_{e, a p p}$ is expected to increase in inverse proportion with $C$. 
Measurements of intraparticle transport can be made either macroscopically based on batch adsorption or chromatographic experiments, or microscopically based on a determination of intraparticle concentration profile. Macroscopic measurements usually are easier to implement but they normally cannot directly reveal the actual transport mechanism. In this case, only apparent or average diffusivity values can be obtained by fitting the data collected with models describing different mechanisms. Microscopic methods, on the other hand, provide greater insight since very different intraparticle concentration profile are expected for different transport mechanisms [43]. For example, for pore diffusion, if the isotherm is favorable and external mass transfer resistance is negligible, a sharp adsorption front is expected to be formed within the profile. In this case movement of the adsorption front with time, $t$, is expected to be expressed by the following equation [44]:

$$
2 \rho_{s}^{3}-3 \rho_{s}^{2}+1=\frac{6 D_{e} C t}{q_{m} r_{p}^{2}}
$$

where $\rho_{s}=r_{s} / r_{p}$ is the dimensionless radial position of the adsorption front, $q_{m}$ is the equilibrium binding capacity, and $r_{p}$ is the particle radius. For solid diffusion, smooth intraparticle concentration profiles are expected instead [45]. In this case, protein molecules reach the center of the particle quickly but approach equilibrium slowly. This behavior has been reported by many researchers, mainly for the stationary phases that have small mesh pore size or have incorporated a grafted polymers or soft gel phase within a large porous structure $[3,20,46]$. For example, Tao et al. observed smooth intraparticle protein concentration profiles for the adsorption of $\mathrm{mAb}$ variants in Capto $\mathrm{S}$, a dextran grafted cation exchanger [46]. The behavior of multicomponent adsorption under solid diffusion mechanism is also very different from that under pore diffusion mechanism. For pore diffusion, protein can move in either direction towards 
or away from the particle center while for solid diffusion in polymer grafted materials counterdiffusion is highly hindered, as reported by Tao et al. [46] and Almodovar et al. [23] for the adsorption of a mAb on polymer grafted cation exchangers.

\subsection{Specific research goals and objectives}

The overall objective of this work is to investigate newly developed chromatographic resins functionalized with cationic grafted polymer and with anionic multimodal ligands. All of these resins are based on a relatively rigid macroporous hydrophilic matrix formed by the copolymerization of acrylamido and vinyl comonomers and available commercially under the trade name UNOsphere from Bio-Rad Laboratories (Hercules, CA).

Three anion exchangers with different degrees of polymer grafting are considered:

UNOsphere Diol Q (hereinafter referred to as UNO Q) has no grafted polymers but only a short cationic functional ligand; Nuvia Q has relatively long polymeric surface extenders; and Nuvia HR Q has grafted polymers with intermediated length. Native BSA and PEGylated BSA with different PEG sizes, and thyroglobulin will be used as model proteins to characterize protein adsorption equilibrium and transport in these materials. The principle aims of this work are:

1. To characterize the physical properties of all resins.

2. To determine the effects of the polymer grafts on adsorption and transport of native BSA and PEGylated BSA for both single component adsorption and multicomponent adsorption.

3. To investigate the effects of PEGylation on the adsorption equilibrium and kinetics in resins with different matrix structures.

4. To understand the adsorption behavior as a function of the relative size of protein and grafted polymer. 
Chapter 2 of this dissertation describes the work that was done to address Objective 1. Chapter 3 deal with Objective 2 and 3. Chapter 4 addresses Objective 4.

The multimodal resin, Nuvia cPrime, also based on the UNOsphere matrix, is considered next and compared with an agarose-based resin with a similar ligand, Capto MMC. Both of these resins are functionalized with a multimodal ligand that contains a phenyl group, a peptide bond, and a carboxyl group. However, the arrangement of these moieties in the ligand is different in the two resins resulting in a different presentation of hydrophobic and charged groups to the adsorbate molecules. The aims of the work on these two resins are:

1. To characterize the physical and chemical properties of both resins

2. To understand protein adsorption equilibrium and kinetics both for lysozyme, which is a relatively small protein, and for, a monoclonal antibody (mAb), which is a relatively large protein.

3. To determine the transport mechanisms of $\mathrm{mAb}$ on both resin at different ionic strength and $\mathrm{pH}$ conditions.

These objectives are addressed in Chapter 5.

\subsection{List of symbols}

c liquid-phase concentration $(\mathrm{mg} / \mathrm{mL})$

$D_{0} \quad$ free solution diffusivity $\left(\mathrm{cm}^{2} / \mathrm{s}\right)$

$\mathrm{D}_{\mathrm{e}} \quad$ effective pore diffusivity $\left(\mathrm{cm}^{2} / \mathrm{s}\right)$

$D_{e, a p p}$ apparent diffusivity $\left(\mathrm{cm}^{2} / \mathrm{s}\right)$

$D_{s} \quad$ diffusivity of the protein in solid phase $\left(\mathrm{cm}^{2} / \mathrm{s}\right)$

$J \quad$ mass transfer flux $(\mathrm{mg} / \mathrm{cm} / \mathrm{s})$

$q \quad$ solid-phase concentration $(\mathrm{mg} / \mathrm{mL})$ 
$q_{m} \quad$ equilibrium binding capacity $(\mathrm{mg} / \mathrm{mL})$

$r_{p} \quad$ particle radius $(\mu \mathrm{m})$

$r_{s} \quad$ radius of adsorption front in CLSM image

$\varepsilon_{p} \quad$ intraparticle porosity

$\rho_{s} \quad r_{s} / r_{p}$, the dimensionless position of the adsorption front

$\tau_{p} \quad$ tortuosity factor

$\psi_{p} \quad$ hindrance factor

\subsection{Reference}

[1] D. Low, R. O'Leary, N.S. Pujar, Future of antibody purification., J. Chromatogr. B. Analyt. Technol. Biomed. Life Sci. 848 (2007) 48-63.

[2] P. Gagnon, Technology trends in antibody purification., J. Chromatogr. A. 1221 (2012) $57-70$.

[3] E.X. Pérez Almodóvar, Y. Tao, G. Carta, Protein adsorption and transport in cation exchangers with a rigid backbone matrix with and without polymeric surface extenders., Biotechnol. Prog. 27 (2011) 1264-72.

[4] G. Carta, A. Jungbauer, Protein Chromatography: Process Development and Scale-Up, John Wiley \& Sons, 2010.

[5] E. Müller, Comparison between mass transfer properties of weak-anion-exchange resins with graft-functionalized polymer layers and traditional ungrafted resins, J. Chromatogr. A. 1006 (2003) 229-240.

[6] G. Zhao, X.-Y. Dong, Y. Sun, Ligands for mixed-mode protein chromatography: Principles, characteristics and design., J. Biotechnol. 144 (2009) 3-11. 
[7] B.K. Nfor, M. Noverraz, S. Chilamkurthi, P.D.E.M. Verhaert, L. a M. van der Wielen, M. Ottens, High-throughput isotherm determination and thermodynamic modeling of protein adsorption on mixed mode adsorbents., J. Chromatogr. A. 1217 (2010) 6829-50.

[8] Y. Yang, X. Geng, Mixed-mode chromatography and its applications to biopolymers., J. Chromatogr. A. 1218 (2011) 8813-25.

[9] J. Chen, J. Tetrault, Y. Zhang, A. Wasserman, G. Conley, M. Dileo, et al., The distinctive separation attributes of mixed-mode resins and their application in monoclonal antibody downstream purification process., J. Chromatogr. A. 1217 (2010) 216-24.

[10] H.O. Johansson, J.M. Van Alstine, Modeling of protein interactions with surface-grafted charged polymers. Correlations between statistical molecular modeling and a mean field approach, Langmuir. 22 (2006) 8920-8930.

[11] Y. Hou, S.M. Cramer, Evaluation of selectivity in multimodal anion exchange systems: a priori prediction of protein retention and examination of mobile phase modifier effects., $\mathrm{J}$. Chromatogr. A. 1218 (2011) 7813-20.

[12] M. a Holstein, S. Parimal, S. a McCallum, S.M. Cramer, Mobile phase modifier effects in multimodal cation exchange chromatography., Biotechnol. Bioeng. 109 (2012) 176-86.

[13] A. Hirano, T. Arakawa, T. Kameda, Interaction of arginine with Capto MMC in multimodal chromatography., J. Chromatogr. A. 1338 (2014) 58-66.

[14] K.A. Kaleas, M. Tripodi, S. Revelli, V. Sharma, S.A. Pizarro, Evaluation of a multimodal resin for selective capture of CHO-derived monoclonal antibodies directly from harvested cell culture fluid., J. Chromatogr. B. Analyt. Technol. Biomed. Life Sci. 969 (2014) 256-63. 
[15] C. Wang, L. Wang, X. Geng, Renaturation with simultaneous purification of rhG-CSF from Escherichia coli by ion exchange chromatography., Biomed. Chromatogr. 21 (2007) 12916.

[16] G. Carta, A. Jungbauer, Protein Chromatography: Process Development and Scale-Up, John Wiley \& Sons, 2010.

[17] A.M. Lenhoff, Protein adsorption and transport in polymer-functionalized ionexchangers., J. Chromatogr. A. 1218 (2011) 8748-59.

[18] L.-L. Yu, Q.-H. Shi, Y. Sun, Effect of dextran layer on protein uptake to dextran-grafted adsorbents for ion-exchange and mixed-mode chromatography., J. Sep. Sci. 34 (2011) 2950-9. [19] M.C. Stone, G. Carta, Protein adsorption and transport in agarose and dextran-grafted agarose media for ion exchange chromatography., J. Chromatogr. A. 1146 (2007) 202-15. [20] M.C. Stone, Y. Tao, G. Carta, Protein adsorption and transport in agarose and dextrangrafted agarose media for ion exchange chromatography: Effect of ionic strength and protein characteristics., J. Chromatogr. A. 1216 (2009) 4465-74.

[21] E.X.P. Almodovar, B. Glatz, G. Carta, Counterion effects on protein adsorption equilibrium and kinetics in polymer-grafted cation exchangers., J. Chromatogr. A. 1253 (2012) 83-93.

[22] E.X. Perez-Almodovar, Y. Wu, G. Carta, Multicomponent Adsorption ofMonoclonal Antibodies onMacroporous and Polymer Grafted Cation Exchangers, J. Chromatogr. A. (2012). [23] E.X. Perez-Almodovar, Y. Wu, G. Carta, Multicomponent adsorption of monoclonal antibodies on macroporous and polymer grafted cation exchangers., J. Chromatogr. A. 1264 (2012) 48-56. 
[24] J. Thömmes, Investigations on protein adsorption to agarose-dextran composite media, Biotechnol. Bioeng. 62 (1999) 358-362.

[25] L.L. Yu, S.P. Tao, X.Y. Dong, Y. Sun, Protein adsorption to poly(ethylenimine)modified Sepharose FF: I. A critical ionic capacity for drastically enhanced capacity and uptake kinetics, J. Chromatogr. A. 1305 (2013) 76-84.

[26] Y. Tao, G. Carta, G. Ferreira, D. Robbins, Adsorption of deamidated antibody variants on macroporous and dextran-grafted cation exchangers: II. Adsorption kinetics, J. Chromatogr. A. 1218 (2011) 8027-8035.

[27] Q. Wang, L. Yu, Y. Sun, Grafting glycidyl methacrylate to Sepharose gel for fabricating high-capacity protein anion exchangers, J. Chromatogr. A. 1443 (2016) 118-125.

[28] J.E. Basconi, G. Carta, M.R. Shirts, Effects of polymer graft properties on protein adsorption and transport in ion exchange chromatography: A multiscale modeling study, Langmuir. 31 (2015) 4176-4187.

[29] L.L. Yu, Y. Sun, Protein adsorption to poly(ethylenimine)-modified Sepharose FF: II. Effect of ionic strength, J. Chromatogr. A. 1305 (2013) 85-93.

[30] K. Kallberg, K. Becker, L. Bülow, Application of a pH responsive multimodal hydrophobic interaction chromatography medium for the analysis of glycosylated proteins, $\mathrm{J}$. Chromatogr. A. 1218 (2011) 678-683.

[31] D. Gao, D.-Q. Lin, S.-J. Yao, Patch controlled protein adsorption in mixed-mode chromatography with benzylamine as functional ligand, Biochem. Eng. J. 38 (2008) 355-361. [32] W.K. Chung, A.S. Freed, M. a Holstein, S. a McCallum, S.M. Cramer, Evaluation of protein adsorption and preferred binding regions in multimodal chromatography using NMR., Proc. Natl. Acad. Sci. U. S. A. 107 (2010) 16811-6. 
[33] W. Schwartz, D. Judd, M. Wysocki, L. Guerrier, E. Birck-Wilson, E. Boschetti, Comparison of hydrophobic charge induction chromatography with affinity chromatography on protein A for harvest and purification of antibodies, J. Chromatogr. A. 908 (2001) 251-263.

[34] D. Gao, D.-Q. Lin, S.-J. Yao, Mechanistic analysis on the effects of salt concentration and $\mathrm{pH}$ on protein adsorption onto a mixed-mode adsorbent with cation ligand., J. Chromatogr. B. Analyt. Technol. Biomed. Life Sci. 859 (2007) 16-23.

[35] J. Pezzini, G. Joucla, R. Gantier, M. Toueille, A.-M. Lomenech, C. Le Sénéchal, et al., Antibody capture by mixed-mode chromatography: a comprehensive study from determination of optimal purification conditions to identification of contaminating host cell proteins., $\mathrm{J}$. Chromatogr. A. 1218 (2011) 8197-208.

[36] D. Gao, D.-Q. Lin, S.-J. Yao, Measurement and Correlation of Protein Adsorption with Mixed-Mode Adsorbents Taking into Account the Influences of Salt Concentration and pH, J. Chem. Eng. Data. 51 (2006) 1205-1211.

[37] K. Srinivasan, S. Parimal, M.M. Lopez, S.A. McCallum, S.M. Cramer, Investigation into the molecular and thermodynamic basis of protein interactions in multimodal chromatography using functionalized nanoparticles., Langmuir. 30 (2014) 13205-16.

[38] Y.F. Lee, H. Graalfs, C. Frech, Thermodynamic modeling of protein retention in mixedmode chromatography: An extended model for isocratic and dual gradient elution chromatography, J. Chromatogr. A. 1464 (2016) 87-101.

[39] M. a Holstein, A. a M. Nikfetrat, M. Gage, A.G. Hirsh, S.M. Cramer, Improving selectivity in multimodal chromatography using controlled $\mathrm{pH}$ gradient elution., J. Chromatogr. A. $1233(2012) 152-5$. 
[40] R.-Z. Wang, D.-Q. Lin, H.-F. Tong, H.-L. Lu, S.-J. Yao, Evaluation of mixed-mode chromatographic resins for separating IgG from serum albumin containing feedstock., J.

Chromatogr. B. Analyt. Technol. Biomed. Life Sci. 936 (2013) 33-41.

[41] G. Zhao, G. Peng, F. Li, Q. Shi, Y. Sun, 5-Aminoindole, a new ligand for hydrophobic charge induction chromatography., J. Chromatogr. A. 1211 (2008) 90-8.

[42] D. Gao, D.-Q. Lin, S.-J. Yao, Protein adsorption kinetics of mixed-mode adsorbent with benzylamine as functional ligand, Chem. Eng. Sci. 61 (2006) 7260-7268.

[43] G. Carta, A.R. Ubiera, T.M. Pabst, Protein mass transfer kinetics in ion exchange media: Measurements and interpretations, Chem. Eng. Technol. 28 (2005) 1252-1264.

[44] D.M. Ruthven, Principles of Adsorption and Adsorption Processes, John Wiley \& Sons, 1984.

[45] A.M. Lenhoff, Multiscale modeling of protein uptake patterns in chromatographic particles, Langmuir. 24 (2008) 5991-5995.

[46] Y. Tao, E.X.P. Almodovar, G. Carta, G. Ferreira, D. Robbins, Adsorption kinetics of deamidated antibody variants on macroporous and dextran-grafted cation exchangers. III. Microscopic studies, J. Chromatogr. A. 1218 (2011) 8027-8035. 


\section{Chapter 2}

\section{Structure Characterization of Anion Exchangers with Varying Length of}

\section{Polymer Grafting}

\subsection{Introduction}

Both external and internal resin structure are important properties of chromatographic stationary phases. Externally, the particle size and particle size distribution are critical since they affect both mass transfer and pressure in a packed column. The particle size can be obtained either through specialized particle size analyzers, or directly from microphotographs. The latter method is used in this work.

Internally, the pore size and pore size distribution affect both protein adsorption equilibrium and kinetics. On one hand, smaller pore sizes leads to larger binding area, and hence higher capacity as well as greater binding strength. On the other hand, pores that are too small will exclude biological molecules and hinder their transport space [1,2]. Knowledge of pore structure is important for a better mechanistic understanding of chromatographic behavior and for improving the efficiency of adsorbent screening in process development.

The porosity and pore size of stationary phase can be measured indirectly by a variety of techniques, including nitrogen adsorption [3], mercury intrusion [4] and inverse size exclusion chromatography (iSEC) [5]. Nitrogen adsorption and mercury intrusion can be used only in a dry state which is not suitable for soft particles and gels whose structure depends on hydration. iSEC is based on the chromatographic retention of non-adsorbing solutes of known size [6,7]. It has advantages of measuring hydration particles as well as determine effects of mobile phase composition such as salt concentration, $\mathrm{pH}$, etc. [2,8]. 
Transmission electron microscopy (TEM) techniques are also used frequently to determine the internal pore structure of stationary phases [2]. To retain the hydration structure, the resin particles usually have to be treated with special dehydration procedures. Then, the particles are embedded in a resin, sectioned and stained with suitable contrast agents $[9,10]$.

In this chapter, the pore structures of three anion exchangers with varying length of polymer grafting are characterized by both TEM and iSEC. TEM is used to elucidate the morphology of internal pore structure directly. The porosities and pore sizes under different buffer conditions are obtained by iSEC using proper pore size distribution model.

\subsection{Materials and Methods}

\subsubsection{Materials}

Three anion exchangers with different degrees of polymer grafting were obtained from Bio-Rad Laboratories (Hercules, CA, USA): UNO Q has no grafted polymers but only a short functional ligand; Nuvia Q has relatively long polymeric surface extender and Nuvia HR Q has grafted polymers with intermediated length. The particle size distribution of the resin samples was determined from micrographs at 100X magnification, as shown in Fig. 2.1. The results were subsequently used to analyze mass transfer kinetics in Chapter 3 and Chapter 4 . The density of the resins was determined by a pycnometer and is $1.08 \pm 0.02 \mathrm{~g} / \mathrm{mL}$, the same for all three resins.

Bovine serum albumin (BSA) $\left(\mathrm{M}_{\mathrm{r}} \sim 66 \mathrm{kD}, \mathrm{pI} \sim 5\right)$ with $\geq 98 \%$ purity based on agarose gel electrophoresis was obtained from Sigma-Aldrich (St. Louis, MO, USA, Type A7906). Chemicals for buffer preparation, sodium chloride, BisTris-propane (BTP) and hydrochloric acid, were from Sigma-Aldrich (St. Louis, MO, USA) and Fisher Scientific (Pittsburg, PA, USA). 

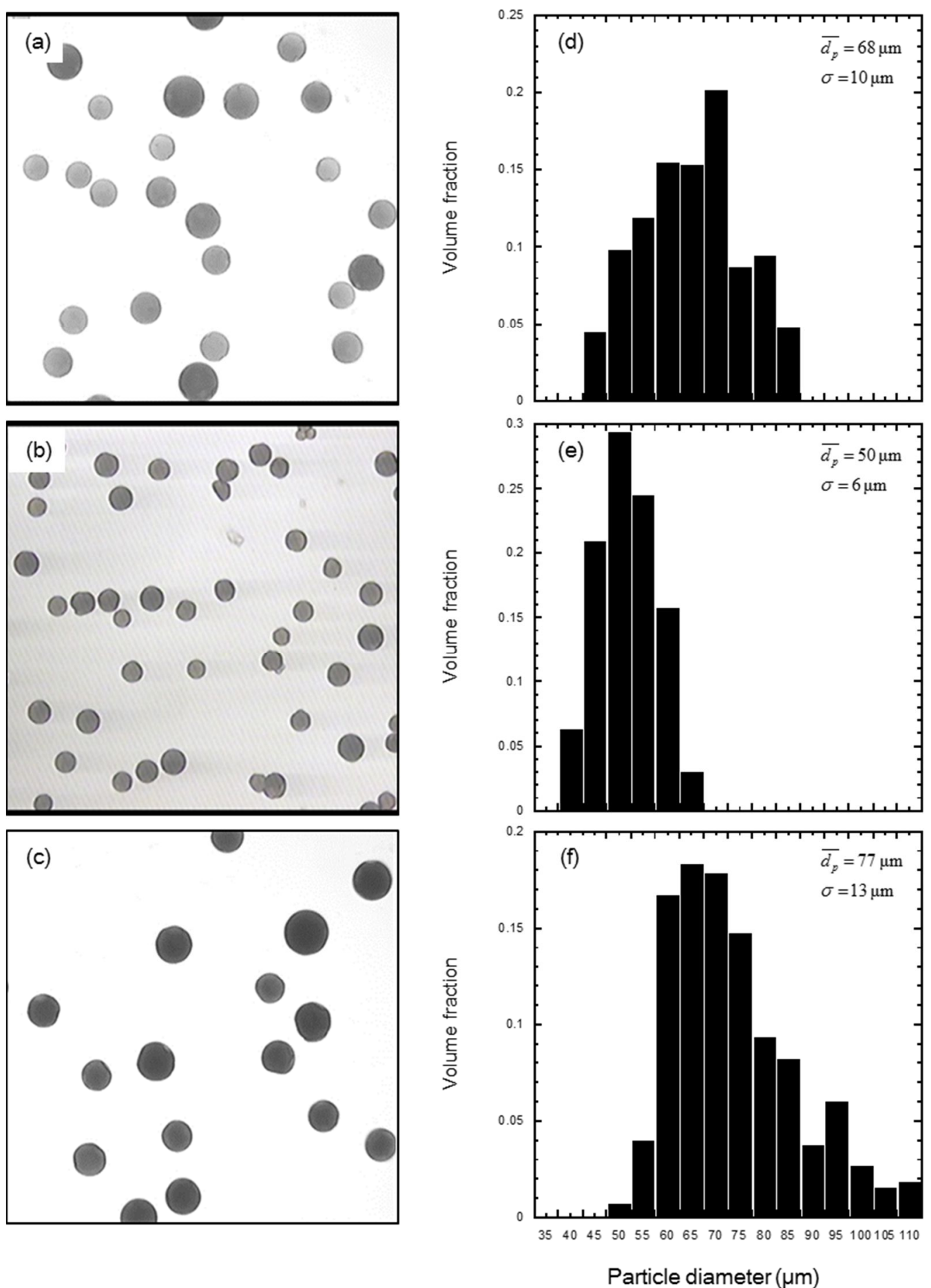

Fig. 2.1 Representative micrographs for and particle size distribution for UNO Q (a,d), Nuvia HR Q (b,e), and Nuvia Q (c,f). 


\subsubsection{Method}

\subsubsection{Transmission electron microscopy (TEM)}

Transmission electron microscopy (TEM) for protein free and BSA-saturated resin was used to determine each resin's backbone structure. For BSA-free samples, the resin beads was firstly dehydrated in a water-ethanol gradient increasing from 0 to $100 \%$ anhydrous ethanol, followed by saturating the resin first with a $50 \%(\mathrm{v} / \mathrm{v})$ mixture of ethanol and LRWhite embedding resin (obtained from London Resin Company Ltd, London, UK), and then with $100 \%$ LRWhite resin. LR white is an acrylic resin specifically design for preparing biological specimens for electron microscopy. After curing overnight, the samples were microtomed ( 80 $\mathrm{nm}$ thickness) and viewed with a JEOL $100 \mathrm{CX}$ transmission electron microscope. Resin samples saturated with BSA staining were prepared by first saturating resin beads with $1 \mathrm{mg} / \mathrm{mL}$ BSA at pH 7 and fixing them with 2\% glutaraldehyde, followed by the same dehydration, LRWhite embedding and microtoming procedures as those used for the non-BSA-stained resin. After microtoming, the $80 \mathrm{~nm}$ slices were stained with uranyl acetate and lead citrate before observation. The bound BSA readily takes up the heavy metal stains, enhancing contrast and resolution compared to BSA-free samples.

\subsubsection{Inverse size exclusion chromatography (iSEC)}

Inverse size exclusion chromatography (iSEC) was used to determine the size exclusion limits of all resins and define their porosities and effective pore size. For this purpose, each resin was packed into Tricorn columns from GE Healthcare (Piscataway, NJ, USA) to bed heights of 14.8, 18.2 and15.3 for UNO Q, Nuvia HR Q and Nuvia Q respectively, and subjected to $10 \mu \mathrm{L}$ pulse injections of $5 \mathrm{mg} / \mathrm{mL}$ samples of glucose, dextrans with molecular mass of $4,10,40,70$, 80, 270 and $2000 \mathrm{kD}$ (Amersham Bioscience, Uppsala, Sweden). The hydrodynamic radii, $r_{h}$, of 
glucose and dextran standards were estimated from their molecular weights, $M_{r}$, using the following correlations as discussed in ref. [11]:

$$
r_{h}=0.0271 \cdot M_{r}^{0.498}
$$

The iSEC experiments were performed at $22 \pm 2{ }^{\circ} \mathrm{C}$ on a Waters HPLC system with a Model 214 refractive index detector at a flow rate of $0.5 \mathrm{~mL} / \mathrm{min}$. Three different salt concentration, $0 \mathrm{M}$, $0.15 \mathrm{M}$ and $1 \mathrm{M} \mathrm{NaCl}$, were tested all in $20 \mathrm{mM} \mathrm{BTP}-\mathrm{HCl} \mathrm{pH} 7$ buffer.

\subsection{Result and discussion}

\subsubsection{TEM}

Figure 2.2 shows the TEM images of the three resins with and without BSA staining at 10K magnification. All the images shown were taken near the outer surface of resin particles but are representative for the whole particle. The left column shows the BSA-free resin. The uniform, lighter gray areas are the embedding LR white resin and the darker gray areas are solid matrix. Several white areas visible in the images are imperfections resulting from the embedding and/or ultramicrotome processes. All resin structures are similar to previously reported resins based on UNOsphere matrix, which is consists of irregular microparticulate aggregates defining a random pore network with pores as large as $500 \mathrm{~nm}$ [12]. The grafted polymers in Nuvia Q and Nuvia HR Q is not visible in these images, either because their density is insufficient to provide adequate density contrast with the embedding resin or because they collapse in the embedding process.

While the BSA-free samples gave similar images for the three resins, images for BSA saturated samples reveal huge differences in structure. In these images, the stained protein has a darker color than the backbone matrix. For UNO Q, the pore structure of BSA-free and BSAsaturated resin is similar, with only a thin layer of bound BSA appearing on the backbone matrix 

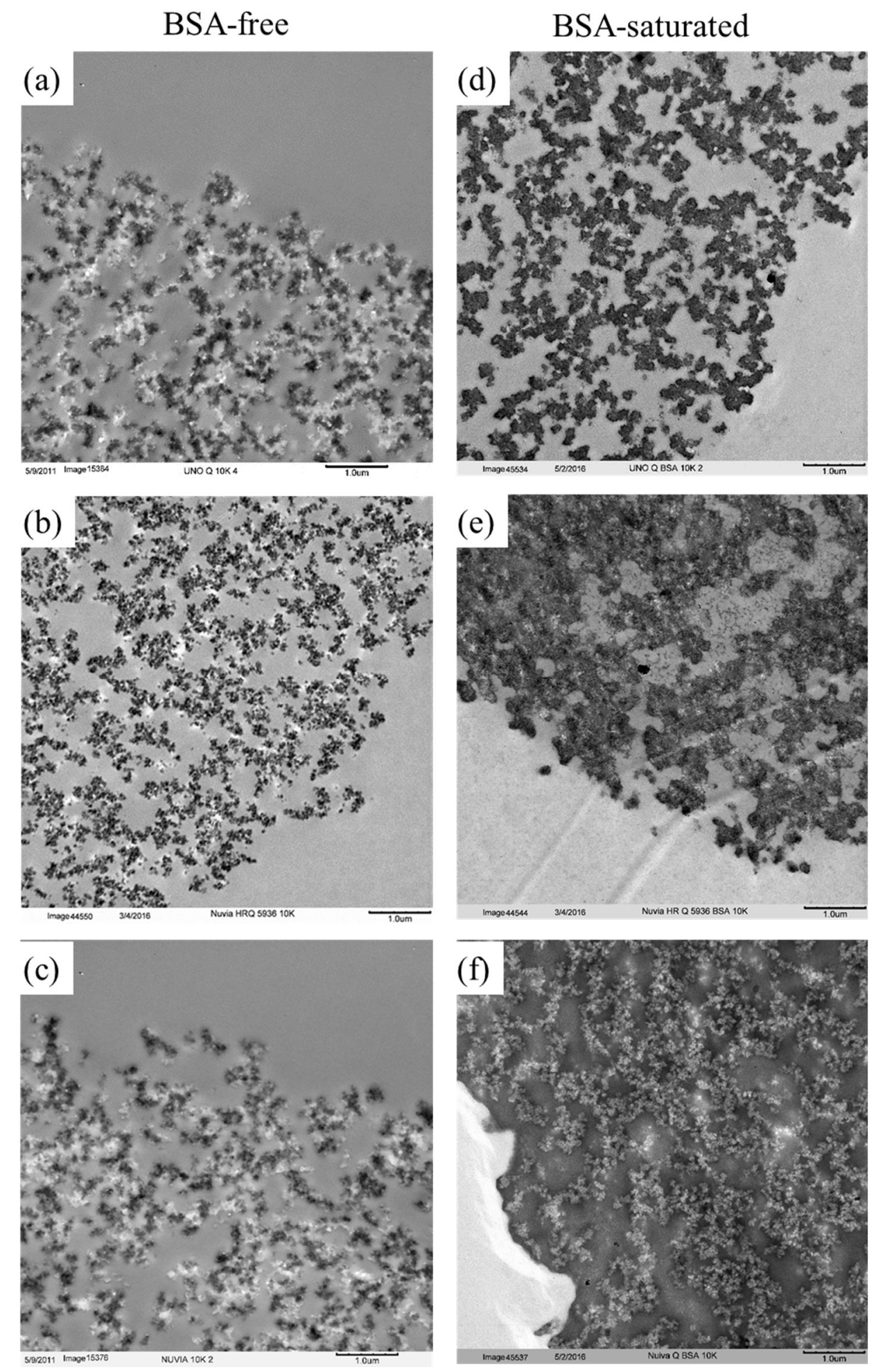

Fig. 2.2 TEM images of BSA-free and BSA-saturated resin samples at $10 \mathrm{~K}$ magnification for UNO (a,d), Nuvia HR Q (b,e), and Nuvia Q (c,f). 
surface. For Nuvia Q, the pore area appears to be almost fully occupied by bound BSA with almost no space left, indicating the grafted polymers fill the pore area and the protein binding happens throughout the pore volume of the support matrix. Nuvia HR Q appears to be intermediate between the other two resins. In this case, while a relatively thick layer of bound BSA is evident surrounding the backbone matrix, substantial open pore areas are still observed.

\subsection{2 iSEC}

Figures 2.3, 2.4 and 2.5 show the iSEC chromatograms for the three resins. For UNO Q (Fig. 2.3), all of the dextran probes up to $r_{h} \sim 40 \mathrm{~nm}$ gain significant access to the particle interior and their retention remains essentially the same at different salt concentrations, indicating that this resin contains relatively large macropores with a rigid structure. For Nuvia HR Q (Fig. 2.4), although retention is less than for UNO Q, all dextrans probes still have some access to the particle interior, the salt concentration has a significant effect resulting in somewhat greater retention at higher salt. This result supports that the grafted polymers in Nuvia HR Q are extended into the pore volume at low salt but collapse slightly at higher salt, likely as a result of shielding of repulsive intrachain and interchain electrostatic interactions [13-15]. For Nuvia Q Fig. 2.5), all dextran probes with hydrodynamic radius greater than about $3 \mathrm{~nm}$ are essentially largely excluded. The salt concentration has again only a small effect suggesting that the grafted polymers form a fairly stable structure. This behavior is similar to that observed previously for other polymer-grafted ion exchangers with a degree of grafting where the polymers essentially fill the intraparticle voids forming a gel phase that prevents access by non-interacting macromolecules [12,14-16]. 

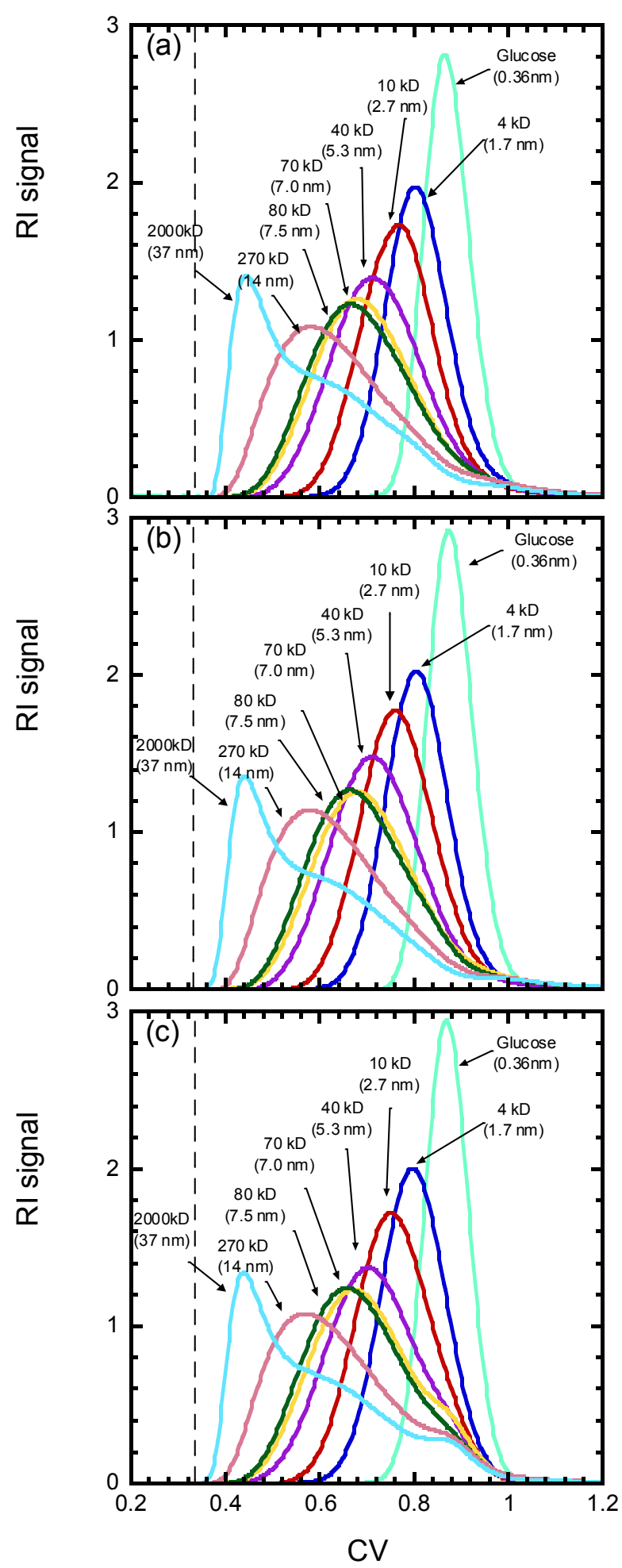

Fig. 2.3 iSEC results for UNO Q in pH 7 buffer containing (a) $0 \mathrm{M}$, (b) $0.15 \mathrm{M}$ and (c) $1 \mathrm{M}$ $\mathrm{NaCl}$. The vertical dash line indicates the estimated extraparticle porosity, $\varepsilon$, obtained from column pressure drop. 

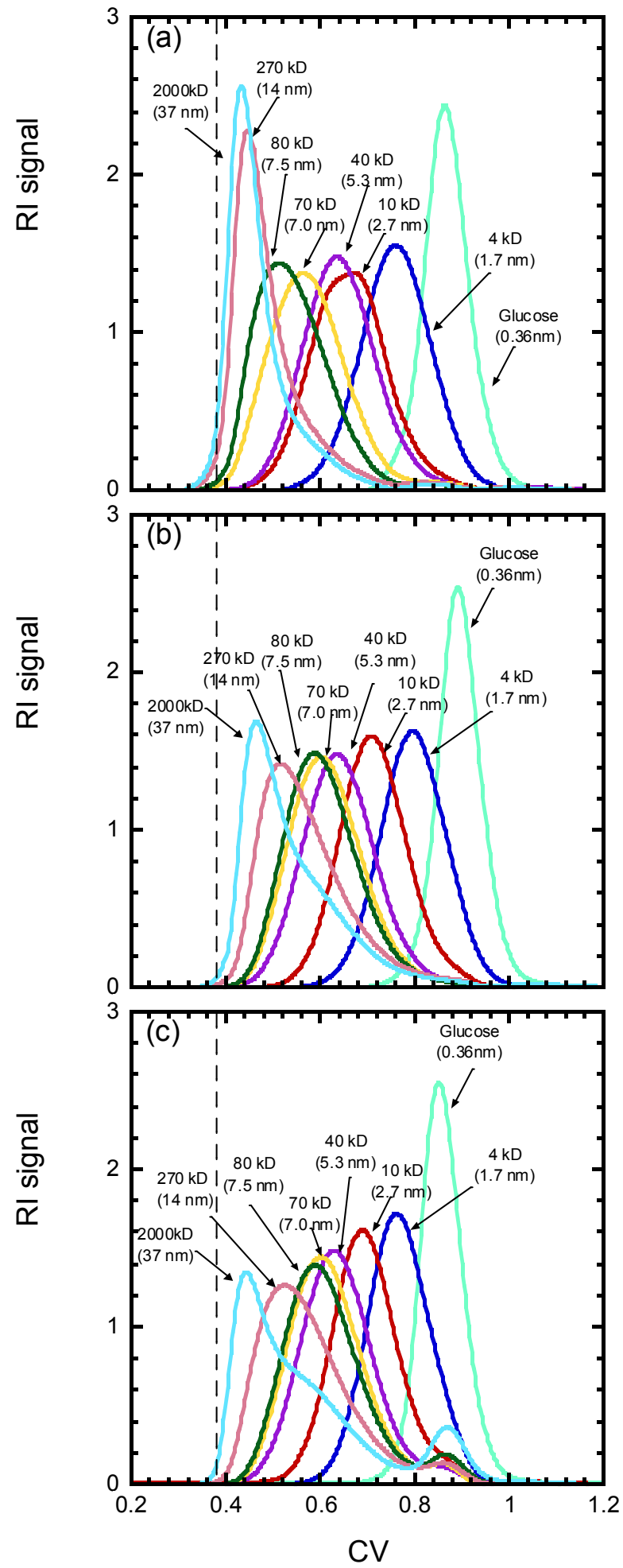

Fig. 2.4 iSEC results for Nuvia HR Q in pH 7 buffer containing (a) $0 \mathrm{M}$, (b) $0.15 \mathrm{M}$ and (c) $1 \mathrm{M}$ $\mathrm{NaCl}$. The vertical dash line indicates the estimated extraparticle porosity, $\varepsilon$, obtained from column pressure drop. 

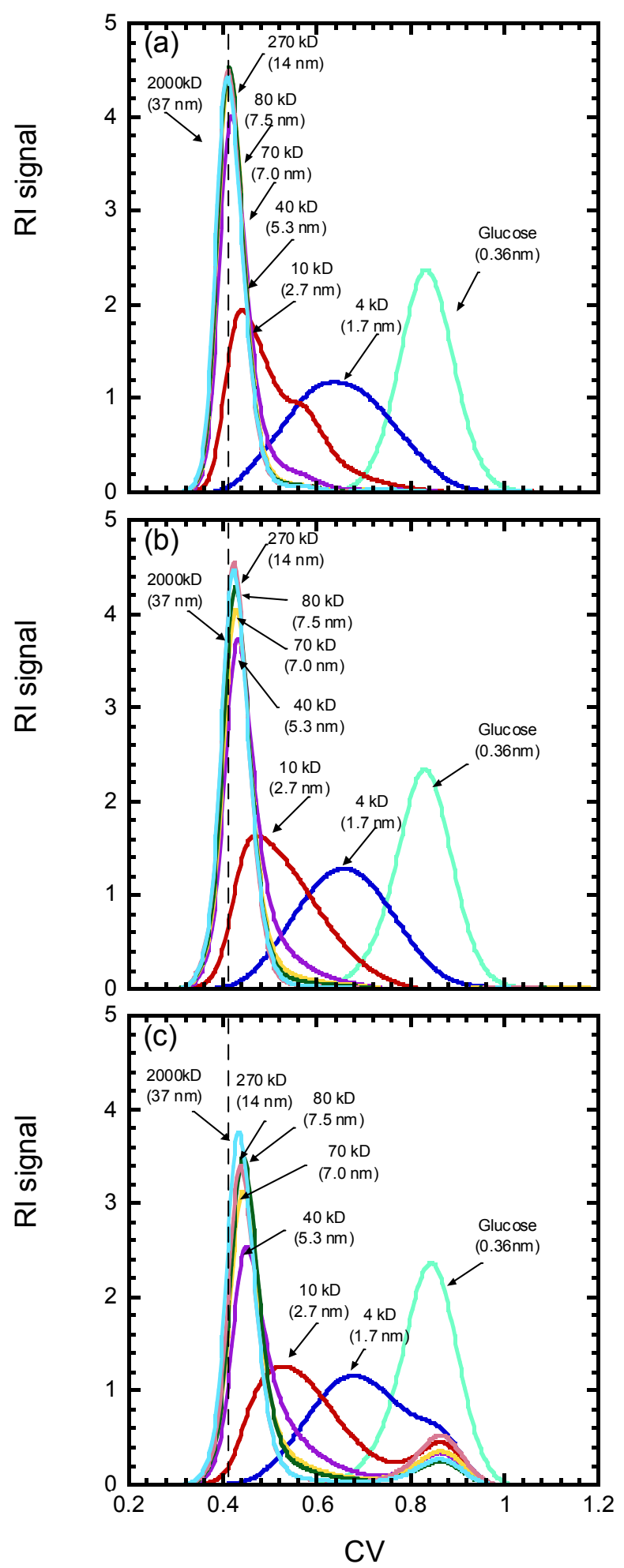

Fig. 2.5 iSEC results for Nuvia Q in pH 7 buffer containing (a) $0 \mathrm{M}$, (b) $0.15 \mathrm{M}$ and (c) $1 \mathrm{M}$

$\mathrm{NaCl}$. The vertical dash line indicates the estimated extraparticle porosity, $\varepsilon$, obtained from 2000 $\mathrm{kD}$ dextran retention. 
Porosities and pore radii obtained from iSEC results are shown in Table 2.1. In each case, an experimental partition coefficient, $K_{D}$, was calculated according to the following equation:

$$
K_{D}=\frac{\overline{C V}-\varepsilon}{1-\varepsilon}
$$

where $\overline{C V}$ is the retention volume at the peak maximum (expressed as a function of the column volume) and $\varepsilon$ is the extraparticle void fraction. For Nuvia Q, since all dextran probes larger than $3 \mathrm{~nm}$ are excluded from the particle interior and elutes at the same volume, $\varepsilon$ was set equal to that eluting volume. For Nuvia HR Q and UNO Q, $\varepsilon$ was obtained by measuring the pressure drop through the column as a function of flow rate and comparing its linear slope to that predicted by the Blake-Kozeny equation [17], which is given by the following expression:

$$
\Delta p=150 \frac{(1-\varepsilon)^{2}}{\varepsilon^{3}} \frac{\eta u L}{d_{p}^{2}}
$$

where $\Delta p$ is the pressure drop in a packed bed with column length $L, d_{p}$ is the average particle diameter, $u$ is the superficial velocity, and $\eta$ is the dynamic viscosity of the mobile phase which is estimated as $1 \mathrm{cp}$ for the low salt buffer used in the experiments. The resulting values of $\varepsilon$ were $0.33 \pm 0.01,0.37 \pm 0.01$ and $0.41 \pm 0.01$ for the UNO Q, Nuvia HR Q, and Nuvia Q columns, respectively. $K_{D}$ determined in this matter represents the fraction of total particle volume accessible to a particular solute.

As shown by several authors (e.g. [18]), different functional forms can typically be assumed for the pore size distribution yielding statistically equivalent descriptions of the $K_{D}$ vs. $r_{h}$ curves. For example, assuming a bimodal distribution of pore sizes the following equation is obtained as a special case of Eq. 7 in ref. [8]:

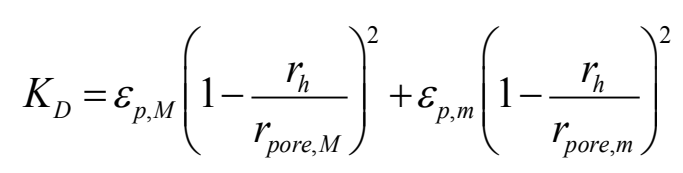


where $\varepsilon_{p, M}$ and $\varepsilon_{p, m}$ are the intraparticle porosities associated with large and small pores, with radius $r_{p o r e, M}$ and $r_{p o r e, m}$, respectively. The parameter values summarized in Table 2.1 were obtained by regressing $K_{D}$ values. Lines calculated from Eq. 2.4 with these parameters are shown in Fig. 2.6. Since directly regressing of the data gave widely varying results for the macropore size, the $K_{D}$ values were regressed using the same macropore radius $(100 \mathrm{~nm})$ for all three resins, and regressing the micropore radius, the microporosity, and the macroporosity.

From the fitting results, for both UNO Q and Nuvia HR Q, the data are consistent with an obviously bimodal distribution of pore sizes and associated porosities. However, both the micropore radius and the macroporosity of UNO Q are larger than those of Nuvia HR Q in all salt concentration. For Nuvia Q, there is almost no macroporosity and the micropore radius is only about $5 \mathrm{~nm}$, indicating that the pores of the support matrix are essentially completely occupied by the polymer grafts. 
Table 2.1 Structure properties of the resins in this work

\begin{tabular}{|c|c|c|c|c|c|c|c|c|c|}
\hline \multirow[b]{2}{*}{ Salt concentration } & \multicolumn{3}{|c|}{ UNO Q } & \multicolumn{3}{|c|}{ Nuvia HR Q } & \multicolumn{3}{|c|}{ Nuvia Q } \\
\hline & $0 \mathrm{M}$ & $0.15 \mathrm{M}$ & $1 \mathrm{M}$ & $0 \mathrm{M}$ & $0.15 \mathrm{M}$ & $1 \mathrm{M}$ & $0 \mathrm{M}$ & $0.15 \mathrm{M}$ & $1 \mathrm{M}$ \\
\hline $\begin{array}{l}\text { Extraparticle } \\
\text { porosity } \varepsilon^{\text {(a) }}\end{array}$ & 0.33 & 0.33 & 0.33 & 0.38 & 0.38 & 0.38 & 0.41 & 0.41 & 0.41 \\
\hline $\begin{array}{l}\text { Total porosity } \\
\varepsilon_{\text {p,total }}\end{array}$ & 0.80 & 0.81 & 0.80 & 0.78 & 0.79 & 0.75 & 0.72 & 0.71 & 0.73 \\
\hline $\begin{array}{l}\text { Microporosity } \\
\varepsilon_{\mathrm{p}, \mathrm{m}}^{(\mathrm{c})}\end{array}$ & 0.33 & 0.35 & 0.36 & 0.61 & 0.55 & 0.46 & 0.71 & 0.68 & 0.66 \\
\hline $\begin{array}{l}\text { Macroporosity } \\
\varepsilon_{\mathrm{p}, \mathrm{M}}^{(\mathrm{c})}\end{array}$ & 0.47 & 0.46 & 0.44 & 0.17 & 0.24 & 0.29 & 0.003 & 0.03 & 0.07 \\
\hline $\begin{array}{l}\text { Micropore radius } \\
(\mathrm{nm}) \mathrm{r}_{\text {pore, } \mathrm{m}}\end{array}$ & 17 & 17 & 17 & 13 & 12 & 12 & 4.9 & 5.2 . & 5.8 \\
\hline $\begin{array}{l}\text { Macropore radius } \\
(\mathrm{nm}) \mathrm{r}_{\text {pore, } \mathrm{M}}\end{array}$ & 100 & 100 & 100 & 100 & 100 & 100 & 100 & 100 & 100 \\
\hline
\end{tabular}

(a) Based on pressure drop for UNO Q and Nuvia HR Q and based on retention of $2000 \mathrm{kD}$ dextran for Nuvia Q.

(b) Based on glucose retention.

(c) Based on bimodal pore size distribution model (Eq. 2.4). 

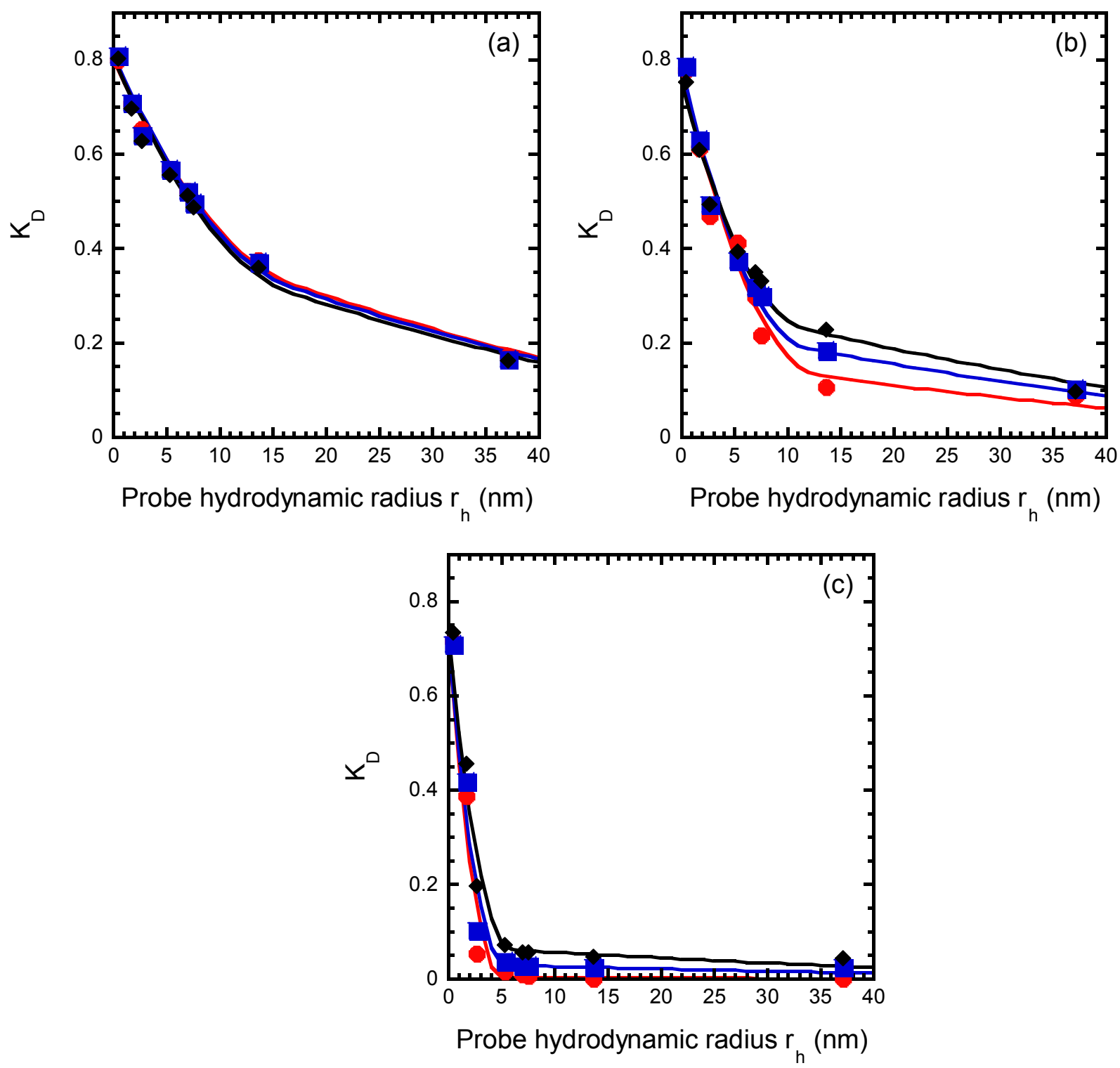

Fig. 2.6 Distribution coefficient $K_{D}$ for glucose, 4, 10, 40, 70, 80, 270 and $2000 \mathrm{kD}$ dextran standards plotted as a function of their hydrodynamic radius for UNO Q (a), Nuvia HR Q (b) and Nuvia Q (c) in pH 7 buffer containing $20 \mathrm{mM} \mathrm{BTP-HCl}$ and $0(\bullet), 0.15$ ( $)$ and $1 \mathrm{M}$ $(\bullet) \mathrm{NaCl}$. The lines are calculated from Eq. 2.3 using the parameters in Table 2.1. 


\subsection{Conclusions}

The pore structures of three anion exchangers based on UNOsphere matrix have been examined. The base matrixes are very similar for all three resins based on the TEM result without protein staining. However, the porosities and pore sizes are highly different after cooperating the matrix with varying length of polymer grafts. For Nuvia Q, the long polymergrafts forms a gel phase occupying almost the whole internal area of the base matrix which excludes neutral probes larger than $3 \mathrm{~nm}$. The pore size barely changes with salt concentration for Nuvia Q indicating the polymers grafted are probably crosslinked into each other and are not easy to collapse. Interestingly, BSA can resolve into Nuvia Q particle under binding condition even though its size is larger than $3 \mathrm{~nm}$. The short grafted polymers in Nuvia HR Q also take up some pore volume and they tend to collapse more as salt concentration increase. What remains to see is how the difference in pore morphology affects protein binding and transport. This is dealt with in Chapter 3 and Chapter 4.

\subsection{List of symbols}

$K_{D} \quad$ partition coefficient in SEC

L column length

$\Delta p \quad$ the pressure drop in a packed bed

$r_{h} \quad$ hydrodynamic radius of size standards (nm)

$r_{p} \quad$ particle radius $(\mathrm{cm})$

$r_{\text {pore }, m}$ radius of small pores $(\mathrm{nm})$

$r_{\text {pore } M}$ radius of large pores $(\mathrm{nm})$

$u \quad$ the superficial velocity

$V_{C} \quad$ column volume 
$V_{R} \quad$ retention volume at the peak maximum of size standards

$\varepsilon \quad$ extraparticle column porosity

$\varepsilon_{p, m} \quad$ intraparticle porosity associated with small pores

$\varepsilon_{p, M} \quad$ intraparticle porosity associated with large pores

$\eta \quad$ the dynamic viscosity of mobile phase

\subsection{Reference}

[1] Y. Yao, A.M. Lenhoff, Pore size distributions of ion exchangers and relation to protein binding capacity, J. Chromatogr. A. 1126 (2006) 107-119.

[2] G. Carta, A. Jungbauer, Protein Chromatography: Process Development and Scale-Up, John Wiley \& Sons, 2010.

[3] S. Brunauer, P.H. Emett, E. Teller, Adsorption of Gases in Multimolecular Layers, J. Am. Chim. Soc. 60 (1936) 309-319.

[4] H.L. Ritter, L.C. Drake, Pressure Porosimeter and Determination of Complete MacroporeSize Distributions. Pressure Porosimeter and Determination of Complete Macropore-Size Distributions, Ind. Eng. Chem. Anal. Ed. 17 (1945) 782-786.

[5] L.G. Aggebrandt, O. Samuelson, Penetration of water-soluble polymers into cellulose fibers, J. Appl. Polym. Sci. 8 (1964) 2801-2812.

[6] J.H. Knox, H.P. Scott, Theoretical models for size-exclusion chromatography and calculation of pore size distribution from size-exclusion chromatography data, J. Chromatogr. A. 316 (1984) 311-332.

[7] I. Halász, K. Martin, Pore Sizes of Solids, Angew. Chemie Int. Ed. English. 17 (1978) $901-908$. 
[8] P. DePhillips, A.M. Lenhoff, Pore size distributions of cation-exchange adsorbents determined by inverse size-exclusion chromatography, J. Chromatogr. A. 883 (2000) 3954.

[9] Practical electron microscopy for biologists., Wiley, 1976.

[10] A.K. Hunter, G. Carta, Protein adsorption on novel acrylamido-based polymeric ionexchangers. I. Morphology and equilibrium adsorption., J. Chromatogr. A. 897 (2000) 6580.

[11] M.C. Stone, G. Carta, Patterns of protein adsorption in chromatographic particles visualized by optical microscopy., J. Chromatogr. A. 1160 (2007) 206-14.

[12] E.X. Pérez Almodóvar, Y. Tao, G. Carta, Protein adsorption and transport in cation exchangers with a rigid backbone matrix with and without polymeric surface extenders., Biotechnol. Prog. 27 (2011) 1264-72.

[13] A.R. Ubiera, G. Carta, Radiotracer measurements of protein mass transfer: kinetics in ion exchange media., Biotechnol. J. 1 (2006) 665-74.

[14] M.C. Stone, G. Carta, Protein adsorption and transport in agarose and dextran-grafted agarose media for ion exchange chromatography., J. Chromatogr. A. 1146 (2007) 202-15.

[15] Y. Tao, G. Carta, G. Ferreira, D. Robbins, Adsorption of deamidated antibody variants on macroporous and dextran-grafted cation exchangers: I. Adsorption equilibrium., J. Chromatogr. A. 1218 (2011) 1519-29.

[16] A.M. Lenhoff, Protein adsorption and transport in polymer-functionalized ionexchangers., J. Chromatogr. A. 1218 (2011) 8748-59.

[17] B. R.B., S. W.E., E.N. Lightfoot, Transport Phenomena, John Wiley \& Sons, 1960. 
[18] L. Hagel, M. Östberg, T. Andersson, Apparent pore size distributions of chromatography media, J. Chromatogr. A. 743 (1996) 33-42. 


\section{Chapter 3}

\section{Adsorption Equilibrium and Transport of Native and PEGylated BSA on}

\section{Anion Exchange Resins with Varying of Polymer Grafting}

\subsection{Introduction}

BSA and PEGylated BSA were used as model proteins to characterize the protein adsorption properties of the anion exchange resins described in Chapter 2. As a model system used to compare adsorption behaviors as a function of grated polymer content, PEGylation offers the ability of change the protein size as well as protein surface interactions without having to change the protein itself.

PEGylated BSA has also practical value as a model for therapeutic proteins. In fact, the conjugation of poly(ethylene glycol) chains, commonly referred to as PEGylation, is an established method to improve biotherapeutics [1-3]. PEGylation can improve pharmacokinetics and pharmacodynamics by prolonging in-vivo half-life and reducing immunogenicity, and improve shelf life by increasing water solubility and reducing aggregation [4,5]. These beneficial effects result mainly from increased molecular size and surface protection, which occur when the neutral, chemically inert PEG polymers are conjugated with the protein. However, as noted by several authors $[2,3,5,6]$, the same altered molecular properties that make PEGylation attractive from a therapeutic viewpoint, also introduce downstream processing complexities. Since PEGylation reactions are seldom completely quantitative, separation of PEGylated protein from native protein and unreacted PEG is often needed. Moreover, when multiple PEGylated species are formed as a result of random or residue-specific PEGylation, the separation of species with different degree of PEGylation as well as the separation of positional isomers may be needed 
[6,7]. While the latter can be minimized by implementing site-directed PEGylation, either through site-directed mutagenesis [8] or via the incorporation of non-natural amino acids [9], the former remains a challenge.

The separation of PEGylated and native protein species can be based on differences in size, charge, or a combination of both. Size exclusion chromatography (SEC) is a direct way of separating PEGylated protein from native protein, but its low productivity makes it undesirable for large-scale manufacture. Thus, SEC is primarily used as an analytical tool while separations based on electrostatic interactions by ion exchange chromatography (IEC), are usually preferred for preparative applications $[5,6,10]$, especially when PEGylation involves reaction with the protein amine groups, which, in turn, changes the protein net charge. Even when PEGylation occurs by reaction with free sulphydryl groups, which are not charged at the $\mathrm{pH}$ values typically used in protein chromatography, specific interactions with the resin surface are often quite different for native and PEGylated molecules as a result of the partial shielding of charged residues caused by the PEG chains. It has been shown that retention of PEGylated species on IEC resin is weaker than that of the corresponding native protein, that it decreases with PEG molecular mass, and that it decreases for multiply PEGylated species on both anion and cation exchangers compared to mono-PEGylated forms [7,11]. The separation of positional isomers is also possible by IEC since the effective surface charge of different isomers can vary with the site of conjugation [6,7,11]. Maiser et al. [11], for example, described the separation of five positional isoforms of mono-PEGylated lysozyme by $\mathrm{pH}$ gradient elution chromatography with a $10 \mu \mathrm{m}$ diameter cation exchanger. However, although the separation was possible, the selectivity was relatively low requiring very high plate numbers usually only obtained at the analytical scale. 
PEGylation also plays a role in the binding capacity and energetics of adsorption on IEC resins. Blaschke et al. [12] recently reported the equilibrium binding capacity of bovine serum albumin (BSA) PEGylated with a $12 \mathrm{kD}$ PEG for several different commercial anion exchangers. The capacity varied from resin to resin but was always lower for the PEGylated protein compared to the native form. The authors concluded that for strong anion exchangers, BSA binding is exothermic and enthalpy driven while the adsorption of PEG-BSA is either endothermic or exothermic dependent on the particular resin. In general, polymer grafted matrices gave higher capacities for both forms.

Finally, PEGylation and the accompanying large increase in molecular size is also likely to affect diffusional hindrance in the stationary phase and, hence, reduce resolution and dynamic binding capacity. Pabst et al. [5], using PEGylated BSA and a range of commercial anion exchange resins at a 1 min residence time, observed reductions in dynamic binding capacity (DBC) between 48 and 92\% for 12 kD PEG-BSA and between 74 and 99\% for $30 \mathrm{kD}$ PEG-BSA, both compared to native BSA at the same residence time. Similar reductions in DBC were reported by Moosmann et al. [3] for 30 kD PEG-lysozyme on several commercial cation exchangers. In that study, however, the effects of PEGylation were less pronounced at low $\mathrm{pH}$ and low salt, when protein binding was strong for both native and PEGylated lysozyme, but quite large at higher $\mathrm{pH}$ values, where binding of PEGylated lysozyme became very weak or nonexistent. Although adsorption kinetics has been postulated to be the underlying reason for the dramatic effects of PEGylation on DBC, to our knowledge direct measurements of adsorption isotherms and kinetics are lacking and only tenuous connections have been made for PEGylated proteins between adsorption kinetics and resin architecture. The kinetics of displacement of native and PEGylated proteins is also not completely understood. As noted by Fee and Van 
Alstine [6], when a mixture of native and PEGylated proteins is loaded onto a chromatography column, sample self-displacement can occur as a result of competition for the same binding sites. On the other hand, this effect is likely impacted by the adsorption kinetics, which, in turn, is influenced by both the molecular properties of native and PEGylated species and the physical properties of the stationary phase.

The objective of here is thus two-fold. The first is to determine single-component adsorption equilibrium properties and binding kinetics for native and PEGylated proteins on anion exchangers with varying grafting polymer length-one with a macroporous structure and the other two based on the same backbone matrix, but with different length of grafted polymer. The second is to determine the multicomponent adsorption kinetics when native and PEGylated proteins are loaded either simultaneously or sequentially on these materials. BSA and BSA PEGylated with 10 and $30 \mathrm{kD}$ PEG chains are used as a model. Adsorptive properties of native and PEGylated BSA are obtained through a combination of chromatographic, batch adsorption, and confocal laser scanning microscopy (CLSM) experiments.

\subsection{Materials and Method}

\subsubsection{Materials}

The anion exchangers used in this work are the same as those described in Chapter 2. The resins are UNO Q, which has no grafted polymers but only short functional ligand; Nuvia HR Q, which has a moderate grafted polymers content; and Nuvia Q, which has a high grafted content. The "grafted polymer content" is defined here based on the iSEC behavior. Since the backbone matrix is the same, resins with higher grafted polymer content (Nuvia Q) exclude dextrans to a greater extent. Based on information obtained from the resin manufacturer, the apparent grafted polymer content and the size exclusion behavior also correlate with the length of the grafted 
polymer, with Nuvia Q having much longer polymer grafts compared to Nuvia HR Q. Unfortunately, precise information about different polymer lengths is not available. We thus refer to the iSEC behavior and the associated porosity and pore radius values, as metrics to define grafted polymer content. All resins are based on the same polymeric backbone and contain quaternary ammonium ion functional groups. Relevant properties of these materials are summarized in Table 2.1 in Chapter 2.

Bovine serum albumin (BSA) $\left(\mathrm{M}_{\mathrm{r}} \sim 66 \mathrm{kD}, \mathrm{pI} \sim 5\right)$ with $\geq 98 \%$ purity based on agarose gel electrophoresis was obtained from Sigma-Aldrich (St. Louis, MO, USA, Type A7906). The sample was further purified by SEC using a Superdex 200 column from GE Healthcare (Piscataway, NJ, USA) to remove the BSA dimers and oligomers that were found present at a level of about $20 \%$ of the total protein. Maleimido-PEG reagents were obtained to produce PEGBSA conjugates. Linear 10 kD PEG-maleimido reagent was from Jenkem Technology (Beijing, China) while linear 30 kD PEG-maleimido reagent was from NOF Corporation (White Plains, NY, USA). Chemicals for buffer preparation, Tris, BisTris-propane (BTP) and $\mathrm{HCl}$, were from Sigma-Aldrich (St. Louis, MO, USA) and Fisher Scientific (Pittsburg, PA, USA). For consistency with prior $[4,13]$, all protein concentrations reported in this work, both in solution and adsorbed, are expressed in terms of the mass of BSA alone whether the protein was PEGylated or not. Concentrations were thus calculated using the BSA extinction coefficient determined experimentally at $280 \mathrm{~nm}$. The total concentration including the mass of PEG conjugated is found simply by multiplying the protein concentration times $76 / 66$ for $10 \mathrm{kD}$ PEGBSA and times $96 / 66$ for $30 \mathrm{kD}$ PEG-BSA. 


\subsubsection{Methods}

\subsubsection{PEGylation reactions}

PEGylations were conducted by dissolving the crude BSA in $20 \mathrm{mM} \mathrm{BTP-HCl}$ at $\mathrm{pH} 7.0$, adding the PEG-maleimido reagent to the solution in a 1:1 in molar ratio, and allowing the reaction to proceed for $24 \mathrm{~h}$ at room temperature $\left(22 \pm 2{ }^{\circ} \mathrm{C}\right)$ under gentle agitation. The progress of the reaction was monitored by SEC with a Superdex 200 column from GE Healthcare (Piscataway, NJ, USA). Preparative separation of unreacted PEG, PEG-BSA, and unreacted BSA was obtained by loading $16 \mathrm{~mL}$ of reaction mixture on a 10x100 mm Source 15Q column from GE Healthcare (Piscataway, NJ, USA), washing with $2 \mathrm{CV}$ of the load buffer to remove unreacted PEG-reagent, and eluting the PEG-BSA at an intermediate salt concentration (85 mM $\mathrm{NaCl}$ for $10 \mathrm{kD}$ PEG-BSA and $50 \mathrm{mM} \mathrm{NaCl}$ for $30 \mathrm{kD}$ PEG-BSA). After elution, the column was regenerated with $1 \mathrm{M} \mathrm{NaCl}$ to remove unreacted BSA, BSA oligomers, and PEGylated BSA oligomers. Both elution and regeneration were conducted at $3 \mathrm{~mL} / \mathrm{min}$. Hydrodynamic radii of the components in the fractions isolated from these runs were obtained at $20{ }^{\circ} \mathrm{C}$ by dynamic light scattering (DLS) using a Dynapro Nanostar unit (Wyatt Technology Corporation, CA, USA). These radii were determined as z-averages using a cumulant fit of the autocorrelation function, which correspond to a single exponential decay [14]. The PEG-BSA conjugates obtained in this manner were found to be relatively stable at $\mathrm{pH}<7.5$ and could be stored at $4^{\circ} \mathrm{C}$ for a few days without detectable change.

\subsubsection{Linear gradient elution}

Linear gradient elution (LGE) experiments were conducted at $22 \pm 2{ }^{\circ} \mathrm{C}$ with an AKTA Explorer 10 from GE Healthcare (Piscataway, NJ, USA) to determine the binding behavior at low protein loads in a $\mathrm{BTP}-\mathrm{HCl} \mathrm{pH} 7$ buffer. For this purpose, UNO Q and Nuvia Q were slurry 
packed in $5 \times 100 \mathrm{~mm}$ Tricorn columns to bed heights of 10.0 and $10.5 \mathrm{~cm}$, respectively. Nuvia HR Q was slurry packed in $5 \times 200 \mathrm{~mm}$ Tricorn column to bed heights of $18.2 \mathrm{~cm}$. Samples $(0.2$ $\mathrm{mL}$ ) containing ca. $1 \mathrm{mg} / \mathrm{mL}$ concentration of either BSA or PEG-BSA were loaded into the column, washed with two column volumes of the load buffer, and eluted at flowrate of 2 min residence time with linear $\mathrm{NaCl}$ gradients with lengths between 2.5 and $20 \mathrm{CV}$.

\subsubsection{Adsorption isotherms and batch adsorption kinetics}

Adsorption isotherms were obtained at $22 \pm 2{ }^{\circ} \mathrm{C}$ by first equilibrating resin samples with $20 \mathrm{mM}$ BTP- $\mathrm{HCl}$ buffer at $\mathrm{pH} 7.0$ and then centrifuging them at $5000 \mathrm{rpm}$ for $20 \mathrm{~min}$ in a microcentrifuge filter to remove the extraparticle solution. Weighed samples of each centrifuged resin were then added to $1.5 \mathrm{~mL}$ tubes containing solutions with different initial protein concentrations in $20 \mathrm{mM}$ BTP-HCl buffer at $\mathrm{pH}$ 7. The amount of resin added to each tube was estimated to provide a $50 \%$ change in protein concentration. After rotating the tubes end-overend at a low rpm for 20 to $24 \mathrm{~h}$, the supernatant protein concentration was measured with a NanoVue spectrophotometer (GE Healthcare, Piscataway, NJ, USA). The adsorbed protein concentration per unit of volume of the hydrated particle was then calculated by mass balance using a resin hydrated particle density of $1.08 \mathrm{mg} / \mathrm{mL}$ for both materials as determined with a pycnometer.

The kinetics of the adsorption process was also investigated by a batch method as described in ref. [15]. In this case, samples of each centrifuged resin were added to $20 \mathrm{~mL}$ of 20 $\mathrm{mM}$ BTP-HCl pH 7 buffer containing $1 \mathrm{mg} / \mathrm{mL}$ protein. The amount of resin added was again estimated to give a $50 \%$ change in the supernatant protein concentration. The solution was agitated with a small paddle stirrer and a stream continuously recirculated through a filter and a 
UV detector connected to a data acquisition system. The amount of protein bound as a function of time was obtained by material balance using the UV readings.

\subsubsection{Confocal microscopy}

Confocal laser scanning microscopy (CLSM) was used to image the movement of BSA and PEGylated BSA inside the resin beads. Rhodamine $\operatorname{Red}^{\mathrm{TM}}-\mathrm{X}$ dye and Rhodamine Green ${ }^{\mathrm{TM}}-$ X dye, obtained from Invitrogen Corporation (Carlsbad, CA, USA), were used to fluorescently label BSA and PEGylated BSA, respectively, by reaction mostly with primary amine residues. The reactions were conducted for $1 \mathrm{~h}$ at room temperature in the dark with a dye-to-protein molar ratio of 3:1 at $\mathrm{pH} 8.5$ and 7.5 for BSA and PEGylated BSA, respectively. The unreacted dye was separated by size exclusion chromatography using an Econo-Pac 10 DG desalting column from Bio-Rad Laboratories (Hercules, CA, USA). Average labeling ratios of 0.18 and 0.08 were obtained for BSA and PEGylated BSA, respectively. For the CLSM experiment, each labeled protein was diluted with unlabeled protein in a ratio of 1:20 and 1:10 for BSA and PEGylated BSA, respectively. In order to test whether the dyes used cause aggregation or affect interactions with the anion exchangers in this work, we tested the BSA labeled with Rhodamine Red by SEC with the Superdex column described in Section 3.2.2.1 and by LGE with the UNO Q and Nuvia Q columns described in Sections 3.2.2.2, both with detection at 280nm and at 570 $\mathrm{nm}$, which is the dye absorption maximum. As shown in Figs 3.1 and 3.2, conjugation with the dye had no effect on SEC and did not significantly change retention in the LGE experiments suggesting that for these conditions labeling did not affect protein-protein interactions or interactions between the protein and the anion exchange resins. Similar results were obtained for dye-labeled $10 \mathrm{kD}$ and $30 \mathrm{kD}$ PEG-BSA. 
CLSM was carried with a Zeiss LSM 510 microscope with a Plan-Apochromat 63X/1.4 NA oil objective (Carl Zeiss MicroImaging, LLC, Thornwood, NY, USA). A buffered 50\% $(\mathrm{w} / \mathrm{w})$ sucrose solution was used as a refractive index matching fluid to obtain transparent views of the resin beads as discussed in refs. [16] and [17]. For one and two-component co-adsorption experiments, a small amount of each resin was placed in vials containing an excess volume of protein solution and gently rotate end-over-end. At periodic times, a small amount of the suspension was pipetted out and rapidly centrifuged to separate the particles. The particles were then placed in sucrose solution on a microscope slide and imaged by CLSM. For the sequential adsorption experiments, resin samples saturated overnight with PEGylated BSA were isolated by centrifugation and added to an excess volume of a $1 \mathrm{mg} / \mathrm{mL}$ BSA solution. The procedure described above was then repeated to monitor the sequential binding process by CLSM. All CLSM experiments were conducted at $22 \pm 2{ }^{\circ} \mathrm{C}$.

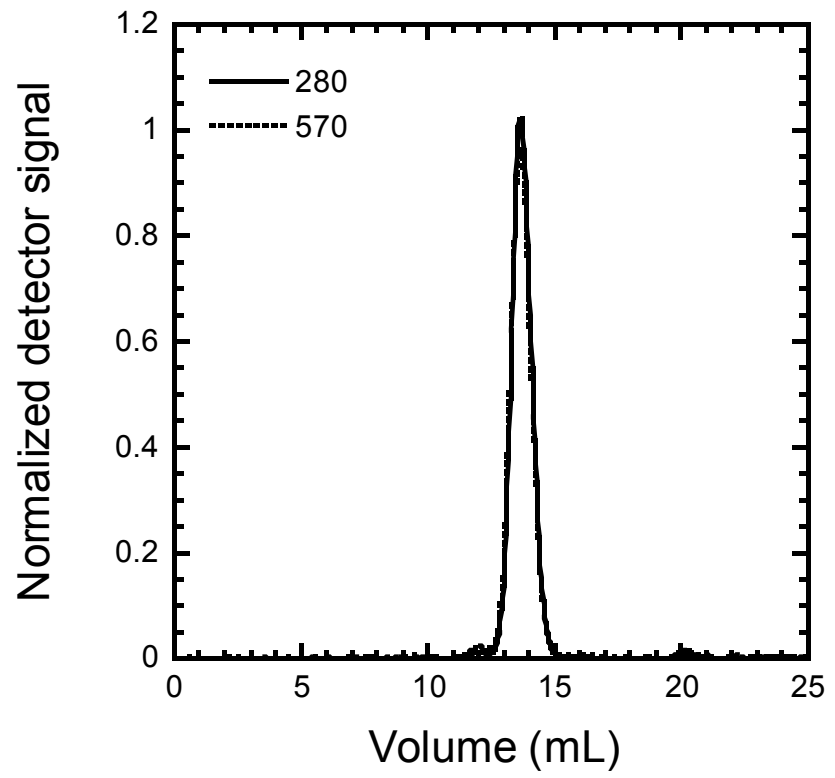

Fig. 3.1. SEC analysis of Rhodamine Red labeled BSA on a Superdex 200 column (GE Healthcare, Piscataway, NJ, USA). The labeling ratio was 0.18. 

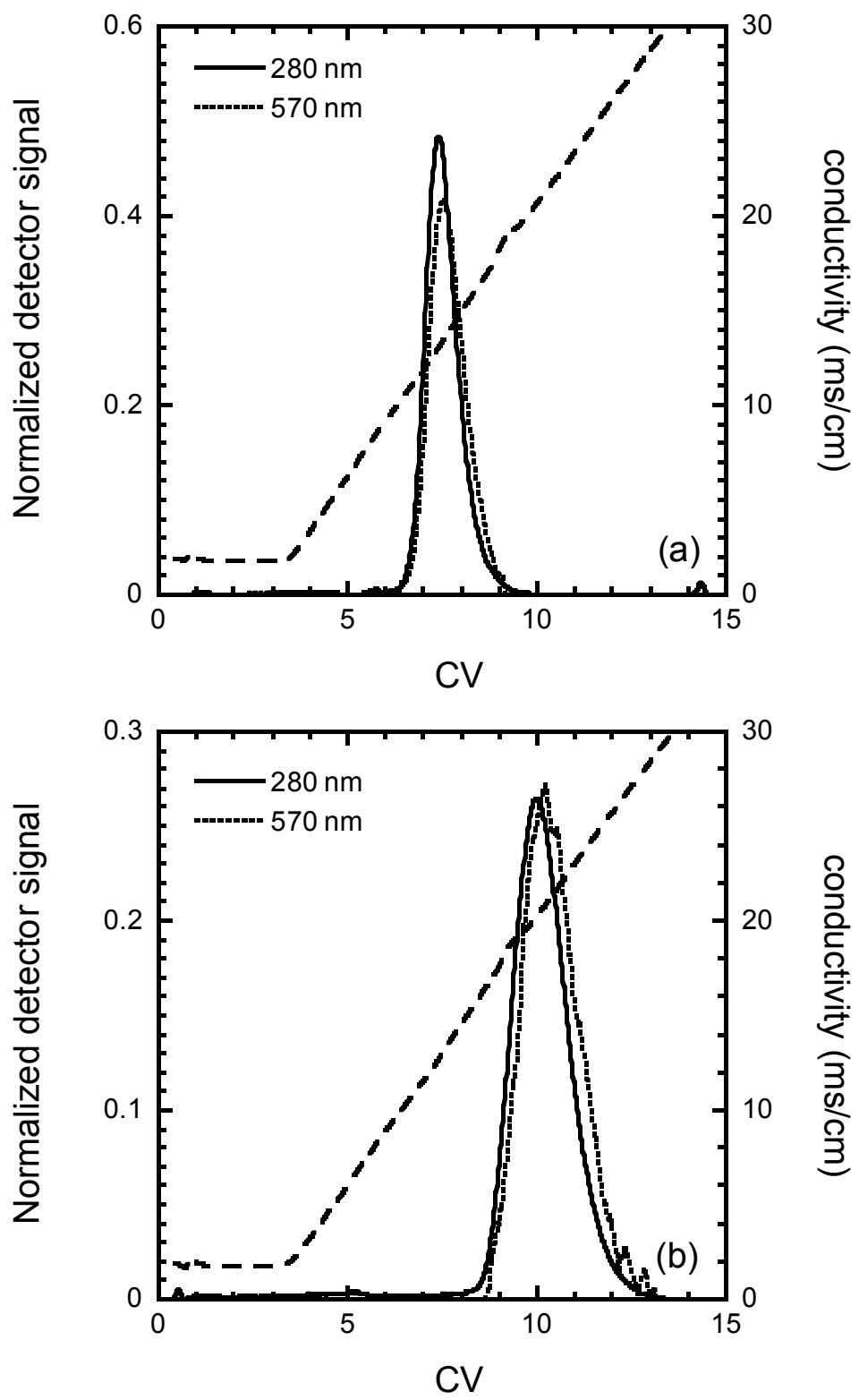

Fig. 3.2. LGE analysis of Rhodamine Red labeled BSA on a $0.5 \times 10 \mathrm{~cm}$ UNO Q column (a) and $0.5 \times 10 \mathrm{~cm}$ Nuvia Q column (b). The labeling ratio was 0.18 . Buffer A: $20 \mathrm{mM} \mathrm{BTP-HCl,} \mathrm{pH}$, Buffer B: 1 M NaCl, 20 mM BTP-HCl, pH 7, Flowrate: 1 mL/min, Sample: 2 mg/mL, $200 \mu \mathrm{L}$ injection, Wash $2 \mathrm{CV}$, Gradient: 0-30\% Buffer B in $10 \mathrm{CV}$. 


\subsection{Results and Discussion}

\subsubsection{PEGylation results}

Figure 3.3 shows the preparative purification of $10 \mathrm{kD}$ PEG-BSA along the SEC analyses of the final PEGylation mixture and of the fractions indicated. Similar results were obtained for the synthesis and preparative purification of $30 \mathrm{kD}$ PEG-BSA (results not shown for brevity). The hydrodynamic radius, $r_{h}$, obtained by DLS for the purified fractions are shown in Table 3.1 along with values estimated from the following correlation $[5,13]$ :

$$
r_{h}=0.082\left(M_{r, \text { prot }}\right)^{\frac{1}{3}}+0.373+0.00011 M_{r, \text { PEGtot }}
$$

where $r_{h}$ is in nm and $M_{r, \text { prot }}$ and $M_{r, \text { PEGtot }}$ are the molar masses of the protein and total conjugated PEG chains, respectively. As seen from these results, the early eluting peak is substantially pure by SEC and contains primarily mono PEGylated BSA. This occurs because the maleimido-PEG reagent used is reactive primarily with free sulfhydryl group, of which the BSA molecules have just one [5,18].

Table 3.1 Diffusivity and hydrodynamic radius of purified BSA and PEGylated BSA.

\begin{tabular}{|l|c|c|c|}
\hline & $D_{0}\left(10^{-7} \mathrm{~cm}^{2} / \mathrm{s}\right)^{(\mathrm{a})}$ & $r_{h}(\mathrm{~nm})^{(\mathrm{a})}$ & Estimated $r_{h}(\mathrm{~nm})^{(\mathrm{b})}$ \\
\hline BSA & $6.0 \pm 0.2$ & $3.7 \pm 0.2$ & 3.7 \\
\hline $10 \mathrm{kD}$ PEG-BSA & $4.5 \pm 0.2$ & $4.8 \pm 0.2$ & 4.8 \\
\hline $30 \mathrm{kD}$ PEG-BSA & $3.1 \pm 0.1$ & $6.6 \pm 0.2$ & 7.0 \\
\hline
\end{tabular}

(a) determined by DLS

(b) estimated from Eq. 3.1 for mono PEGylated BSA 


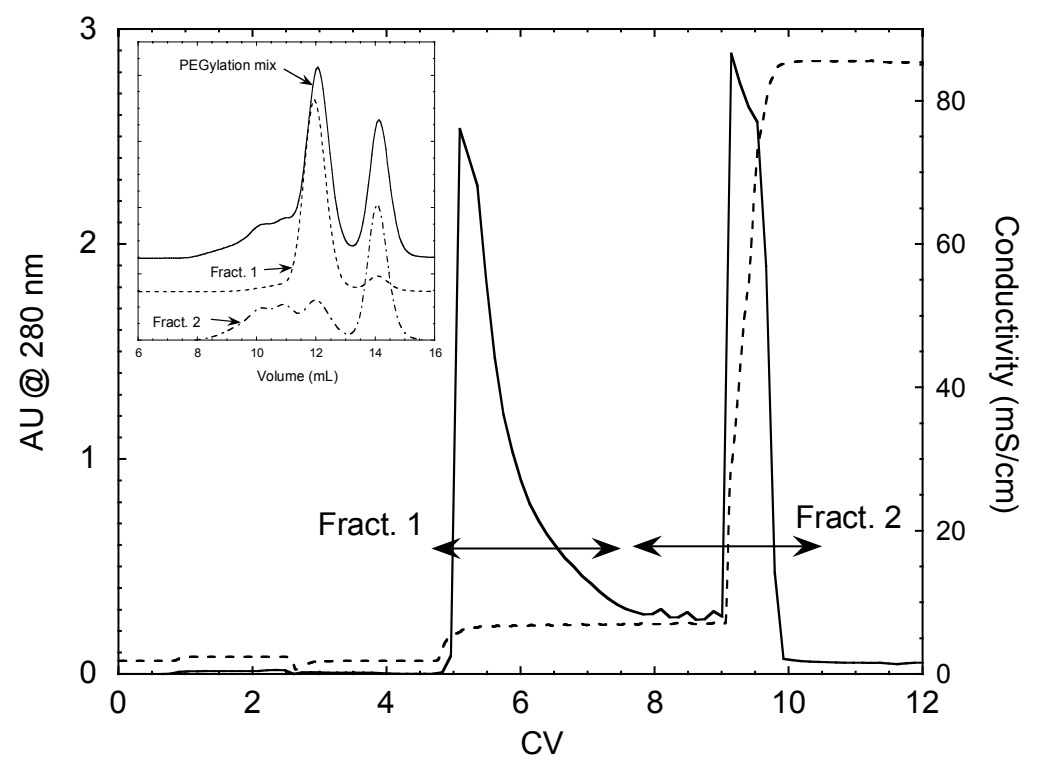

Fig. 3.3. Preparative separation of BSA and $10 \mathrm{kD}$ PEG-BSA by step elution with a $10 \times 100 \mathrm{~mm}$ Source 15Q column. Inset shows the SEC analyses of the PEGylation mixture and of the fractions indicated conducted with a Superdex 200 SEC column

\subsubsection{Retention behavior}

Figure 3.4 shows representative LGE results for both single species and mixture using 20 $\mathrm{CV}$ gradients from 0 to $400 \mathrm{mM} \mathrm{NaCl}$ at $\mathrm{pH}$ 7. The resolution is affected by the combination of the strength of electrostatic interaction and steric hindrance. For all resins, the 30 and $10 \mathrm{kD}$ PEG-BSA elute earlier than native BSA. Similar results have been reported by several researchers with smaller proteins like lysozyme [5-7]. On the other hand, it is evident that greater resolution is attained with the polymer grafted resins especially with Nuvia Q. For BSA, clearly, the retention on Nuvia HR Q and Nuvia Q is much stronger comparing to UNO Q. For $10 \mathrm{kD}$ PEG-BSA, retention is greater for the grafted resins as indicated by the higher conductivity at elution. For $30 \mathrm{kD}$ PEG-BSA, grafting also increases retention, but only for Nuvia HR Q. Retention is almost the same for UNO Q and Nuvia Q. We summarize that while, in general, the charged grafted polymers provide stronger interactions regardless of the 
PEGylation, size exclusion effects become increasingly dominant as grafting is increased, and eventually offsetting the increase in electrostatic interaction. 


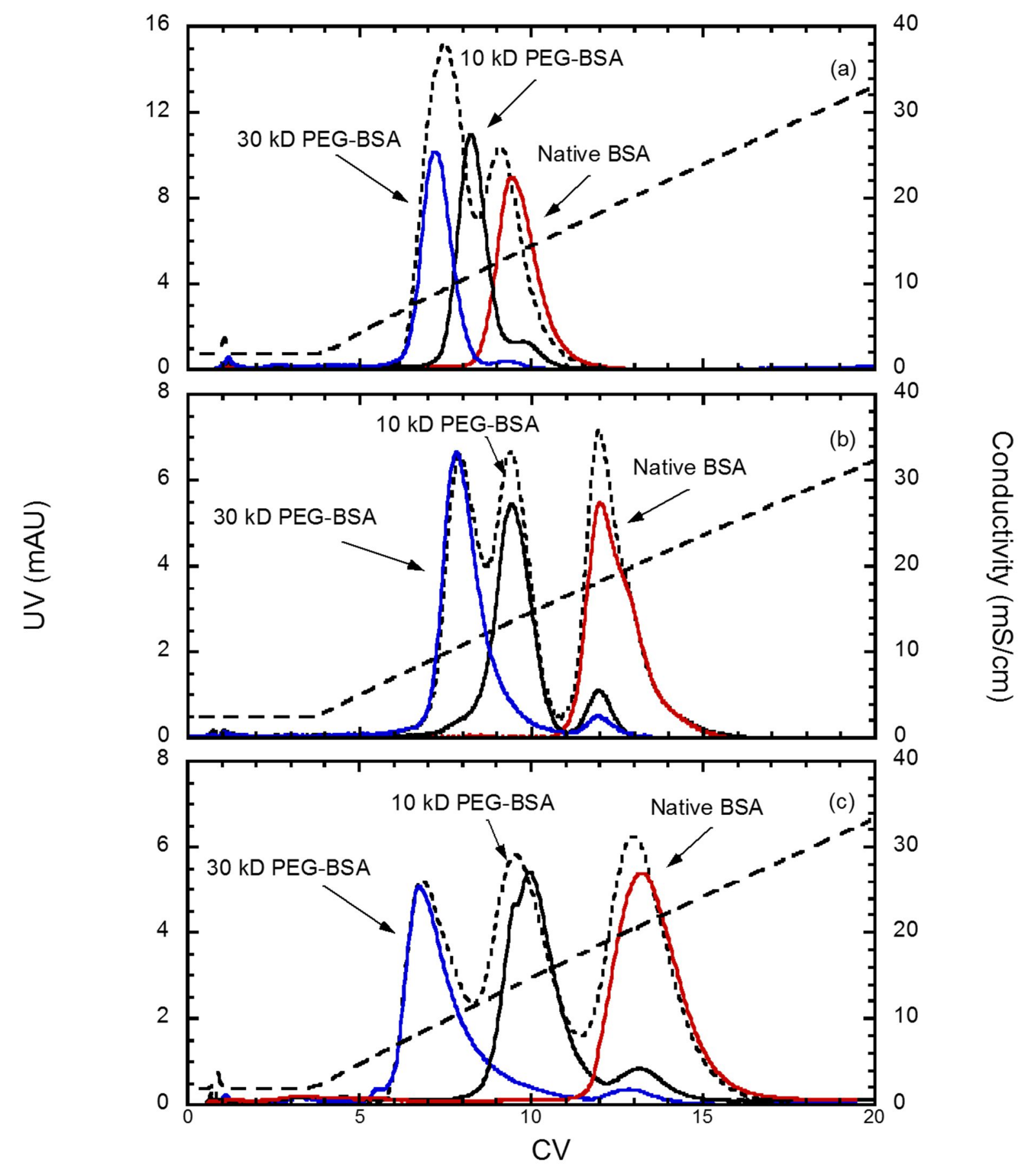

Fig. 3.4. LGE chromatograms of BSA, 10 kD PEG-BSA, and 30 kD PEG-BSA on UNO Q (a), Nuvia HR Q (b) and Nuvia Q (c) using 20 CV, 0-400 mM NaCl gradients in $20 \mathrm{mM}$ BTP-HCl pH 7 buffer at flowrate equivalent to 2 minute residence time. The short dashed lines show the UV trace obtained by injecting a mixture of the three components. 
Figure 3.5 shows the effect of the normalized gradient slope, $\gamma=\varepsilon\left(C_{C l^{-}}^{f}-C_{C l^{-}}^{0}\right) / C V_{G}$, on the concentration of the displacing ion $\left(\mathrm{Cl}^{-}\right)$at elution, $\mathrm{C}_{\mathrm{Cl}^{-}}^{\mathrm{E}}$, where $\mathrm{C}_{\mathrm{Cl}^{-}}^{0}$ and $\mathrm{C}_{\mathrm{Cl}^{-}}^{f}$ are the initial and final $\mathrm{Cl}^{-}$concentrations, respectively, and $C V_{G}$ is the gradient duration in $\mathrm{CV}$ units. The results show that the salt concentration at elution is lower for shallower gradients as expected. Following Yamamoto et al. $[19,20]$, the relationship between $\gamma$ and $C_{C l^{-}}^{E}$ can be written as $[15,21]:$

$$
\gamma=\int_{C_{C l^{-}}^{0}}^{C_{C l^{-}}^{E}} \frac{d C_{C l^{-}}}{k^{\prime}-k_{C l^{-}}^{\prime}}
$$

where $k^{\prime}=A\left(C_{C l^{-}}\right)^{-z}+k_{\infty}^{\prime}$ is the protein retention factor, $k_{C l^{-}}^{\prime}$ is the retention factor of the displacing ion, and $k_{\infty}^{\prime}$ is the protein retention factor when $C_{C^{-}} \rightarrow \infty$, i.e. for non-binding conditions. The effective charge $z$ and the parameter $A$ describe how the protein interacts with the resin. According to the stoichiometric displacement model[22-24], $z$ describes the number of charged ligands that interact with the bound protein molecule while $A$ is related to the binding affinity. These parameters were obtained by regressing Eq. 3.2 to the data in Fig. 3.5 using values of $k_{\mathrm{Cl}^{-}}^{\prime}$ and $k_{\infty}^{\prime}$ estimated from pulse injections of $\mathrm{NaCl}$ and of each protein in $\mathrm{BTP}-\mathrm{HCl}$ pH 7 buffer containing $500 \mathrm{mM} \mathrm{NaCl}$. The resulting values of $k_{\mathrm{Cl}^{-}}^{\prime}$ were $1.69 \pm 0.05,1.17 \pm 0.01$ and $1.37 \pm 0.01$, for the UNO Q, Nuvia HR Q, and Nuvia Q columns, respectively. The values of $k_{\infty}^{\prime}$ are given in Table 3.2. As seen from this table, the $z$-values decrease significantly with PEGylation for UNO Q. However, they remain approximately constant for Nuvia HR Q and Nuvia Q. These results suggest that retention on the surface of the macroporous resin UNO Q is likely more orientation specific; i.e. dependent on a patch of negatively charged residues on the 
protein surface that becomes increasingly shielded with PEGylation. On the other hand, retention within the gel phase formed by the grafted polymers in Nuvia Q and Nuvia HR Q may be more closely associated with the protein net charge. In this case, retention may become weaker because of size exclusion rather than charge shielding.

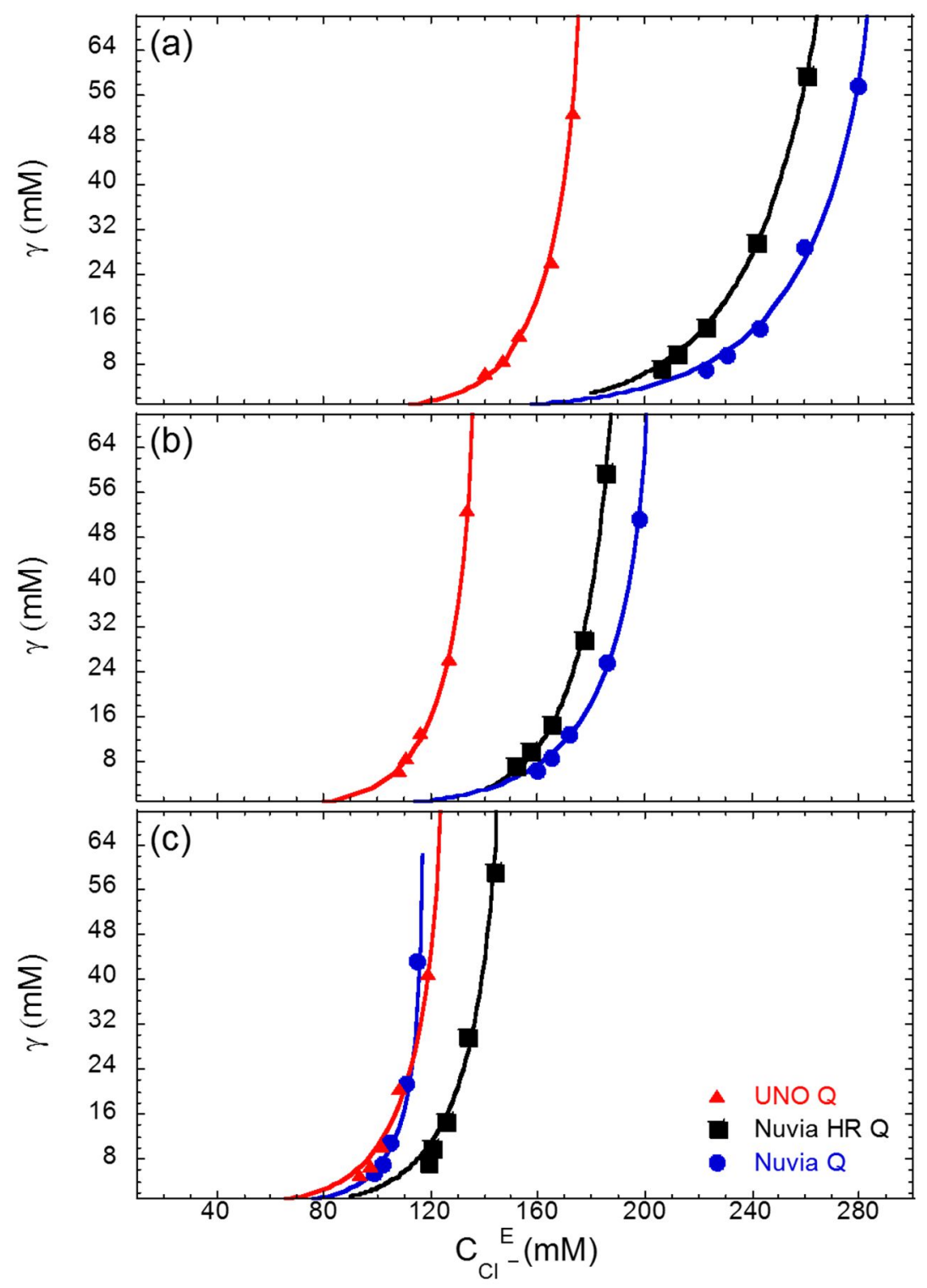

Fig. 3.5. Plot of normalized gradient slope vs. chloride concentration at elution for BSA (a), 10 kD PEG-BSA (b) and $30 \mathrm{kDa}$ PEG-BSA (c). Lines are calculated from Eq. 3.2 with parameters in Table 3.2. 
Table 3.2 Retention parameters based on LGE results.

\begin{tabular}{|c|c|c|c|c|c|c|c|c|c|}
\hline & \multicolumn{3}{|l|}{ UNO Q } & \multicolumn{3}{|c|}{ Nuvia HR Q } & \multicolumn{3}{|l|}{ Nuvia Q } \\
\hline & $\mathrm{z}$ & $\begin{array}{l}\log \mathrm{A} \\
(\mathrm{mM})^{\mathrm{z}}\end{array}$ & $k_{\infty}^{\prime}$ & $\mathrm{z}$ & $\begin{array}{l}\log \mathrm{A} \\
(\mathrm{mM})^{\mathrm{z}}\end{array}$ & $k_{\infty}^{\prime}$ & z & $\begin{array}{l}\log \mathrm{A} \\
(\mathrm{mM})^{\mathrm{z}}\end{array}$ & $k_{\infty}^{\prime}$ \\
\hline BSA & $7.05 \pm 0.23$ & $15.67 \pm 0.51$ & $1.12 \pm 0.02$ & $6.42 \pm 0.41$ & $15.42 \pm 0.98$ & $0.79 \pm 0.01$ & $5.17 \pm 0.22$ & $12.85 \pm 0.54$ & $0.17 \pm 0.02$ \\
\hline $\begin{array}{l}10 \mathrm{kD} \\
\text { PEG-BSA }\end{array}$ & $5.65 \pm 0.13$ & $11.92 \pm 0.28$ & $1.03 \pm 0.02$ & $7.48 \pm 0.15$ & $16.77 \pm 0.33$ & $0.73 \pm 0.01$ & $4.98 \pm 0.14$ & $11.61 \pm 0.32$ & $0.12 \pm 0.02$ \\
\hline $\begin{array}{l}30 \mathrm{kD} \\
\text { PEG-BSA }\end{array}$ & $4.59 \pm 0.37$ & $9.50 \pm 0.75$ & $0.99 \pm 0.03$ & $6.23 \pm 0.60$ & $13.26 \pm 1.27$ & $0.68 \pm 0.02$ & $5.64 \pm 0.15$ & $11.76 \pm 0.31$ & $0.11 \pm 0.01$ \\
\hline
\end{tabular}

\subsubsection{Adsorption capacity and kinetics}

Figure 3.6 shows the batch adsorption isotherms of the three proteins on all three resins for 20 -hr adsorption time. The average relative standard deviation of these measurements was $15 \%$ based on triplicate runs. The lines shown in this figure are based on a fit of the data with the Langmuir isotherm:

$$
q=\frac{q_{m} K C}{1+K C}
$$

with the regressed parameters shown in Table 3.3. The q-values shown are based on the wet particle volume. This volume can be converted to column binding capacity (in $\mathrm{mg}$ per $\mathrm{mL}$ of packed bed) by multiplying $q$ times $(1-\varepsilon)$ where $\varepsilon$ is the extraparticle porosity of the packed bed. For BSA and $10 \mathrm{kD}$ PEG-BSA, the binding capacity increases with the extent of polymer grafting. This increase can be attributed to the 3-D partitioning of protein inside the gel phase formed by the grafted polymer [25], which is consisted with the TEM result as described in Section 2.3.2. 

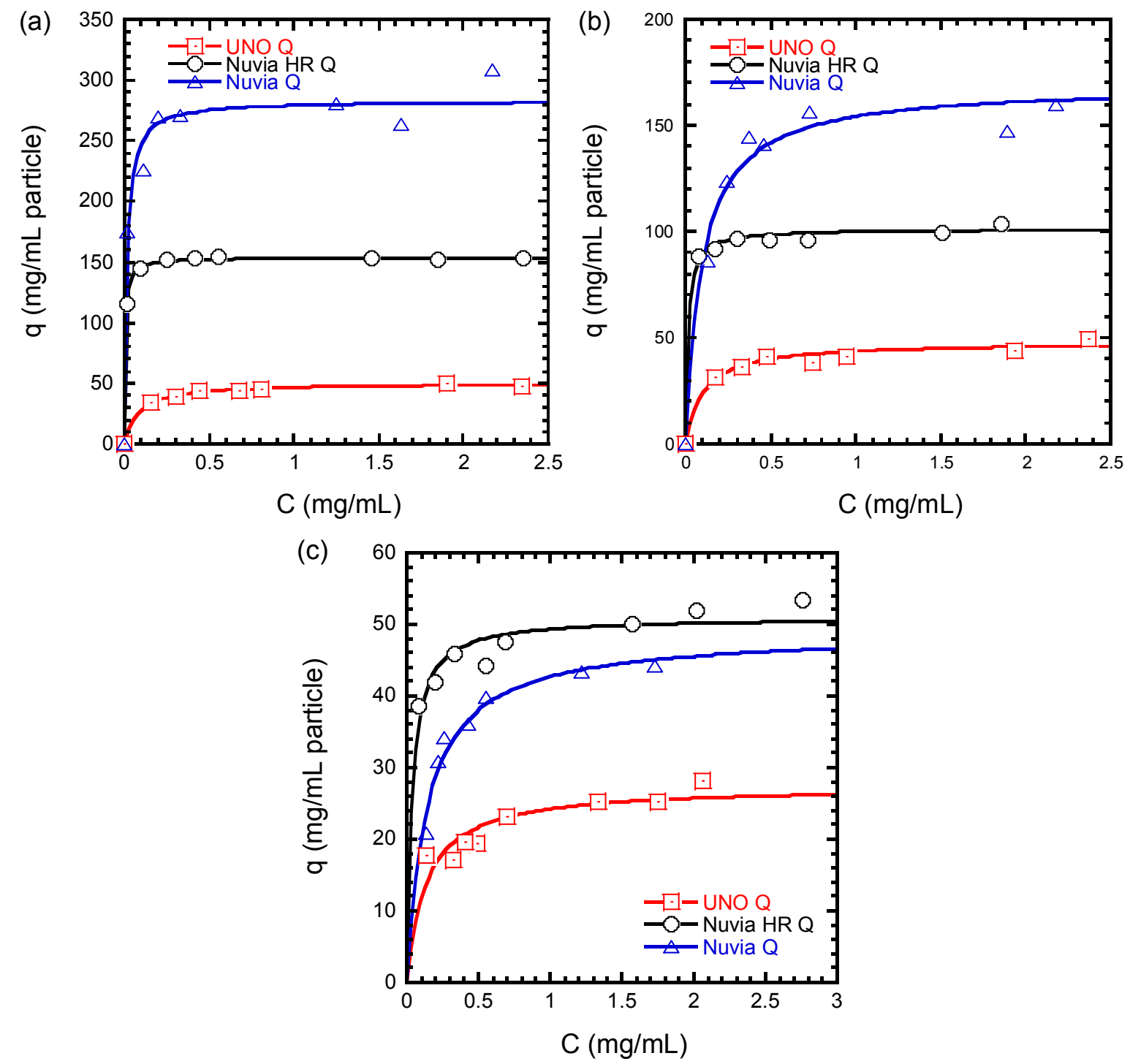

Fig. 3.6 Adsorption isotherms of BSA (a), 10 kD PEG-BSA (b) and 30 kD PEG-BSA (c) obtained for $24 \mathrm{~h}$ contact time in $20 \mathrm{mM} \mathrm{BTP}-\mathrm{HCl} \mathrm{pH} 7$ buffer. Lines are calculated from Eq. 3.3 with parameters in Table 3.3. $q$ and $C$ values are in mg of BSA per $\mathrm{mL}$ excluding the mass of conjugated PEG. Note the different y-axis. 
Table 3.3 Equilibrium isotherm parameters.

\begin{tabular}{|c|c|c|c|c|c|c|}
\hline \multirow[t]{2}{*}{ protein } & \multicolumn{2}{|l|}{ UNO Q } & \multicolumn{2}{|l|}{ HR Q } & \multicolumn{2}{|l|}{ Nuvia $\mathbf{Q}$} \\
\hline & $q_{m}(\mathrm{mg} / \mathrm{mL})$ & $K(\mathrm{~mL} / \mathrm{mg})$ & $q_{m}(\mathrm{mg} / \mathrm{mL})$ & $K(\mathrm{~mL} / \mathrm{mg})$ & $q_{m}(\mathrm{mg} / \mathrm{mL})$ & $K(\mathrm{~mL} / \mathrm{mg})$ \\
\hline BSA & $53.5 \pm 1.0$ & $24.2 \pm 5.1$ & $154 \pm 1$ & $200 \pm 9$ & $276 \pm 5$ & $31.4 \pm 4.8$ \\
\hline $\begin{array}{l}10 \mathrm{kD} \\
\text { PEG-BSA }\end{array}$ & $48.1 \pm 1.7$ & $9.9 \pm 2.4$ & $101 \pm 1$ & $74 \pm 19$ & $169 \pm 6$ & $10.4 \pm 2.9$ \\
\hline $\begin{array}{l}30 \mathrm{kD} \\
\text { PEG-BSA }\end{array}$ & $27.5 \pm 1.8$ & $7.6 \pm 2.5$ & $52.6 \pm 1.6$ & $24.1 \pm 6.9$ & $50.5 \pm 1.9$ & $6.5 \pm 1.0$ \\
\hline
\end{tabular}

The enhancement of binding capacity varies however with the extent of PEGylation. For native BSA, a dramatic increase of the capacity is seen for grafted $v s$. ungrafted resins. The capacity is about three-fold on Nuvia HR Q and about six-fold on Nuvia Q compared to UNO Q. Less enhancement is seen for $10 \mathrm{kD}$ PEG-BSA. The capacity doubles on Nuvia HR Q and triples on Nuvia Q. For 30 kD PEG-BSA, however, the capacity is slightly higher on Nuvia HR Q comparing to that on Nuvia Q and both of them are about twice the UNO Q capacity. For all resins, the binding capacity decreases dramatically with PEGylation, but this effect is more pronounced for Nuvia Q. A similar trend of greater sensitivity to PEGylation for polymer-grafted matrices was also found by Pabst et al. [5] based on dynamic experiments with different grafted and non-grafted anion exchangers. This behavior is consistent with the different architecture of these adsorbents. For UNO Q, protein binding is likely limited to monolayer coverage of the relatively small surface defined by its large pores. PEGylation reduces the binding strength, as also determined from the LGE experiments, which reduces the initial slope of the isotherm, but also lowers the binding capacity because it increases the protein footprint. For Nuvia HR Q and Nuvia Q, the binding capacity is increased by the charged polymeric surface extenders, which 
provide a gel phase within the pores of the support matrix throughout which the protein is bound. However, as molecular size increases as a result of PEGylation, size exclusion from the gel phase formed by the grafted polymers becomes increasingly significant, eventually limiting the amount of protein that can be bound. Thus, PEGylation has a most dramatic effect for Nuvia Q where the binding capacity drops 39 and $82 \%$ for $10 \mathrm{kD}$ and $30 \mathrm{kD}$ PEG, respectively, compared to UNO Q, where the binding capacity drops 10 and $49 \%$ for $10 \mathrm{kD}$ and $30 \mathrm{kD}$ PEG.

Figure 3.7 shows the batch uptake curves obtained as described in Section 3.2.2.3 at 1 $\mathrm{mg} / \mathrm{mL}$ initial protein concentration. The time scale for these experiments is less than an hour and is much shorter than the $20 \mathrm{hr}$ used for the adsorption isotherm experiments. The final qvalues obtained in the batch uptake experiments are comparable to these obtained for isotherm experiments for BSA, but they are about $20 \%$ less for $10 \mathrm{kD}$ PEG-BSA, and $40 \%$ less for $30 \mathrm{kD}$ PEGBSA. The difference is probably caused by the heterogeneous pore size distribution of the UNOsphere matrix where the smaller pores are likely difficult to access for large protein molecules in 30 min. Nevertheless, the capacity trends for the different resins are the same as those of the isotherm experiments. For BSA and 10 kD PEG-BSA, Nuvia $\mathrm{Q}$ has the highest binding capacity at the end of the batch uptake experiments while for $30 \mathrm{kD}$ PEG-BSA Nuvia HR Q has the highest binding capacity. 

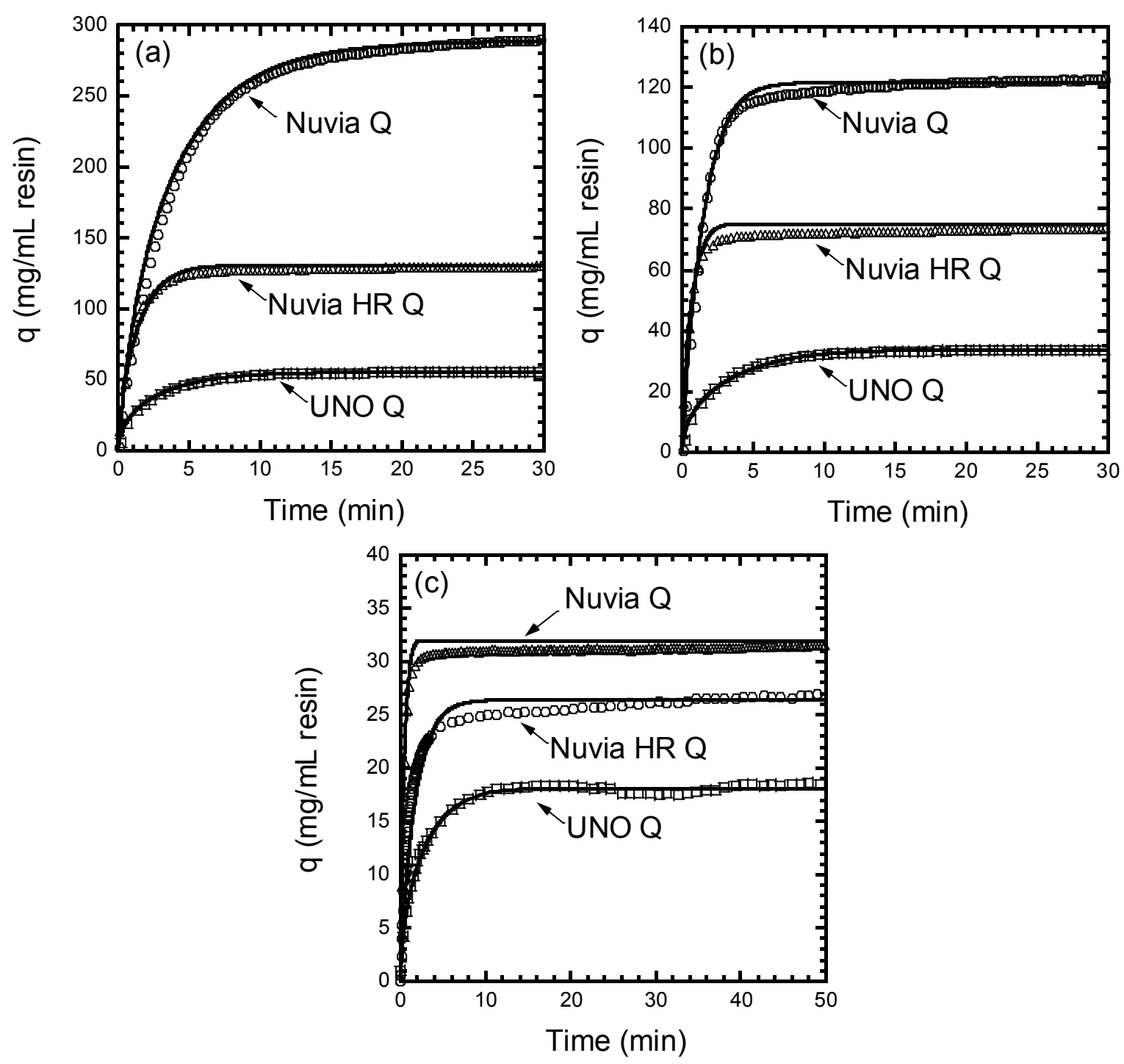

Fig. 3.7. Batch adsorption kinetics of $1 \mathrm{mg} / \mathrm{mL}$ BSA (a), $10 \mathrm{kD}$ PEG-BSA(b) and $30 \mathrm{kD}$ PEGBSA (c) in 20 mM BTP-HCl pH 7 buffer on UNO Q, Nuvia HR Q and Nuvia Q. Lines are calculated from the pore diffusion model accounting for particle size distribution and assuming a rectangular isotherm. Note that $q$ values are in mg of BSA per $\mathrm{mL}$ excluding the mass of conjugated PEG.

Although the time to approach equilibrium is similar for all resins, much more protein is absorbed in Nuvia Q and Nuvia HR Q for all three proteins, compared to UNO Q. Thus, the adsorption kinetics on the grafted resins is considerably faster than on UNO Q, especially for 
BSA and $10 \mathrm{kD}$ PEG-BSA. The average particle size is also different as described in Chapter 2. Nuvia Q has the largest size and Nuvia HR Q have the smallest size. Because of these differences, an effective pore diffusivity was determined by fitting the pore diffusion model assuming a rectangular isotherm and taking into account the particle size distribution of each resin sample, based on Eqs. A16-A18 in ref. [26]. The boundary layer mass transfer coefficient used for these calculations was estimated based on a Sherwood number $\left(\mathrm{Sh}=k_{f} r_{p} / D_{0}\right)$ of 27, consistent with prior determinations in ref. [26] for particles with a size similar to that of the resins used in this work. In practice, this value had no significant effect on the fit since the corresponding Biot number $\left(\mathrm{Bi}=k_{f} r_{p} / D_{e}\right)$ was greater than 10 in all cases. As seen in Fig. 3.7, the model fit was nearly perfect for the UNO Q data, but only approximate for Nuvia HR Q and

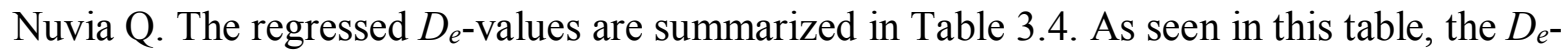
values are much larger for Nuvia Q and Nuvia HR Q than for UNO Q, indicating that the intrinsic adsorption kinetics on the grafted resin is much faster. For UNO Q the ratio $D_{e} / D_{0}$ is much smaller than 1 and consistent with ordinary pore diffusion for all three proteins. However, for Nuvia Q and Nuvia HR Q, $D_{e} / D_{0}$ is substantially larger than 1 for both BSA and $10 \mathrm{kD}$ PEGBSA, suggesting that protein transport occurs by a different mechanism and is enhanced by the polymeric surface extenders. The extent of grafting polymer has no obvious effect on transport rate of native BSA and $10 \mathrm{kD}$ PEG-BSA. For both proteins, similar transport rates are seen on Nuvia HR Q and Nuvia Q. Yet for $30 \mathrm{kD}$ PEG-BSA, the $D_{e}$ value is about twice on Nuvia HR Q of that on Nuvia Q, suggesting that size exclusion effects begin to severely limit transport in Nuvia Q.

For comparison purposes, the effective pore diffusivity was also determined for UNO Q and Nuvia HR Q by performing pulse injection experiments for non-binding conditions at 
superficial velocities between 300 and $900 \mathrm{~cm} / \mathrm{h}$ and calculating the HETP with the moment method [27]. $D_{e}$ was then calculated from the slope of a plot of reduced HETP, $h=H E T P / d_{p}$, vs. reduced velocity, $v^{\prime}=v d_{p} / D_{0}$, according to the following relationship [27]:

$$
\frac{D_{e}}{D_{0}}=\frac{1}{30} \frac{\varepsilon}{1-\varepsilon}\left(\frac{k_{\infty}^{\prime}}{1+k_{\infty}^{\prime}}\right)^{2}\left(\frac{d h}{d v^{\prime}}\right)^{-1}
$$

The results are shown in Fig. 3.8 and the values of $D_{e}$ are shown in Table 3.4. For UNO Q, the values are in fairly good agreement with the values determined from the batch uptake curves, indicating that protein binding does not affect transport in a significant way in UNO Q. On the contrary, for Nuvia $\mathrm{HR} \mathrm{Q}$, the values from pulse injection are much smaller than values of $D_{e}$ obtained from batch uptake experiments, but they are comparable to values of UNO Q, indicating that the transport process is coupled with protein binding under binding conditions. For Nuvia Q, $D_{e}$ could not be determined from pulse injection runs under non-binding conditions since in this case $k_{\infty}^{\prime} \sim 0$ making the slope $d h / d v^{\prime}$ too small to be determined with any accuracy. In this case, since all three proteins are nearly completely excluded from the particles, extraparticle effects dominate band broadening.

Table 3.4 Effective pore diffusivities $D_{e}$ in $10^{-7} \mathrm{~cm}^{2} / \mathrm{s}$.

\begin{tabular}{|c|c|c|c|c|c|c|c|c|c|}
\hline \multirow[t]{3}{*}{ Protein } & \multicolumn{3}{|l|}{ UNO Q } & \multicolumn{3}{|c|}{ Nuvia HR Q } & \multicolumn{3}{|l|}{ Nuvia Q } \\
\hline & \multirow{2}{*}{$\begin{array}{l}\text { pulse } \\
\text { response } \\
D_{e}\end{array}$} & \multicolumn{2}{|c|}{ batch uptake } & \multirow{2}{*}{$\begin{array}{l}\text { pulse } \\
\text { response } \\
D_{e}\end{array}$} & \multicolumn{2}{|c|}{ batch uptake } & \multirow{2}{*}{$\begin{array}{l}\text { pulse } \\
\text { response } \\
D_{e}\end{array}$} & \multicolumn{2}{|c|}{ batch uptake } \\
\hline & & $D_{e}$ & $D_{e} / D_{0}$ & & $D_{e}$ & $D_{e} / D_{0}$ & & $D_{e}$ & $D_{e} / D_{0}$ \\
\hline Native BSA & 1.7 & 2.0 & 0.33 & 1.5 & 14 & 2.3 & ND & 15 & 2.5 \\
\hline 10 kD PEG-BSA & 1.1 & 0.90 & 0.20 & 0.95 & 13 & 2.9 & ND & 20 & 4.4 \\
\hline $30 \mathrm{kD}$ PEG-BSA & 0.73 & 0.57 & 0.18 & 0.57 & 5.0 & 1.6 & ND & 2.2 & 0.71 \\
\hline
\end{tabular}




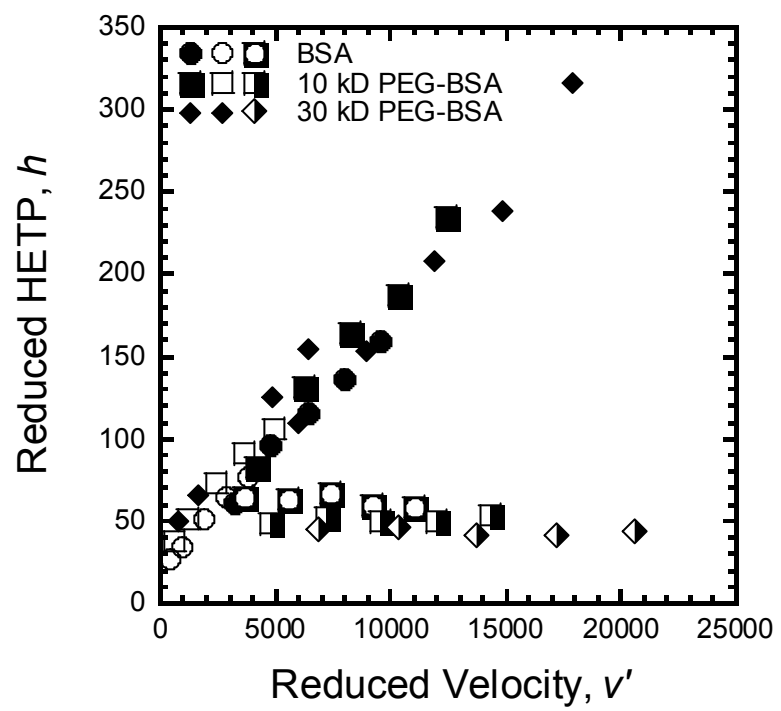

Fig. 3.8 Reduced HETP vs. reduced velocity obtained from pulse injection at $1 \mathrm{M} \mathrm{NaCl}$ for BSA, 10 kD PEG-BSA, and 30 kD PEG-BSA on UNO Q (filled), Nuvia HR Q (open) and Nuvia Q (half-filled).

\subsubsection{Confocal microscopy}

Figure 3.9 shows the evolution of intraparticle bound protein concentration for single component adsorption of $1 \mathrm{mg} / \mathrm{mL}$ BSA (red in the images) and $30 \mathrm{kD}$ PEG-BSA (green in the images) for all three resins. In all cases, the time scale needed to approach equilibrium (as indicated by a nearly uniform distribution of fluorescence intensity) is similar to that observed in the corresponding batch uptake experiments. However, the shapes of the intraparticle profiles are different. A fairly sharp front separating an advancing protein-saturated layer from a protein-free core is visible for $\mathrm{UNO} \mathrm{Q}$, consistent with an ordinary pore diffusion mechanism [15].

Conversely, the profiles are smooth for both BSA and 30 kD PEG-BSA, with fluorescence intensity increasing gradually over time for Nuvia HR Q and Nuvia Q. This behavior is consistent with a "solid" or "adsorbed phase" diffusion mechanism, where protein transport occurs while continuously interacting with the resin's charged ligands. The results also reveal a 
faster adsorption rate of 30 PEG-BSA on Nuvia HR Q compared to Nuvia Q, as the intensity at 2.5 min for Nuvia HR Q has almost reached the maximum while for Nuvia Q the intensity is about half of the maximum.
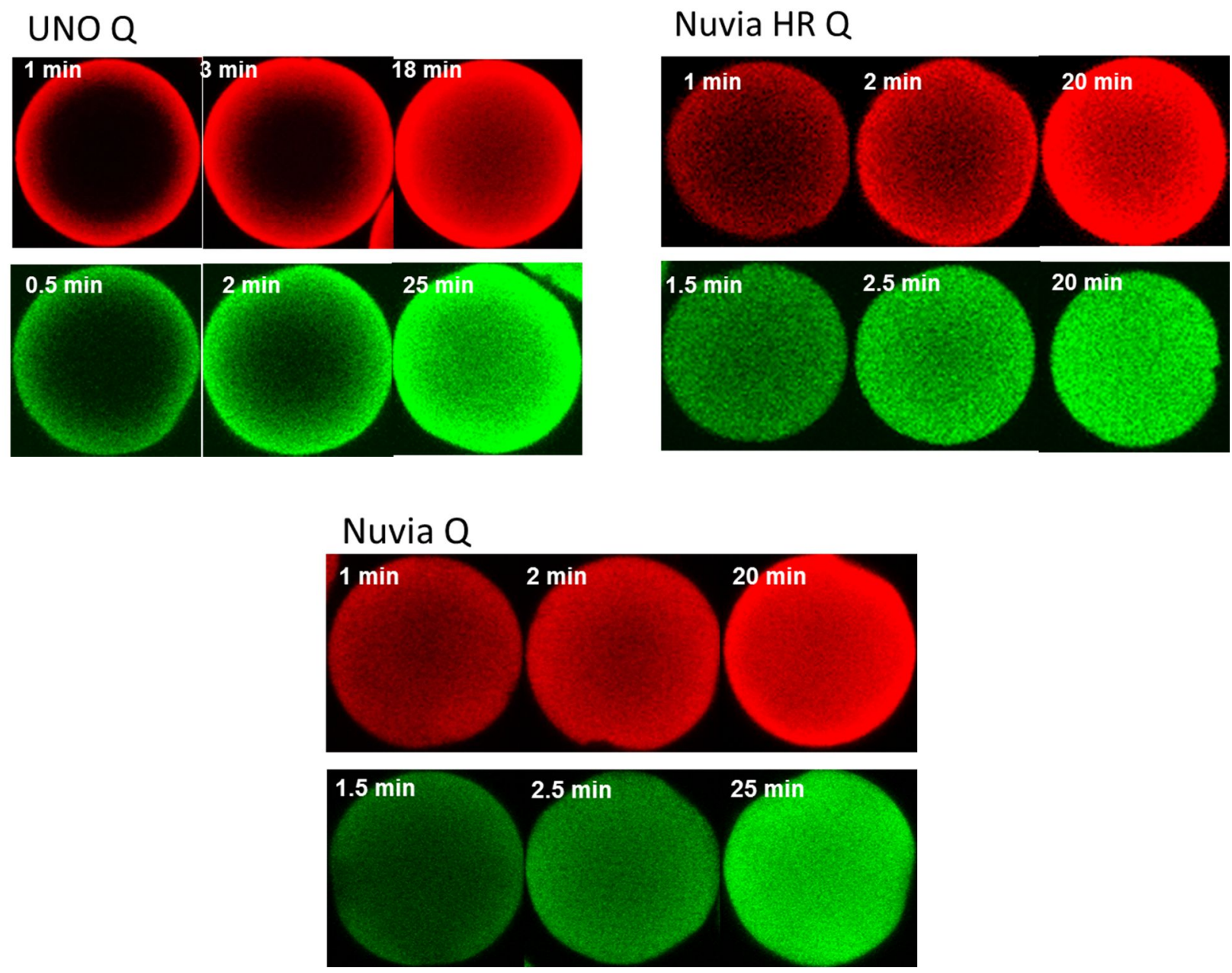

Fig. 3.9. CLSM images of one component adsorption on UNO Q, Nuvia HR Q and Nuvia Q for $1 \mathrm{mg} / \mathrm{mL}$ BSA (top row) and $30 \mathrm{kD}$ PEG-BSA (bottom row) in $20 \mathrm{mM} \mathrm{BTP-HCl} \mathrm{pH} 7$ buffer. Actual diameters of the particle shown are about 70, 50 and $80 \mu \mathrm{m}$ for UNO Q, Nuvia HR Q and Nuvia Q, respectively. Laser intensities were kept constant for each time series.

Figure 3.10 shows the results for adsorption of BSA on UNO Q and Nuvia Q particles that were presaturated with $10 \mathrm{kD}$ PEG-BSA. The intraparticle displacement effect is clearly 
visible for UNO Q with the PEGylated protein (green) partially and temporarily accumulating near the particle core prior to diffusing outward and being replaced by BSA (red). The time scale is similar to that of the single component adsorption experiments, indicating that diffusion rates are not dependent on the direction of transport as a result of the large pore size of this resin. On the other hand, for Nuvia Q, while it is evident that BSA gradually replaces PEGylated BSA in this sequential adsorption experiment, the process occurs over much longer time scales indicating that counter-diffusion of BSA and PEG-BSA is strongly hindered. Similar behavior has been reported previously for the sequential adsorption of multiple monoclonal antibodies [28] and antibody variants [16,29] in polymer grafted cation exchangers suggesting that transport mechanisms are similar in these materials.

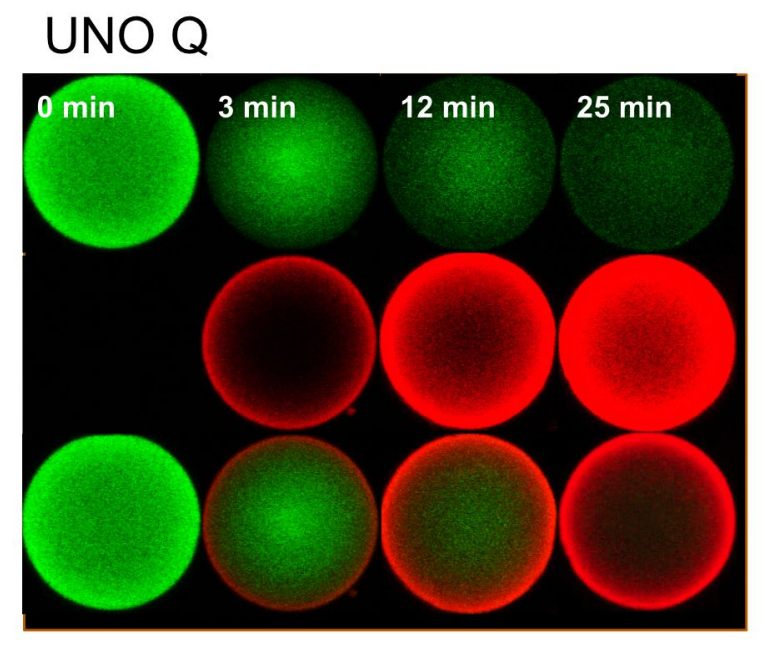

\section{Nuvia Q}

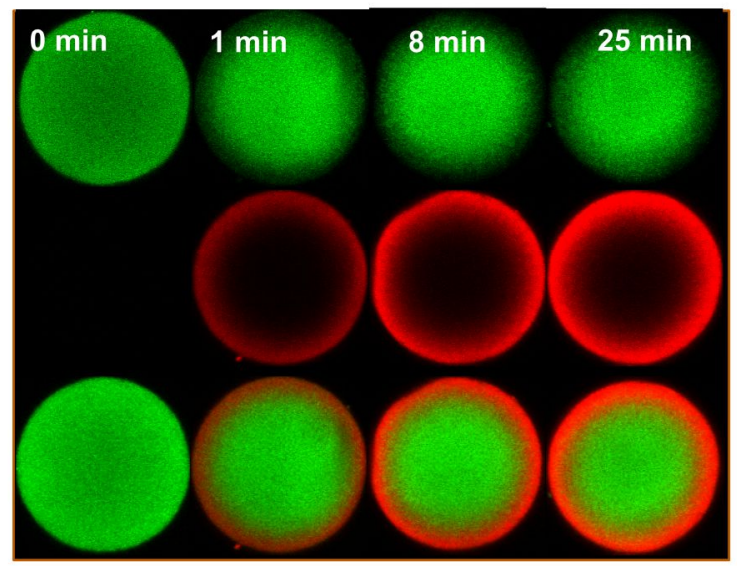

Fig. 3.10. CLSM images of two-component sequential adsorption on UNO Q and Nuvia Q of 1 $\mathrm{mg} / \mathrm{mL}$ BSA (middle row) on beads pre-saturated with10 kD PEG-BSA (top row) in $20 \mathrm{mM}$ BTP-HCl pH 7 buffer. The bottom row shows a composite of red and green images. Actual diameters for the particles shown are about 70 and $80 \mu \mathrm{m}$ for UNO Q and Nuvia Q, respectively. The difference for adsorption on Nuvia HR Q and Nuvia Q can be seen from the result of co-adsorption of native BSA and $10 \mathrm{kDa}$ PEG-BSA, as shown in Fig. 3.11. The top row is the 
profile of $10 \mathrm{kDa}$ PEG-BSA, the middle row is profile of native $\mathrm{BSA}$ and the bottom row is the overlay profiles of two channels. In this case, the bound protein concentration profiles are different for all three resins. For UNO Q, displacement of 10 kD PEG-BSA (green in the images) by BSA (red in the images) clearly occurs within the resin beads. Two fronts are temporarily established within the beads - one corresponding to the displacement of $10 \mathrm{kD}$ PEG-BSA by BSA and one corresponding to rebinding of displaced PEGylated BSA closer to the particle center. This behavior is analogous to that observed for other proteins in macroporous cation exchangers [30-31]. Note, however, that a slight overshoot in fluorescence intensity occurs at the adsorption front of $10 \mathrm{kD}$ PEG-BSA, which is probably a result of slightly different binding affinities for labeled and unlabeled species. Moreover, some residual bound PEGylated protein is apparently left, indicating that displacement by BSA is not complete. In contrast, the images obtained for Nuvia Q show that both BSA and 10 kD PEG-BSA co-diffuse within the particle with little evidence of internal displacement of one species by the other. The adsorption profile on Nuvia HR Q is a combination of the other two. Displacement of $10 \mathrm{kDa}$ PEG-BSA by native BSA happens on Nuvia HR Q. Unlike Nuvia Q, the over concentration of $10 \mathrm{kDa}$ PEG-BSA was observed at the center of Nuvia HR Q resin and eventually almost all $10 \mathrm{kDa}$ PEG-BSA was displaced by native BSA and diffused out of the resin. On the other hand, the profiles of both species were much smoother comparing to that on UNO Q, indicating solid diffusion inside the grafted polymer phase also occurs in this case. Moreover, the saturation time of native BSA on UNO Q in co-adsorption is similar to the time in the single component adsorption. Due to the large pore of UNO Q, the counter diffusion of native BSA and $10 \mathrm{kDa}$ PEG-BSA is not a problem. Whereas for Nuvia HR Q, the saturation time of native BSA in co-adsorption is much longer because of the decrease of pore size causing by grafted polymer. 


\section{UNO Q}

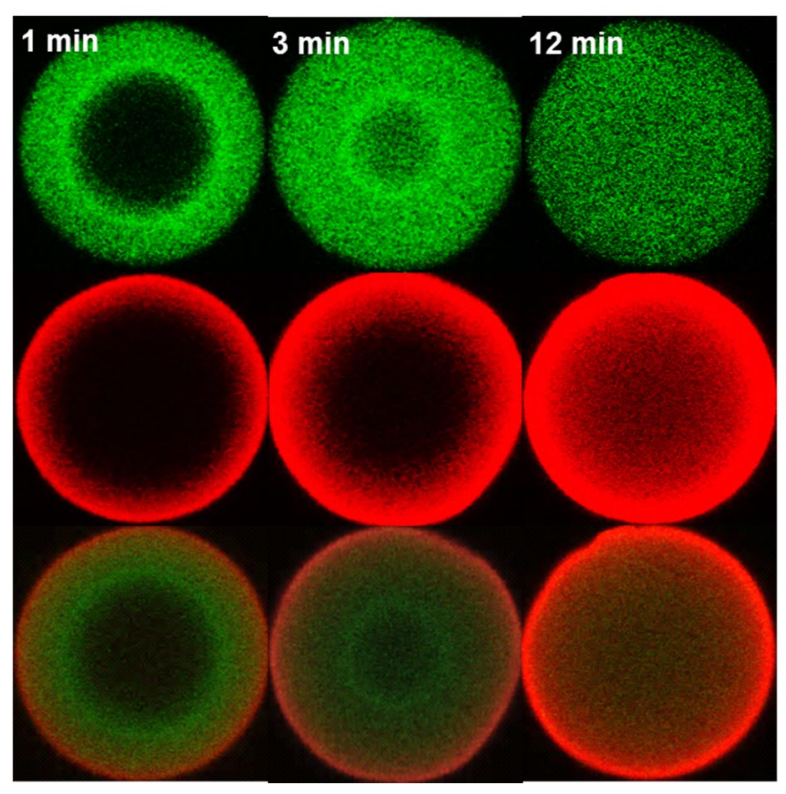

Nuvia HR Q

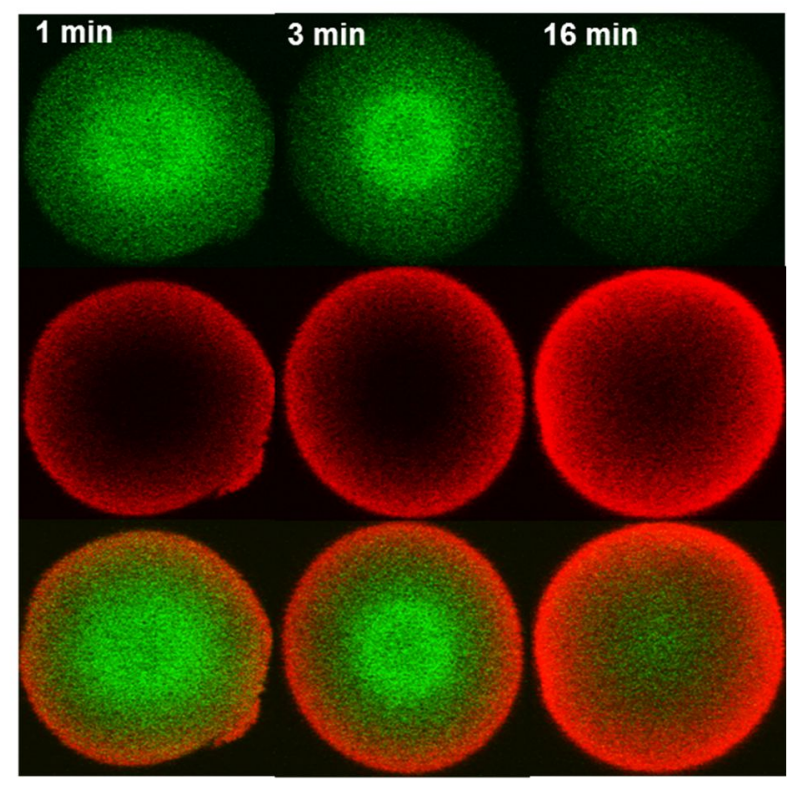

Nuvia Q

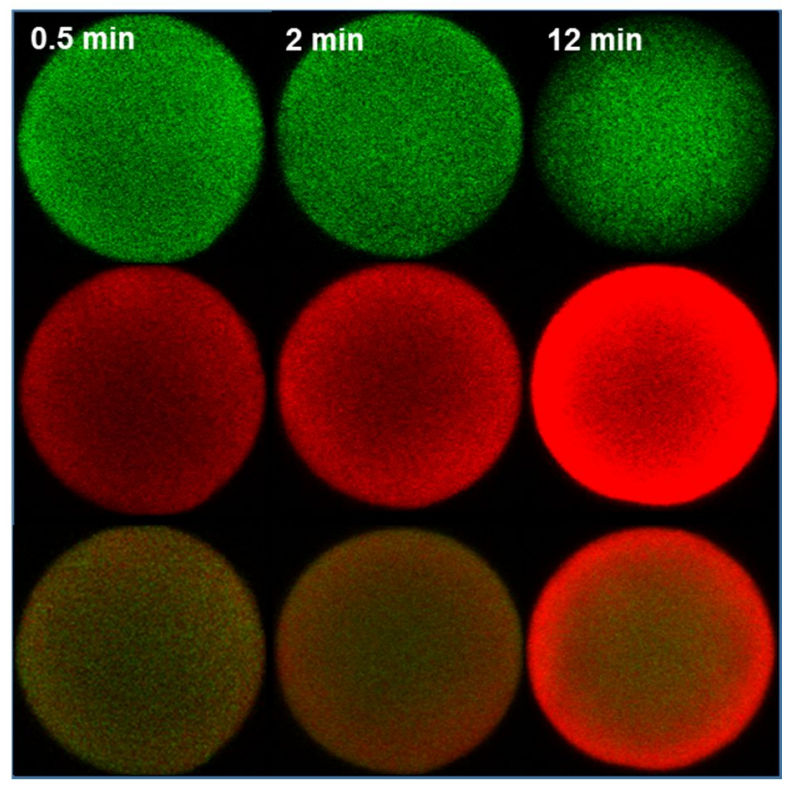

Fig. 3.11. CLSM images of two-component co-adsorption on UNO Q, Nuvia HR Q and Nuvia Q of $1 \mathrm{mg} / \mathrm{mL}$ each of BSA (middle row) and $10 \mathrm{kD}$ PEG-BSA (top row) in $20 \mathrm{mM} \mathrm{BTP-HCl} \mathrm{pH} 7$ buffer. The bottom row shows a composite of the red and green images. Actual diameters of particles shown are about 70, 50 and $80 \mu \mathrm{m}$ for UNO Q, Nuvia HR Q, and Nuvia Q, respectively. 


\subsection{Conclusions}

The behavior of native and PEGylated BSA in the macroporous resin UNO Q and in the polymer-grafted resins Nuvia Q and Nuvia HR Q is distinctly different both with regards to protein-ligand interactions and to adsorption kinetics. Stronger chromatographic retention is observed with the polymer-grafted resins compared to the macroporous resin for both BSA and $10 \mathrm{kD}$ PEG-BSA. The difference becomes smaller however as the degree of PEGylation increases and is almost nil for $30 \mathrm{kD}$ PEG-BSA on Nuvia Q, likely a result of increased size exclusion effects for the polymer-grafted material. The binding capacity at low ionic strengths is also much greater for the polymer grafted resin compared to the macroporous resin for both BSA and $10 \mathrm{kD}$ PEG-BSA, but the difference becomes again smaller for $30 \mathrm{kD}$ PEG-BSA. The adsorption kinetics also follows this trend, especially for Nuvia Q. Much faster kinetics are observed for BSA and PEGylated BSA on polymer grafted resins compared to UNO Q and are attributed to the different intraparticle transport mechanisms that dominate the kinetics in the polymer-grafted and macroporous resins. Under strong binding conditions (i.e. at low ionic strengths), the kinetics are enhanced as a result of favorable partitioning of both native and PEGylated protein molecules in the polymer-grafted matrix. However, under the conditions of the LGE experiments the kinetics are slowed down in the polymer-grafted matrix resulting in broader and more tailing peaks. The CLSM results confirm the two different mechanisms. They also illustrate how co-adsorption and sequential adsorption of BSA and PEGylated BSA take place. The two-component kinetic behavior of PEGylated proteins is analogous to that reported previously for mixtures of similar size proteins in macroporous and polymer-grafted cation exchangers suggesting that the underlying molecular phenomena are virtually the same for the multicomponent adsorption of proteins with vastly different sizes. 


\subsection{List of symbols}

$C \quad$ protein concentration in solution excluding mass of conjugated PEG $(\mathrm{mg} / \mathrm{mL})$

$C_{C l^{-}}^{E} \quad$ chloride concentration at elution $(\mathrm{mM})$

$C_{\mathrm{Cl}^{-}}^{f} \quad$ final chloride concentration $(\mathrm{mM})$

$C_{C^{-}}^{0} \quad$ initial chloride concentration (mM)

CV number of column volumes

$C V_{G}$ duration of gradient in $C V$ units

$d_{p} \quad$ particle diameter $(\mathrm{cm})$

$D_{e} \quad$ effective pore diffusivity $\left(\mathrm{cm}^{2} / \mathrm{s}\right)$

$D_{0} \quad$ free solution diffusivity $\left(\mathrm{cm}^{2} / \mathrm{s}\right)$

$h \quad$ reduced $\operatorname{HETP}\left(=H / d_{p}\right)$

$k_{f} \quad$ boundary layer mass transfer coefficient $(\mathrm{cm} / \mathrm{s})$

$k^{\prime} \quad$ protein retention factor

$k_{C l^{-}}^{\prime} \quad$ retention factor of chloride ion

$k_{\infty}^{\prime} \quad$ protein retention factor for non-binding conditions

$K \quad$ parameter in Langmuir isotherm $(\mathrm{mL} / \mathrm{mg})$

$q \quad$ bound protein concentration excluding mass of conjugated PEG $(\mathrm{mg} / \mathrm{mL})$

$q_{m} \quad$ parameter in Langmuir isotherm $(\mathrm{mg} / \mathrm{mL})$

$r_{h} \quad$ hydrodynamic radius $(\mathrm{nm})$

$r_{p} \quad$ particle radius $(\mathrm{cm})$

$v \quad$ mobile phase velocity $(\mathrm{cm} / \mathrm{s})$

$v^{\prime} \quad$ reduced velocity $\left(=v d_{p} / D_{0}\right)$ 
$V_{C} \quad$ column volume $(\mathrm{mL})$

$V_{R} \quad$ retention volume $(\mathrm{mL})$

$z \quad$ protein effective binding charge

$\varepsilon \quad$ extraparticle column porosity

$\gamma \quad$ normalized gradient slope $\left[\varepsilon\left(C_{C l^{-}}^{f}-C_{C l}^{0}\right) / C V_{G}\right]$

\subsection{Reference}

[1] Y.-S. Wang, S. Youngster, M. Grace, J. Bausch, R. Bordens, D.F. Wyss, Structural and biological characterization of pegylated recombinant interferon alpha- $2 \mathrm{~b}$ and its therapeutic implications., Adv. Drug Deliv. Rev. 54 (2002) 547-70.

[2] C.J. Fee, J.A. Van Alstine, PEG-proteins: Reaction engineering and separation issues, Chem. Eng. Sci. 61 (2006) 924-939.

[3] A. Moosmann, J. Christel, H. Boettinger, E. Mueller, Analytical and preparative separation of PEGylated lysozyme for the characterization of chromatography media., J. Chromatogr. A. 1217 (2010) 209-15.

[4] B. Plesner, C.J. Fee, P. Westh, A.D. Nielsen, Effects of PEG size on structure, function and stability of PEGylated BSA., Eur. J. Pharm. Biopharm. 79 (2011) 399-405.

[5] T.M. Pabst, J.J. Buckley, N. Ramasubramanyan, A.K. Hunter, Comparison of strong anion-exchangers for the purification of a PEGylated protein., J. Chromatogr. A. 1147 (2007) 172-82.

[6] C.J. Fee, J.M. Van Alstine, Purification of pegylated proteins., in: Methods Biochem. Anal., 2011: pp. 339-62. 
[7] M. Abe, P. Akbarzaderaleh, M. Hamachi, N. Yoshimoto, S. Yamamoto, Interaction mechanism of mono-PEGylated proteins in electrostatic interaction chromatography., Biotechnol. J. 5 (2010) 477-83.

[8] C. Colonna, B. Conti, P. Perugini, F. Pavanetto, T. Modena, R. Dorati, et al., Ex vivo evaluation of prolidase loaded chitosan nanoparticles for the enzyme replacement therapy., Eur. J. Pharm. Biopharm. 70 (2008) 58-65.

[9] I. Kwon, S.I. Lim, Non-Natural Amino Acids for Protein Engineering and New Protein Chemistries, Macromol. Chem. Phys. 214 (2013) 1295-1301.

[10] J.E. Seely, C.W. Richey, Use of ion-exchange chromatography and hydrophobic interaction chromatography in the preparation and recovery of polyethylene glycol-linked proteins., J. Chromatogr. A. 908 (2001) 235-41.

[11] B. Maiser, F. Kröner, F. Dismer, G. Brenner-Weiss, J. Hubbuch, Isoform separation and binding site determination of mono-PEGylated lysozyme with $\mathrm{pH}$ gradient chromatography., J. Chromatogr. A. 1268 (2012) 102-8.

[12] T. Blaschke, A. Werner, H. Hasse, Microcalorimetric study of the adsorption of native and mono-PEGylated bovine serum albumin on anion-exchangers., J. Chromatogr. A. 1277 (2013) 58-68.

[13] C.J. Fee, J.M. Van Alstine, Prediction of the viscosity radius and the size exclusion chromatography behavior of PEGylated proteins, Bioconjug. Chem. 15 (2004) 1304 1313.

[14] K. Mattison, A. Morfesis, M. Kaszuba, A primer on particle sizing using dynamic light scattering, Am. Biotechnol. (2003). 
[15] G. Carta, A.R. Ubiera, T.M. Pabst, Protein mass transfer kinetics in ion exchange media: Measurements and interpretations, Chem. Eng. Technol. 28 (2005) 1252-1264.

[16] E.X. Pérez Almodóvar, Y. Tao, G. Carta, Protein adsorption and transport in cation exchangers with a rigid backbone matrix with and without polymeric surface extenders., Biotechnol. Prog. 27 (2011) 1264-72.

[17] E.X. Perez-Almodovar, Y. Wu, G. Carta, Multicomponent adsorption of monoclonal antibodies on macroporous and polymer grafted cation exchangers., J. Chromatogr. A. 1264 (2012) 48-56.

[18] J. Janatova, J. Fuller, M. Hunter, The heterogeneity of bovine albumin with respect to sulfhydryl and dimer content, J. Biol. Chem. 243 (1968) 3612-3622.

[19] S. Yamamoto, K. Nakanishi, R. Matsuno, T. Kamijubo, Ion exchange chromatography of proteins-predictions of elution curves and operating conditions. II. Experimental verification., Biotechnol. Bioeng. 25 (1983) 1373-91.

[20] S. Yamamoto, K. Nakanishi, R. Matsuno, T. Kamikubo, Ion exchange chromatography of proteins-prediction of elution curves and operating conditions. I. Theoretical considerations., Biotechnol. Bioeng. 25 (1983) 1465-83.

[21] G. Carta, A. Jungbauer, Protein Chromatography: Process Development and Scale-Up, John Wiley \& Sons, 2010.

[22] W. Kopaciewicz, M.A. Rounds, J. Fausnaugh, F.E. Regnier, Retention model for highperformance ion-exchange chromatography, J. Chromatogr. A. 266 (1983) 3-21.

[23] S. Yamamoto, K. Nakanishi, R. Matsuno, Ion-Exchange Chromatography of Proteins, Marcel Dekker, Inc., 1988. 
[24] C.A. Brooks, S.M. Cramer, Steric mass-action ion exchange: Displacement profiles and induced salt gradients, AIChE J. 38 (1992) 1969-1978.

[25] A.M. Lenhoff, Protein adsorption and transport in polymer-functionalized ionexchangers., J. Chromatogr. A. 1218 (2011) 8748-59.

[26] M.C. Stone, G. Carta, Protein adsorption and transport in agarose and dextran-grafted agarose media for ion exchange chromatography., J. Chromatogr. A. 1146 (2007) 202-15.

[27] B. R.B., S. W.E., E.N. Lightfoot, Transport Phenomena, John Wiley \& Sons, 1960.

[28] E.X. Perez-Almodovar, Y. Wu, G. Carta, Multicomponent Adsorption ofMonoclonal Antibodies onMacroporous and Polymer Grafted Cation Exchangers, J. Chromatogr. A. (2012).

[29] Y. Tao, N. Chen, G. Carta, G. Ferreira, D. Robbins, O.M. Way, Modeling Multicomponent Adsorption of Monoclonal Antibody Charge Variants in Cation Exchange Columns, 58 (2012) 2503-2511.

[30] S.R. Gallant, Modeling ion-exchange adsorption of proteins in a spherical particle, J. Chromatogr. A. 1028 (2004) 189-195.

[31] C. Martin, G. Iberer, A. Ubiera, G. Carta, Two-component protein adsorption kinetics in porous ion exchange media, J. Chromatogr. A. 1079 (2005) 105-115. 


\section{Chapter 4}

\section{Thyroglobulin Adsorption on Anion Exchange Resins with Varying Grafted}

\section{Polymer Content}

\subsection{Introduction}

As mentioned in Chapter 1, polymer grafted adsorbents for ion- exchange chromatography (IEC) is are potentially useful for protein purification at large scale [1-3]. Previous studies have shown that both protein equilibrium binding capacity and mass transfer rates can be enhanced by the inclusion of polymer grafts [4-6]. Generally, high binding capacity is attributed to the multilayer binding throughout the three-dimensional network formed by the polymer grafts with the matrix pores. The mechanism for faster mass transfer is more complicated but is normally attribute to solid or surface diffusion. In this case, the enhancement often depends greatly on ionic strength, $\mathrm{pH}$ of the buffer, grafts properties, and protein properties $[1-4,6-7]$

Various studies have been conducted previously to understand the transport kinetics in polymer grafted adsorbents for IEC as reviewed in Chapter 1. However, few of these studies have addressed the behavior of large proteins. In Chapter 2 we have characterized the structural properties of anion exchangers with varying content of polymer grafting. The content of polymer grafts mainly affects the pore sizes. Chapter 3 has investigated the adsorption properties of BSA and PEGylated BSA on these resins. Higher equilibrium capacities are found for adsorbent with higher content of polymer grafts. Similar mass transfer rate enhancement has been found for single component adsorption while adsorbent with a lower content of polymer grafts is more favorable for multicomponent adsorption. The remaining question now is what will happen if the 
size of protein is large and comparable to the length of the grafted polymers. Separation of very large size biomolecule with high molecular weight, such as $\operatorname{IgM}$, is complicated due to the extremely small diffusivities of these molecules in conventional porous chromatographic adsorbents. To achieve reasonable dynamic binding capacity and resolution, low flowrates are needed which, in turn, reduce productivity [8]. Approaches designed to enhance transport by convection have been proposed for the purification of very large biomolecules, including monolith chromatography $[9,10]$, perfusion chromatography $[11]$ and membrane chromatography $[12,13]$. However, since polymer grafted IEC adsorbents are usually featured with fast adsorption kinetics and high dynamic binding capacity, it is worth to explore the possibility of their use in the purification of very large biomolecules.

In this chapter, we describe the effects of protein size on adsorption equilibrium and kinetics using thyroglobulin $\left(\mathrm{M}_{\mathrm{w}} \sim 700 \mathrm{kD}\right)$ and $\mathrm{BSA}\left(\mathrm{M}_{\mathrm{w}} \sim 65 \mathrm{kD}\right)$ as model proteins. For this purpose, three anion exchangers with different grafted polymer contents, UNO Q, Nuvia HR Q, and Nuvia Q, were used as adsorbents. Adsorption behaviors under two ionic strength condition were obtained. The transport mechanisms were studied by confocal laser scanning microscopy and modeling of batch uptake curves.

\subsection{Materials and methods}

\subsubsection{Materials}

The resins used in this work are the same as those used in Chapter 2 and Chapter 3, obtained from Bio-Rad Laboratories (Hercules, CA, USA): UNO Q, which has no grafted polymers but only short functional ligand; Nuvia HR Q, which has a moderate grafted polymers content and Nuvia Q, which has a high grafted content. All resins are based on the same polymeric backbone and contain quaternary ammonium ion functional groups. Relevant properties of these materials 
are summarized in Table 2.1 in Chapter 2.

The proteins used in this work are thyroglobulin $(\mathrm{Tg})$ from bovine thyroid and bovine serum albumin (BSA), both obtained from Sigma-Aldrich (St. Louis, MO, USA). Both protein samples were further purified by SEC using a Superdex 200 column from GE Healthcare (Piscataway, NJ, USA) to remove the dimers and oligomers that were found present at a level of about $10 \%$ of the total protein for Tg and $20 \%$ for BSA. The hydrodynamic radius, $r_{h}$, and free solution diffusivity, $D_{0}$, of model proteins were measured by dynamic light scattering (DLS) and are listed in Table 4.1.

Table 4.1 Properties of proteins used in this work

\begin{tabular}{|c|c|c|c|c|}
\hline Protein & pI & $\begin{array}{c}\text { Molecular } \\
\text { weight }(\mathrm{kDa})\end{array}$ & $r_{h}(\mathrm{~nm})$ & $D_{0}\left(10^{-7} \mathrm{~cm}^{2} / \mathrm{s}\right)$ \\
\hline BSA & 4.7 & 66 & $3.7 \pm 0.1$ & $6.0 \pm 0.2$ \\
\hline Tg & 4.5 & 660 & $8.7 \pm 0.2$ & $2.2 \pm 0.1$ \\
\hline
\end{tabular}

\subsubsection{Methods}

\subsubsection{Equilibrium isotherms}

Adsorption isotherms were obtained at $22 \pm 2{ }^{\circ} \mathrm{C}$ by first equilibrating resin samples with $20 \mathrm{mM}$ BTP-HCl buffer at $\mathrm{pH} 7.0$ containing $0 \mathrm{mM}$ and $50 \mathrm{mM} \mathrm{NaCl}$ and then centrifuging them at $5000 \mathrm{rpm}$ for $20 \mathrm{~min}$ in a microcentrifuge filter to remove the extraparticle solution. Weighed samples of each centrifuged resin were then added to $1.5 \mathrm{~mL}$ tubes containing solutions with different initial protein concentrations in $20 \mathrm{mM} \mathrm{BTP-HCl}$ buffer at $\mathrm{pH}$ 7. The amount of resin added to each tube was estimated to provide a 50\% change in protein concentration. After rotating the tubes end-over-end at a low rpm for 20 to $24 \mathrm{~h}$, the supernatant protein concentration was 
measured with a NanoVue spectrophotometer (GE Healthcare, Piscataway, NJ, USA). The adsorbed protein concentration per unit of volume of the hydrated particle was then calculated by mass balance using a resin hydrated particle density of $1.08 \mathrm{mg} / \mathrm{mL}$ for both materials as determined with a pycnometer.

\subsubsection{Adsorption kinetics}

The kinetics of the adsorption process was investigated both microscopically by confocal microscopy and macroscopically by measuring a batch uptake kinetics. CLSM imaging was conducted as described by Wu et al. [11]. For this purpose, BSA and Tg were conjugated with the amine-reactive fluorescent dye Rhodamine $\operatorname{Red}^{\mathrm{TM}}$, obtained from Invitrogen Corporation (Carlsbad, CA, USA) as described in ref. [14]. The experiments were conducted as follows. A sample of the resin was added to a plastic tube and mixed, by rotating the tube end-over-end at a few rpm, with $5 \mathrm{~mL}$ of a solution containing $1 \mathrm{mg} / \mathrm{mL}$ of the unlabeled protein mixed with the conjugated protein in a 1/100 conjugated to unconjugated protein molar ratio. At periodic time intervals, a small amount of the suspension was pipetted out of the tube and rapidly processed in a microcentrifuge filter to separate the particles from solution. A buffered $50 \%(\mathrm{w} / \mathrm{w})$ sucrose solution was used as a refractive index matching fluid to obtain transparent views of the resin beads as discussed in refs. [4] and [15]. All sample processing after the collection was done rapidly (less than $1 \mathrm{~min}$ ) in order to minimize any changes in the bound protein. A Zeiss LSM 510 confocal microscope equipped with a Plan-Apochromat 63X/1.4 NA oil objective (Carl Zeiss MicroImaging, LLC, Thornwood, NY, USA) was used to obtain equatorial image of the intraparticle fluorescence.

Batch uptake was conducted as described in ref. [16]. In this case, samples of each centrifuged resin were added to $20 \mathrm{~mL}$ of $20 \mathrm{mM} \mathrm{BTP}-\mathrm{HCl} \mathrm{pH} 7$ buffer containing $1 \mathrm{mg} / \mathrm{mL}$ 
protein. The amount of resin added was estimated to give a $50 \%$ change in the supernatant protein concentration. The solution was agitated with a small paddle stirrer and a stream continuously recirculated through a filter and a UV detector connected to a data acquisition system. The amount of protein bound as a function of time was obtained by material balance using the UV readings.

\subsubsection{Chromatographic analysis for non-binding conditions}

Measurements of the height equivalent to a theoretical plate (HETP) were used to determine the protein mass transfer properties of all stationary phases using non-binding conditions. The experiments were conducted in $20 \mathrm{mM} \mathrm{BTP-HCl}$ buffer at $\mathrm{pH} 7$ containing $1 \mathrm{M}$ $\mathrm{NaCl}$, using slurry-packed Tricorn columns described in Chapter 2. The HETP was obtained using the moment method [17] and the effective pore diffusivity, $D_{e}$, was then calculated from the slope of a plot of reduced HETP, $h=H E T P / d_{p}$, vs. reduced velocity, $v^{\prime}=v d_{p} / D_{0}$, according to the following relationship [17]:

$$
\frac{D_{e}}{D_{0}}=\frac{1}{30} \frac{\varepsilon}{1-\varepsilon}\left(\frac{k^{\prime}}{1+k^{\prime}}\right)^{2}\left(\frac{d h}{d v^{\prime}}\right)^{-1}
$$

where $\varepsilon$ is the extraparticle column porosity (given in Table 2.1 in Chapter 2), $d_{p}$ is the particle diameter, and $k^{\prime}$ is the chromatographic retention factor.

\subsection{Results and discussion}

\subsubsection{Adsorption isotherms}

Figures 4.1 and 4.2 show the adsorption isotherms of BSA and Tg on three resins in $\mathrm{pH} 7$ buffer containing $0 \mathrm{mM}$ and $50 \mathrm{mM} \mathrm{NaCl}$ for 24-hr adsorption time. Lines are based on Langmuir isotherm $q=q_{m} K C /(1+K C)$, with the regressed parameters summarized in Table 4.2. For BSA, the binding capacity increases with the grafted polymer content. The capacity is about 
three-fold higher for Nuvia HR Q and about six-fold higher for Nuvia Q compared to UNO Q at both salt concentrations studied. As the salt concentration increases to $50 \mathrm{mM}$, the protein
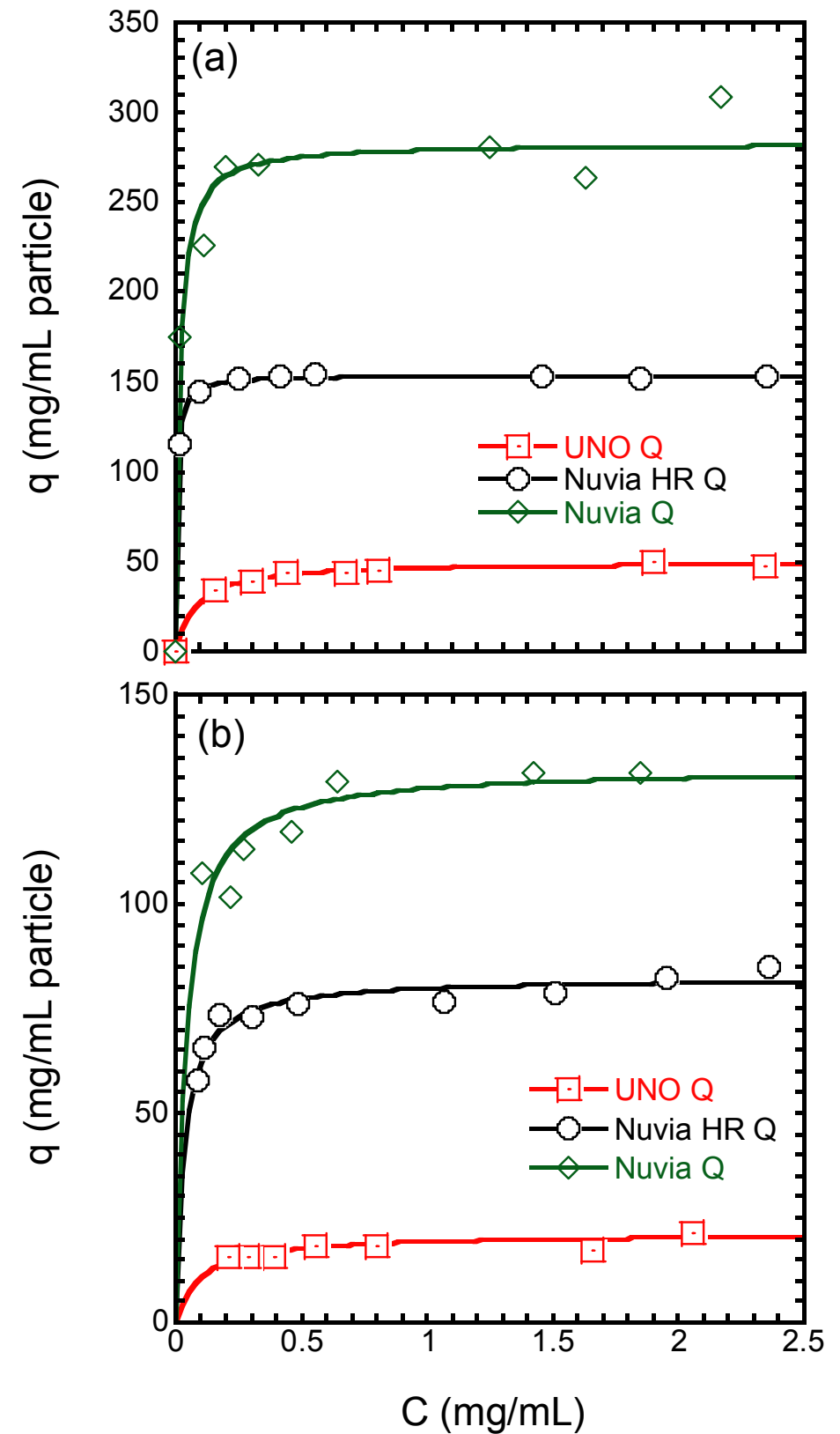

Fig. 4.1. Adsorption isotherms of BSA in $20 \mathrm{mM} \mathrm{BTP-HCl} \mathrm{pH} 7$ buffer containing (a) $0 \mathrm{mM}$ and (b) $50 \mathrm{mM} \mathrm{NaCl}$, obtained for $24 \mathrm{~h}$ contact time. Lines are the Langmuir isotherm model with parameters in Table 4.2. 

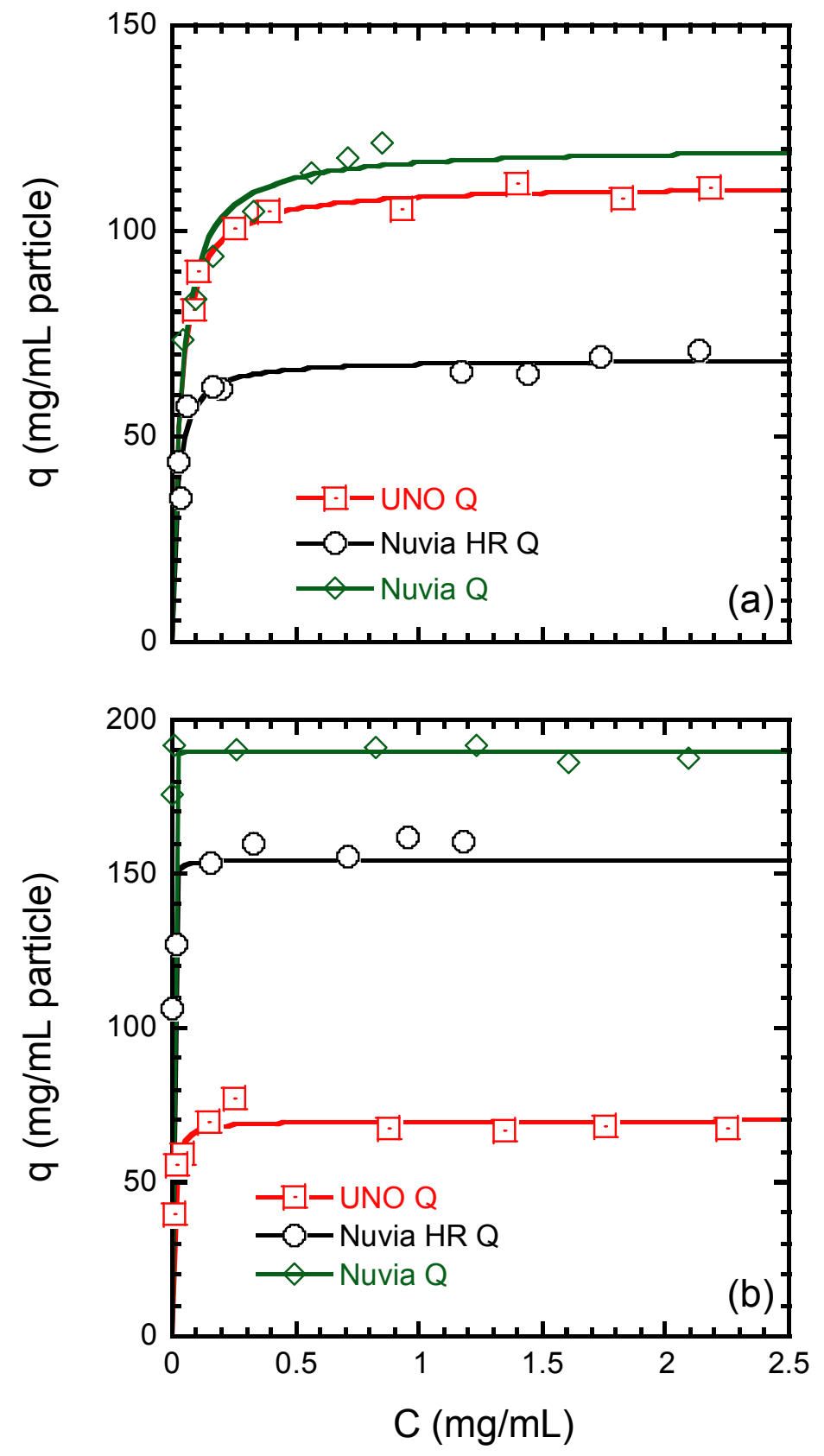

Fig. 4.2. Adsorption isotherms of $\mathrm{Tg}$ in $20 \mathrm{mM} \mathrm{BTP}-\mathrm{HCl} \mathrm{pH} 7$ buffer containing (a) $0 \mathrm{mM}$ and (b) $50 \mathrm{mM} \mathrm{NaCl}$, obtained for $24 \mathrm{~h}$ contact time. Lines are the Langmuir isotherm model with parameters in Table 4.2. 
Table 4.2 Langmuir isotherm parameters for BSA and Thyroglobulin (Tg) in buffers containing $0 \mathrm{mM}$ and $50 \mathrm{mM} \mathrm{NaCl}$.

\begin{tabular}{|c|c|c|c|c|c|c|c|}
\hline \multirow[t]{2}{*}{ Protein } & \multirow{2}{*}{$\begin{array}{c}\mathrm{NaCl} \\
\text { concentration } \\
(\mathrm{mM})\end{array}$} & \multicolumn{2}{|c|}{ UNO Q } & \multicolumn{2}{|c|}{ Nuvia HR Q } & \multicolumn{2}{|c|}{ Nuvia Q } \\
\hline & & $\begin{array}{c}q_{m} \\
(\mathrm{mg} / \mathrm{mL})\end{array}$ & $\begin{array}{c}K \\
(\mathrm{~mL} / \mathrm{mg})\end{array}$ & $\begin{array}{c}q_{m} \\
(\mathrm{mg} / \mathrm{mL})\end{array}$ & $\begin{array}{c}K \\
(\mathrm{~mL} / \mathrm{mg})\end{array}$ & $\begin{array}{c}q_{m} \\
(\mathrm{mg} / \mathrm{mL})\end{array}$ & $\begin{array}{c}K \\
(\mathrm{~mL} / \mathrm{mg})\end{array}$ \\
\hline \multirow[t]{2}{*}{ BSA } & 0 & $53.5 \pm 1.0$ & $24.2 \pm 5.1$ & $154 \pm 1$ & $200 \pm 9$ & $276 \pm 5$ & $31.4 \pm 4.8$ \\
\hline & 50 & $21.2 \pm 0.9$ & $10.1 \pm 3.0$ & $82.4 \pm 1.5$ & $31.1 \pm 4.8$ & $132 \pm 3$ & $26.5 \pm 6.5$ \\
\hline \multirow{2}{*}{$\begin{array}{c}\text { Thyroglobulin } \\
\text { (Tg) }\end{array}$} & 0 & $111 \pm 1$ & $35.1 \pm 3.6$ & $68.7 \pm 2.0$ & $53.0 \pm 9.9$ & $120 \pm 4$ & $29.7 \pm 5.8$ \\
\hline & 50 & $70.0 \pm 2.1$ & $181 \pm 45$ & $154 \pm 5$ & $2040 \pm 720$ & $190 \pm 1$ & $6360 \pm 160$ \\
\hline
\end{tabular}

binding decreases for all three resins but the trends remains the same as those observed without added salt. This is typical for ion exchangers. As salt concentration increase, the strength of electric interaction between ionic ligand and protein decreases and hence the capacity of protein decreases [18], which can be described by several models like stoichiometric displacement model of Kopaciewicz et al. [19] and steric mass action models of Brooks and Cramer [20].

The capacity trends observed for Tg on the polymer grafted resins, Nuvia HR Q and Nuvia Q, are unexpectedly different from the behaviors typically observed for ion exchange. For $\mathrm{UNO} \mathrm{Q}$, the isotherm response of $\mathrm{Tg}$ to salt concentration change is similar to that of BSA. On the other hand, for Nuvia HR Q and Nuvia Q, stronger binding is seen at $50 \mathrm{mM} \mathrm{NaCl}$, resulting in both higher capacity and much larger $K$ values. The observed behavior is also unusual with respect to the grafted polymer content at $0 \mathrm{mM}$ salt. The capacity of Nuvia HR Q is $40 \%$ less than that of UNO Q while the capacity of Nuvia Q is comparable to that of UNO Q. The capacity 
trents are however consistent with those obtained for BSA at $50 \mathrm{mM} \mathrm{NaCl}$. One possibility is that because of the expected slow kinetics, the $\mathrm{Tg}$ binding has not yet reached equilibrium capacities even though a saturation-resin contact time was used in the experiment. Thus, more investigation of protein adsorption kinetics is needed to understand this unexpected behavior.

\subsubsection{Adsorption kinetics}

The evolution of the intraparticle bound protein concentration during adsorption of 1 $\mathrm{mg} / \mathrm{mL} \mathrm{BSA}$ and Tg are shown in Figs 4.3 and 4.4 for each protein. As discussed in Chapter 3, the adsorption of BSA on UNO Q is dominated by a pore diffusion mechanism resulting in a sharp adsorption front defining an empty shrinking pore consistent with the UNO Q imges in Fig. 4.3. Adsorption on Nuvia HR Q and Nuvia Q are dominated instead by solid diffusion mechanism, which results in smooth intraparticle bound protein concentration profile. For BSA, the adsorption rates on Nuvia HR Q and Nuvia Q are comparable. In both cases, the saturation time is about $5 \mathrm{~min}$, much faster compared to the $20 \mathrm{~min}$ time scale require to saturate UNO Q. 


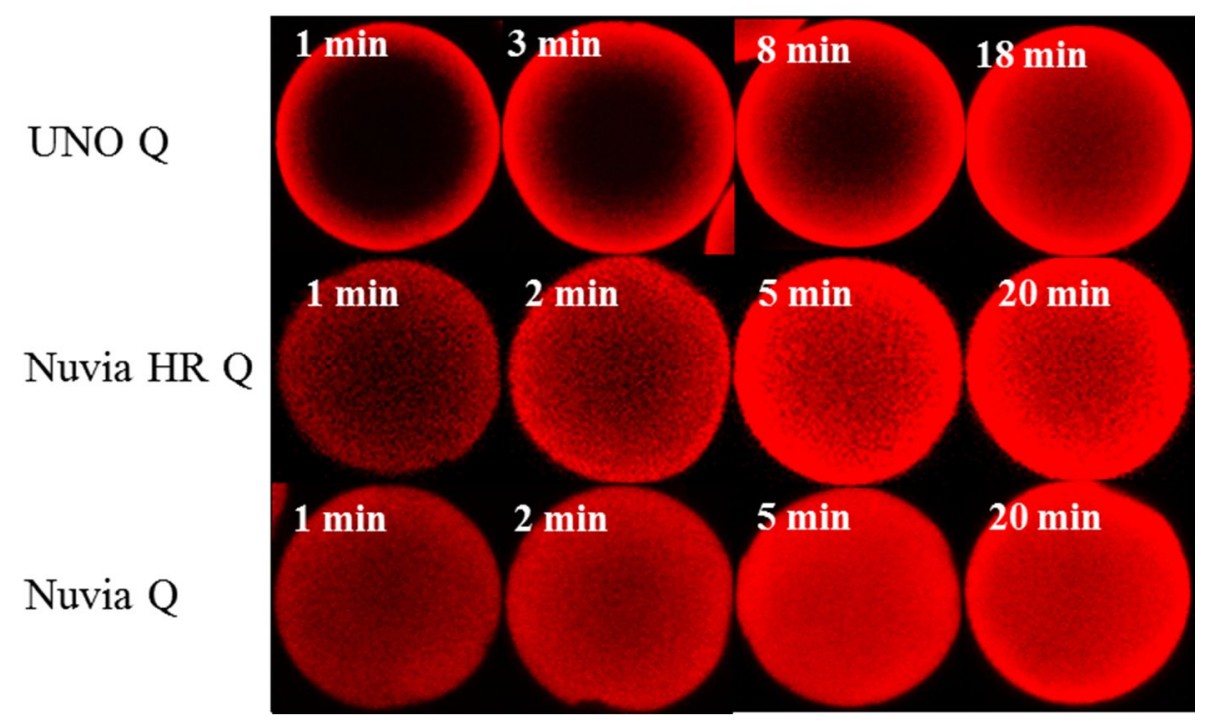

Fig. 4.3. CLSM images of $1 \mathrm{mg} / \mathrm{mL}$ BSA adsorption on UNO Q, Nuvia HR Q and Nuvia Q in 20 mM BTP-HCl pH 7 buffer containing $0 \mathrm{mM} \mathrm{NaCl}$. Actual particle diameters are about 70, 50 and $80 \mu \mathrm{m}$ for UNO Q, Nuvia HR Q, and Nuvia Q, respectively. Laser intensities were kept constant for each time series.

Figures $4.4 \mathrm{a}$ and $4.4 \mathrm{~b}$ show the CLSM results for Tg with $0 \mathrm{mM}$ and $50 \mathrm{mM} \mathrm{NaCl}$, respectively. Adsorption of $\mathrm{Tg}$ on UNO Q appears to be again dominated by pore diffusion at both $0 \mathrm{mM}$ and $50 \mathrm{mM} \mathrm{NaCl}$ (see Figs. 4.4a and 4.4b top row). The adsorption fronts are very sharp and the adsorption rates, indicated by the position of adsorption front relative to the particle size, are about the same at $0 \mathrm{mM}$ and $50 \mathrm{mM} \mathrm{NaCl}$. For Nuvia Q, smooth bound protein concentration profiles are found at both $0 \mathrm{mM}$ and $50 \mathrm{mM} \mathrm{NaCl}$ (see bottom row of Figs. 4.4a and $4.4 \mathrm{~b}$ ), indicating that protein transport again is dominated by a solid diffusion mechanism. Yet, quantitatively, transport rates are different at the two $\mathrm{NaCl}$ concentrations. At $0 \mathrm{mM} \mathrm{NaCl}$, more than $20 \mathrm{~min}$ is needed for Tg to approach near uniform spatial distribution of the protein while less than $3 \mathrm{~min}$ is needed at $50 \mathrm{mM} \mathrm{NaCl}$. For Nuvia $\mathrm{HR}$ Q, at $0 \mathrm{mM} \mathrm{NaCl}$, the adsorption 
(a)

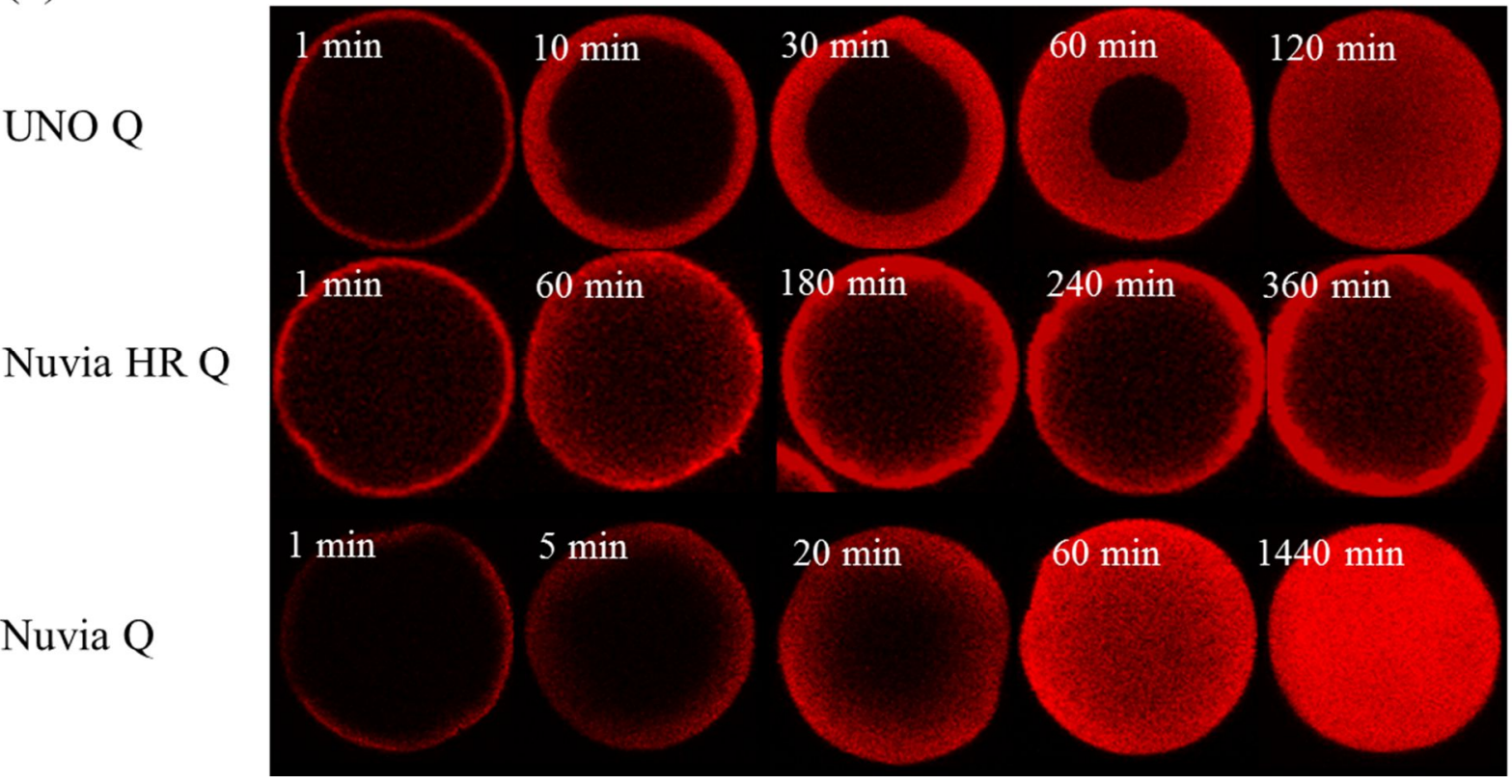

(b)

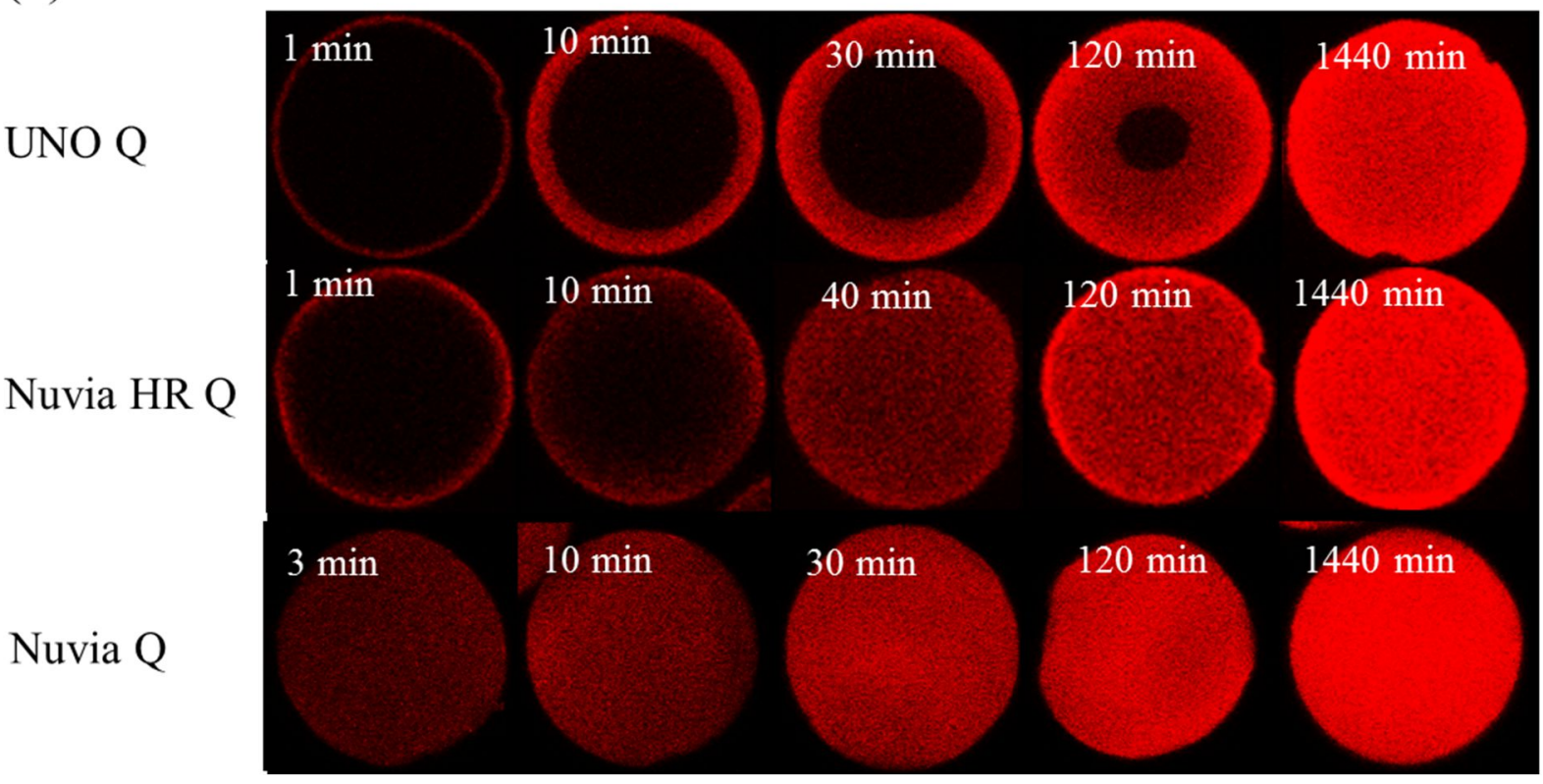

Fig. 4.4. CLSM images of $1 \mathrm{mg} / \mathrm{mL}$ Tg adsorption on UNO Q, Nuvia HR Q and Nuvia Q in 20 mM BTP-HCl pH 7 buffer containing (a) $0 \mathrm{mM}$ and (b) $50 \mathrm{mM} \mathrm{NaCl}$. Actual particle diameters are about 70, 50 and $80 \mu \mathrm{m}$ for UNO Q, Nuvia HR Q and Nuvia Q, respectively. Laser intensities were kept constant for each time series. 
of Tg seems highly hindered with a fully saturated ring occurring near the particle surface and only very limited penetration into the center of the particle even after $6 \mathrm{hr}$ adsorption.

Conversely, the adsorption of Tg at $50 \mathrm{mM}$ happens throughout the whole particle. The profile is relatively smooth, which is consistent with a solid diffusion mechanism. Although at $50 \mathrm{mM}$ $\mathrm{NaCl}$, the pore size is slightly larger than that at $0 \mathrm{mM} \mathrm{NaCl}$ for Nuvia $\mathrm{HR}$ Q as discussed in Chapter 2, the pore size difference alone is too small to account for large difference observed by CLSM.

Figures 4.5 and 4.6 show the batch uptake curves obtained as described in Section 4.2.2.2 at $1 \mathrm{mg} / \mathrm{mL}$ initial protein concentration, for BSA and $\mathrm{Tg}$, respectively. The bound protein concentration is plotted as a function of adsorption time for each resin. For BSA at $0 \mathrm{mM} \mathrm{NaCl}$, the capacities achieved for each resin after 30 min match the isotherm results, showed in Fig. 4.5. Consistent with $24 \mathrm{~h} \mathrm{r}$ measurements, the BSA adsorption capacity is higher for polymer grafted reins even at this short time scales, indicating the adsorption kinetics are considerably faster than on UNO Q. As discussed in Chapter 3, this enhancement of adsorption kinetics is attributed to solid diffusion in the polymer grafted reins where a much larger diffusion flux is driven by the higher bound protein concentration in the polymer grafted resins. 


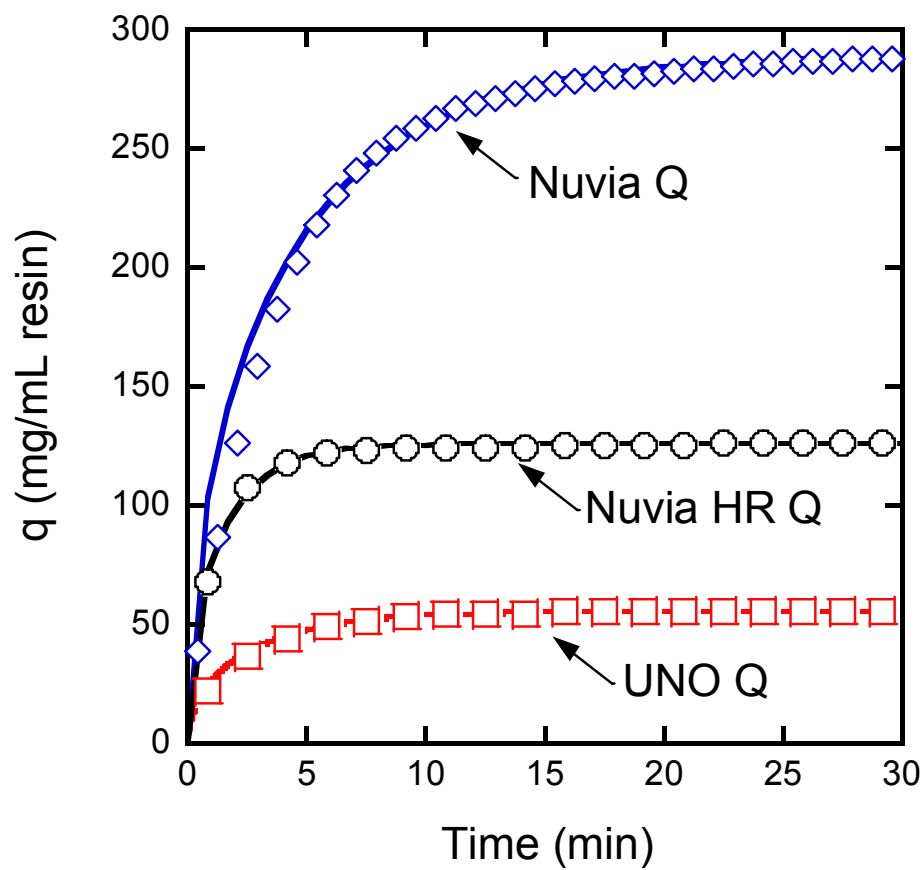

Fig. 4.5. Batch adsorption kinetics of $1 \mathrm{mg} / \mathrm{mL}$ BSA in $20 \mathrm{mM} \mathrm{BTP}-\mathrm{HCl} \mathrm{pH} 7$ buffer containing $0 \mathrm{mM} \mathrm{NaCl}$ on $\mathrm{UNO}$ Q, Nuvia HR Q, and Nuvia Q. Lines are calculated from the pore diffusion model for UNO Q and from the solid diffusion model for Nuvia HR Q and Nuvia Q using parameters in Table 4.3. 

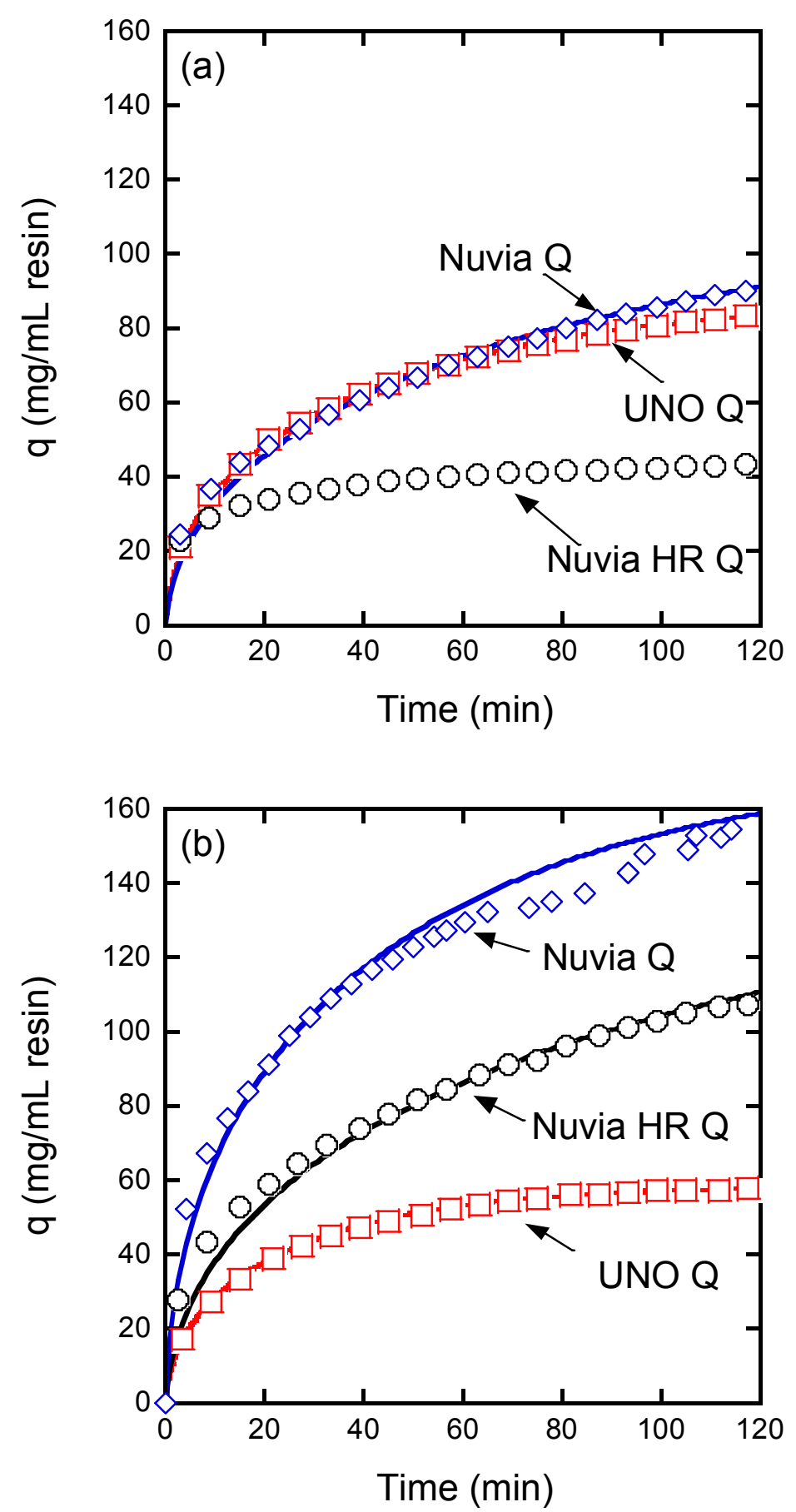

Fig. 4.6. Batch adsorption kinetics of $1 \mathrm{mg} / \mathrm{mL}$ Tg in $20 \mathrm{mM} \mathrm{BTP-HCl} \mathrm{pH} 7$ buffer containing (a) $0 \mathrm{mM}$ and (b) $50 \mathrm{mM} \mathrm{NaCl}$ on UNO Q, Nuvia HR Q, and Nuvia Q. Lines are calculated from the pore diffusion model for UNO Q and from the solid diffusion model for Nuvia HR Q and Nuvia Q using the parameters in Table 4.3. 
In the case of thyroglobulin, Figs $4.6 \mathrm{a}$ and $4.6 \mathrm{~b}$ show that the equilibrium conditions was not obtained in the $120 \mathrm{~min}$ duration of the batch uptake experiments for both $0 \mathrm{mM}$ and $50 \mathrm{mM}$ $\mathrm{NaCl}$. In all cases, the batch uptake curves exhibit rising trend at the end of the experiments indicating that more time is needed to reach adsorption equilibrium. This rising trend is more profound for Nuvia HR Q and Nuvia Q at both $0 \mathrm{mM}$ and $50 \mathrm{mM} \mathrm{NaCl}$. Most striking is the fact that for this large protein the uptake rates on Nuvia HR Q are profoundly affected by the salt concentration (see circles in Figs. 4.6a and 4.6b). Without added salt (Fig. 4.6a), after a rapid initial uptake, the rate slows down dramatically. This behavior is consistent with that observed by CLSM (Fig. 4.4a, middle row) and indicates that diffusion becomes highly hindered beyond a relatively thin shell near the particle surface. Increasing the $\mathrm{NaCl}$ concentration to $50 \mathrm{mM}$ (Fig. 4.6b) increases the adsorption kinetics resulting in greater amounts of bound protein. As seen in Fig. 4.4b (middle row), this result is also consistent with the CLSM observations of much greater penetration toward the particle center for this conditions.

It should be noted that for $\mathrm{UNO}$ Q, although a higher capacity is observed at $0 \mathrm{mM} \mathrm{NaCl}$, the adsorption kinetics are very comparable as indicated by the similar time scales needed to approach equilibrium at each condition (see Figs 4.6a and 4.6b, square symbols).

\subsubsection{Batch uptake modeling}

Based on the CLSM results, two different diffusion models were used to quantitatively describe the adsorption kinetics [5,21]. For BSA and Tg adsorption on UNO Q, the model assumes that pore diffusion is controlling. Neglecting accumulation in the pore space, the model is given by following equations and boundary conditions [21]:

$$
\frac{\partial q}{\partial t}=\frac{D_{e}}{r^{2}} \frac{\partial}{\partial r}\left(r^{2} \frac{\partial c}{\partial r}\right)
$$




$$
\begin{aligned}
& \left.\frac{\partial c}{\partial r}\right|_{r=0}=0 \\
& \left.D e \frac{\partial c}{\partial r}\right|_{r=r_{p}}=k_{f}\left(C-\left.c\right|_{r=r_{p}}\right) \\
& V \frac{d C}{d t}=-\frac{3 V_{M}}{r_{p}} k_{f}\left(C-\left.c\right|_{r=r_{p}}\right) \\
& \left.C\right|_{t=0}=C_{0}
\end{aligned}
$$

where $C$ and $c$ are the protein concentration in the bulk liquid and particle pores respectively, $q$ is the adsorbed protein concentration, $V$ and $V_{M}$ are the volume of protein solution and resin respectively, $D_{e}$ is the effective pore diffusivity, and $k_{f}$ is the external mass transfer coefficient. $q$ and $c$ are correlated by Langmuir isotherm as discussed in section 4.3.1.

For BSA and Tg adsorption on Nuvia HR Q and Nuvia Q, the model assumes that diffusion in the "adsorbed phase" is controlling, which is referred to as solid diffusion. The model is given by following equations and boundary conditions [5]:

$$
\begin{aligned}
& \frac{\partial q}{\partial t}=\frac{D_{s}}{r^{2}} \frac{\partial}{\partial r}\left(r^{2} \frac{\partial q}{\partial r}\right) \\
& \left.\frac{\partial q}{\partial r}\right|_{r=0}=0 \\
& \left.D s \frac{\partial q}{\partial r}\right|_{r=r_{p}}=k_{f}\left(C-C_{s}\right) \\
& V \frac{d C}{d t}=-\frac{3 V_{M}}{r_{p}} k_{f}\left(C-C_{s}\right) \\
& \left.C\right|_{t=0}=C_{0}
\end{aligned}
$$


where $D_{s}$ is the solid diffusivity and $C_{S}$ is the fluid phase concentration at the particle surface.

The latter is related to $\left.q\right|_{r=r_{p}}$ through Langmuir isotherm. Both models were solved numerically by finite differences and the model predictions were compared with the batch uptake curves to determine either $D_{e}$ or $D_{s}$ by minimizing the sum of residual squares between experimental data and predicted values. Estimated errors of the regressed parameters were based on $D_{e}$ or $D_{s}$ value that resulted in $\mathrm{a} \pm 10 \%$ variation of the sum of residual squares.

Model predictions are shown as solid lines in Figs. 4.5 and 4.6, and the fitting parameters are summarized in Table 4.3. The models provide a good description of the batch uptake curve for all cases except for Tg on Nuvia HR Q at $0 \mathrm{mM}$. As indicated by CLSM, the adsorption on Nuvia HR Q is hindered after a layer of Tg bound at the particle surface. Thus the batch uptake curve, in this case, has a relatively steep initial part corresponding to the adsorption of $\mathrm{Tg}$ on the particle surface, then followed by a much shallower part. As a result, since the protein is obviously controlled by two different rate process with different time constants, neither the pore diffusion model nor the solid diffusion model is able to describe this behavior. The solid diffusivity of BSA on Nuvia HR Q is slightly higher than on Nuvia Q but the difference is very small, indicating the mobility of BSA inside the polymer phase of both resin is similar although the grafted polymer contents are different. However, very different values are found for $\mathrm{Tg}$ adsorption at $50 \mathrm{mM}$. The diffusivity on Nuvia Q is about 5 times of that on Nuvia HR Q, indicating the relative size of protein getting closer to the thickness of polymer grafted layer, the mobility of protein decreased greatly. The mobility is also affected by salt concentration. As salt concentration increases from $0 \mathrm{mM}$ to $50 \mathrm{mM}$, the solid diffusivity of Tg on Nuvia Q almost doubled. Similar results have been seen for protein adsorption on polymer grafted cation exchangers [22-24]. Harinarayan et al. studied the adsorption of monoclonal antibodies on SP 
Sepharose XL and found the mass transport rate and the dynamic binding capacity firstly increase with the conductivity and then decrease. They measured the mobility of bound protein by multi-color analysis and found under critic conductivity, increased conductivity results in increased mobility of bound protein [23,24].

Table 4.3 Diffusivity values determined from batch uptake curves. De are based on Eqs. 4.2 and 4.3, while Ds values are based on Eqs. 4.4 and 4.5

\begin{tabular}{|l|l|l|l|l|}
\hline \multirow{2}{*}{ Protein } & Salt & $\begin{array}{l}\text { UNO Q } \\
\text { concentration } \\
(\mathrm{mM})\end{array}$ & $\begin{array}{l}\text { Nuvia HR Q } \\
\left(D_{e} 10^{-7} \mathrm{~cm}^{2} / \mathrm{s}\right)\end{array}$ & $\begin{array}{l}\left(D_{s} 10^{-9} \mathrm{~cm}^{2} / \mathrm{s}\right) \\
\left(D_{s} 10^{-9} \mathrm{~cm}^{2} / \mathrm{s}\right)\end{array}$ \\
\hline BSA & 0 & $2.1 \pm 0.1$ & $5.9 \pm 0.1$ & $4.3 \pm 0.1$ \\
\hline \multirow{2}{*}{ Tg } & 0 & $0.25 \pm 0.01$ & - & $0.25 \pm 0.01$ \\
\cline { 2 - 5 } & 50 & $0.24 \pm 0.01$ & $0.093 \pm 0.001$ & $0.45 \pm 0.01$ \\
\hline
\end{tabular}

\subsubsection{Mass transfer kinetics for non-binding conditions}

For comparison purposes, the effective pore diffusivities were also determined for UNO Q and Nuvia HR Q by performing pulse injection experiments under non-binding conditions at superficial velocities between 300 and $3000 \mathrm{~cm} / \mathrm{h}$. $D_{e}$ was then calculated from Eq. 4.1 and summarized in Table 4.4. Note that for Nuvia Q, again $D_{e}$ could not be determined from pulse injection runs under non-binding conditions since in this case both proteins are nearly completely excluded from the particles and $k^{\prime} \sim 0$ making the slope $d h / d v^{\prime}$ too small to be determined with any accuracy.

For BSA, the diffusivities on UNO Q and Nuvia HR Q are about the same and are in fairly good agreement with the diffusivity obtained from batch uptake curve of BSA adsorption 
on UNO Q, indicating that pore size of UNO Q and Nuvia HR Q are both large enough relative to the small size of BSA and there is no excessive hindrance for BSA to diffuse into the particles. On the contrary, for $\mathrm{Tg}$, the diffusivity on UNO Q at nonbinding condition is much larger than that on Nuvia HR Q, and also larger than the diffusivity from batch uptake curves. Normally, to avoid excessive diffusion hindrance, the pore radius needs to be larger than five to ten times of the protein radius [21]. Due to the large size of $\mathrm{Tg}$, the pore size of Nuvia HR Q is relatively small which results in large hindrance for $\mathrm{Tg}$ diffusion and hence a much smaller diffusivity comparing to UNO Q. Interestingly, the diffusivity of Tg on Nuvia HR Q at nonbinding condition $\left(D_{e}=2.7 \times 10^{-8} \mathrm{~cm}^{2} / \mathrm{s}\right)$ is close to the diffusivity of Tg on UNO Q at binding condition $\left(D_{e}=2.4 \times 10^{-8} \mathrm{~cm}^{2} / \mathrm{s}\right)$, indicating the hindrance introduced by the bound Tg on UNO Q is comparable to the hindrance introduced by the grafted polymer in Nuvia HR Q. In another word, the thickness of gel phase formed by grafted polymer in Nuvia HR Q is about the size of Tg.

Table 4.4 Effective diffusivity values determined from pulse response under nonbinding condition for BSA and Tg.

\begin{tabular}{|c|c|c|c|c|}
\hline \multirow{2}{*}{ Resin } & \multicolumn{2}{|c|}{ BSA } & \multicolumn{2}{c|}{ Tg } \\
\cline { 2 - 5 } & $\begin{array}{c}D_{e} \\
\left(10^{-7} \mathrm{~cm}^{2} / \mathrm{s}\right)\end{array}$ & $D_{e} / D_{0}$ & $D_{e}$ \\
$\left(10^{-8} \mathrm{~cm}^{2} / \mathrm{s}\right)$ & $D_{e} / D_{0}$ \\
\hline UNO Q & 1.7 & 0.28 & 6.4 & 0.25 \\
\hline Nuvia HR Q & 1.5 & 0.25 & 2.7 & 0.11 \\
\hline
\end{tabular}

\subsection{Conclusions}

The adsorption equilibrium and kinetics of small and large protein in anion exchangers with varying content of grafted polymers have been investigated via both microscopic and 
macroscopic methods. Results show that the relative size of protein to the grafted polymer has a great influence on the adsorption behavior. Fast solid diffusion only happens when the polymer content is high enough to form a gel phase trapped protein under strong binding condition.

Transport mechanisms are different for small protein like BSA and large protein like $\mathrm{Tg}$, as shown schematically in Fig. 4.7.

Small protein
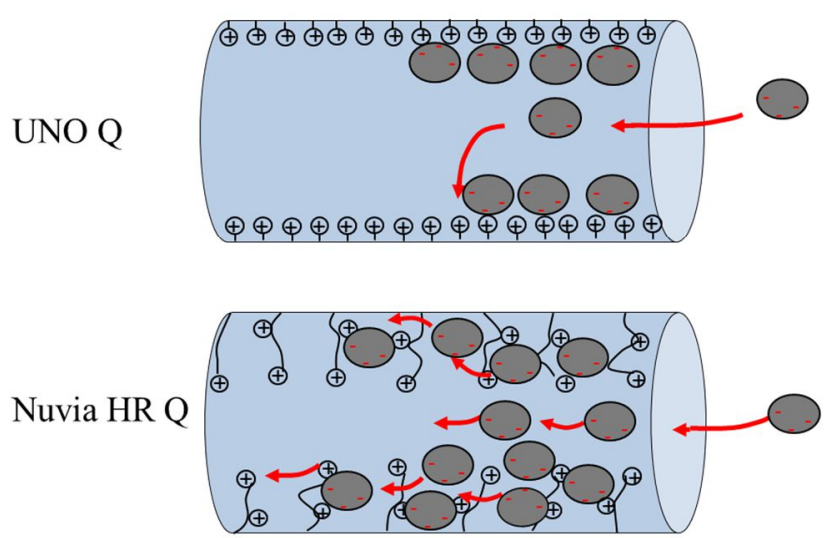

Nuvia Q

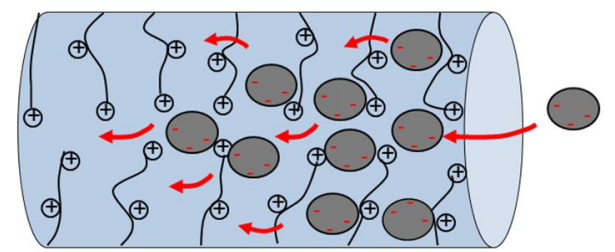

Large protein
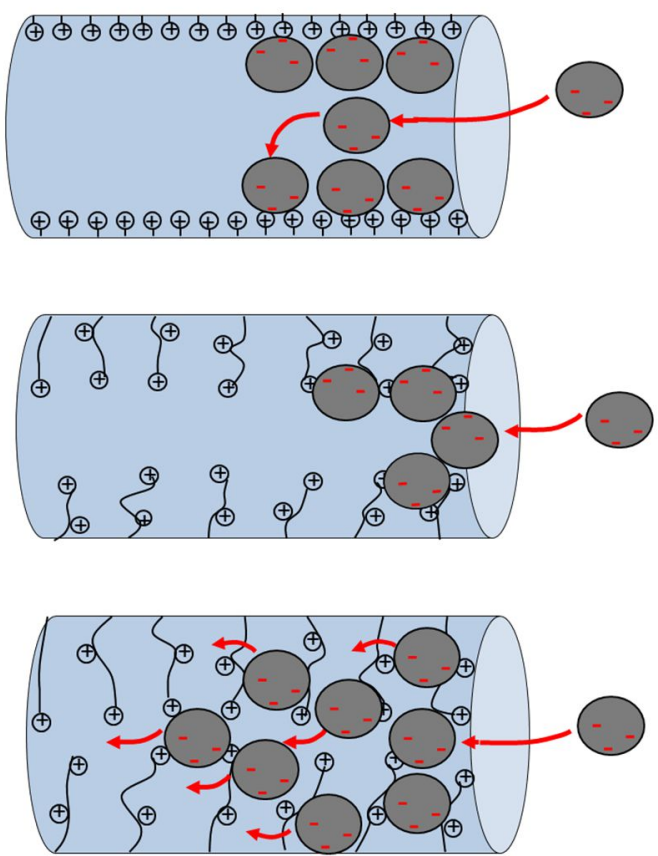

Fig. 4.7. Transport mechanism of small and large protein in anion exchanger with varying length of polymer grafting under strong binding condition.

For small protein, as discussed in Chapter 3, grafted polymers in anion exchanger increase binding capacity and transport rate by multilayer adsorption and solid diffusion. The relative size of protein is small to the size of grafted polymer in both Nuvia HR Q and Nuvia Q, hence the mobility of bound protein in both resins is similar. Protein has no difficulty moving in the gel phase formed by grafted polymer and the whole particle volume is utilized for protein 
adsorption. The adsorption equilibrium then can be reached quickly and the capacity response to conductivity is typical for ion exchanger.

On the other hand, for a a large protein whose size is comparable to the size of grafted polymer, for example, Tg adsorption on Nuvia HR Q in this study, the adsorption and transport of protein is highly influenced by the interaction strength. Under strong binding condition (low conductivity, high protein charge etc.) as shown on the right side of Fig. 4.7, the mobility of bound protein is very limited in Nuvia HR Q. Since the grafted polymers also take up some pore volume, the incoming protein molecules are hindered by the bound protein and the adsorption only happens at the particle surface which leads to very low binding capacity. While as the conductivity increases, the interaction between bound protein and the charged group become weaker. The mobility of bound protein increases and bound protein can move in the polymer gel phase in a manner same as that in Nuvia Q. Thus the newly incoming protein molecules are able to adsorb to the "released" free ligand at the particle surface and the capacity increases.

From a practical viewpoint, the application of polymer grafted IEC adsorbents to the purification of the very large biomolecule requires under carefully screening of resins and buffer conditions. Effective resins will have base matrix containing large pore and high content of polymer grafts. Optimized buffer ionic strengths need to be identified is to achieve high binding capacity and fast kinetics.

\subsection{List of symbols}

c concentration in particle pores $(\mathrm{mg} / \mathrm{mL})$

C fluid phase concentration $(\mathrm{mg} / \mathrm{mL})$

$d_{p} \quad$ particle diameter $(\mathrm{cm})$

$D_{e} \quad$ effective pore diffusivity $\left(\mathrm{cm}^{2} / \mathrm{s}\right)$ 


$$
\begin{array}{ll}
D_{s} & \text { adsorbed phase diffusivity }\left(\mathrm{cm}^{2} / \mathrm{s}\right) \\
D_{0} & \text { free solution diffusivity }\left(\mathrm{cm}^{2} / \mathrm{s}\right) \\
h & \text { reduced HETP }\left(=H E T P / \mathrm{d}_{\mathrm{p}}\right) \\
k^{\prime} & \text { chromatographic retention factor } \\
k_{f} & \text { external film mass transfer coefficient }(\mathrm{cm} / \mathrm{s}) \\
K & \text { parameter in Langmuir isotherm }(\mathrm{mL} / \mathrm{mg}) \\
q & \text { adsorbed phase concentration }(\mathrm{mg} / \mathrm{mL}) \\
q_{m} & \text { parameter in Langmuir isotherm }(\mathrm{mg} / \mathrm{mL}) \\
r & \text { particle radical coordinate }(\mathrm{cm}) \\
r_{h} & \text { hydrodynamic radius }(\mathrm{nm}) \\
r_{p} & \text { particle radius }(\mathrm{cm}) \\
v & \text { mobile phase velocity }(\mathrm{cm} / \mathrm{s}) \\
V_{M} & \text { resin volume }(\mathrm{mL}) \\
V & \text { extraparticle column porosity } \\
v^{\prime} & \text { solution volume }(\mathrm{mL}) \\
&
\end{array}
$$

\subsection{Reference}

[1] A.M. Lenhoff, Protein adsorption and transport in polymer-functionalized ionexchangers., J. Chromatogr. A. 1218 (2011) 8748-59.

[2] H.O. Johansson, J.M. Van Alstine, Modeling of protein interactions with surface-grafted charged polymers. Correlations between statistical molecular modeling and a mean field approach, Langmuir. 22 (2006) 8920-8930. 
[3] L.-L. Yu, Q.-H. Shi, Y. Sun, Effect of dextran layer on protein uptake to dextran-grafted adsorbents for ion-exchange and mixed-mode chromatography., J. Sep. Sci. 34 (2011) 2950-9.

[4] E.X. Pérez Almodóvar, Y. Tao, G. Carta, Protein adsorption and transport in cation exchangers with a rigid backbone matrix with and without polymeric surface extenders., Biotechnol. Prog. 27 (2011) 1264-72.

[5] Y. Tao, G. Carta, G. Ferreira, D. Robbins, Adsorption of deamidated antibody variants on macroporous and dextran-grafted cation exchangers: II. Adsorption kinetics, J. Chromatogr. A. 1218 (2011) 8027-8035.

[6] M.C. Stone, Y. Tao, G. Carta, Protein adsorption and transport in agarose and dextrangrafted agarose media for ion exchange chromatography: Effect of ionic strength and protein characteristics., J. Chromatogr. A. 1216 (2009) 4465-74.

[7] E. Müller, Comparison between mass transfer properties of weak-anion-exchange resins with graft-functionalized polymer layers and traditional ungrafted resins, J. Chromatogr. A. 1006 (2003) 229-240.

[8] S. Gautam, K.C. Loh, Immunoglobulin-M purification - challenges and perspectives, Biotechnol. Adv. 29 (2011) 840-849.

[9] C. Acquah, C.K.S. Moy, M.K. Danquah, C.M. Ongkudon, Development and characteristics of polymer monoliths for advanced LC bioscreening applications: A review, J. Chromatogr. B. 1015-1016 (2016) 121-134.

[10] A. Podgornik, S. Yamamoto, M. Peterka, N.L. Krajnc, Fast separation of large biomolecules using short monolithic columns, J. Chromatogr. B. 927 (2013) 80-89. 
[11] Y. Wu, J. Simons, S. Hooson, D. Abraham, G. Carta, Protein and virus-like particle adsorption on perfusion chromatography media, J. Chromatogr. A. 1297 (2013) 96-105.

[12] R.M. Montesinos-Cisneros, A. Lucero-Ac, J. Ortega, R. Guzmán, A. Tejeda-Mansir, Breakthrough performance of large proteins on ion - exchange membrane columns, Biotechnol . Appl . Biochem. 48 (2007) 117-125.

[13] H. Yang, C. Viera, J. Fischer, M.R. Etzel, Purification of a Large Protein Using IonExchange Membranes, Ind. Eng. Chem. Res. 41 (2002) 1597-1602.

[14] M. Zhu, G. Carta, Adsorption of polyethylene-glycolated bovine serum albumin on macroporous and polymer-grafted anion exchangers., J. Chromatogr. A. 1326 (2014) 2938.

[15] E.X. Perez-Almodovar, Y. Wu, G. Carta, Multicomponent adsorption of monoclonal antibodies on macroporous and polymer grafted cation exchangers., J. Chromatogr. A. 1264 (2012) 48-56.

[16] G. Carta, A.R. Ubiera, T.M. Pabst, Protein mass transfer kinetics in ion exchange media: Measurements and interpretations, Chem. Eng. Technol. 28 (2005) 1252-1264.

[17] B. R.B., S. W.E., E.N. Lightfoot, Transport Phenomena, John Wiley \& Sons, 1960.

[18] Jan-Christer Janson, Protein purification : principles, high resolution methods, and applications, Wiley, 2011.

[19] W. Kopaciewicz, M.A. Rounds, J. Fausnaugh, F.E. Regnier, Retention model for highperformance ion-exchange chromatography, J. Chromatogr. A. 266 (1983) 3-21.

[20] C.A. Brooks, S.M. Cramer, Steric mass-action ion exchange: Displacement profiles and induced salt gradients, AIChE J. 38 (1992) 1969-1978. 
[21] G. Carta, A. Jungbauer, Protein Chromatography: Process Development and Scale-Up, John Wiley \& Sons, 2010.

[22] D.S. Hart, C. Harinarayan, G. Malmquist, A. Axén, M. Sharma, R. van Reis, Surface extenders and an optimal pore size promote high dynamic binding capacities of antibodies on cation exchange resins, J. Chromatogr. A. 1216 (2009) 4372-4376.

[23] C. Harinarayan, J. Mueller, A. Ljunglöf, R. Fahrner, J. Van Alstine, R. Van Reis, An exclusion mechanism in ion exchange chromatography, Biotechnol. Bioeng. 95 (2006) $775-787$.

[24] A. Ljunglöf, K.M. Lacki, J. Mueller, C. Harinarayan, R. Van Reis, R. Fahrner, et al., Ion exchange chromatography of antibody fragments, Biotechnol. Bioeng. 96 (2007) 515524. 


\section{Chapter 5}

\section{Protein Adsorption Equilibrium and Kinetics in Multimodal Cation Exchange}

\section{Resins}

\subsection{Introduction}

As mentioned in Chapter 1, multimodal chromatography utilizes stationary phases that contain ligands capable of multiple interaction types with protein molecules. The combination brings several advantages for multimodal resin compared to conventional single-mode chromatography, such as high selectivity and the ability to bind protein at relatively high ionic strength [1-4]. However multimodal interactions are generally also harder to describe because of their complex dependence on $\mathrm{pH}$, salt concentration, temperature, and the presence of mobile phase additives, such as arginine [5-7]. Application of multimodal chromatography often requires extensive experimental studies in order to determine conditions that are appropriate for binding and elution $[8,9]$. The more rational design of multimodal chromatography requires a better understanding of both protein-ligand interactions and transport mechanisms.

This chapter has two main objectives. The first is to understand the effects of resin structure and ligand chemistry on protein adsorption equilibrium and kinetics both for lysozyme, which is a relatively small protein, and for a monoclonal antibody (mAb), which is a relatively large protein. Two commercial resins are used for this study, one based on the same UNOsphere backbone matrix of the resins studied in the previous chapters of this dissertation and containing relatively large pores, and the other based on an agarose backbone and containing relatively small pores. The ligands in these resins contain essentially the same chemical moieties, but their arrangement is different potentially resulting in different interactions with adsorbed protein. The 
second objective is to elucidate the intraparticle transport mechanism of both proteins by examining their movement within the resin particles during transient adsorption using confocal laser scanning microscopy (CLSM).

\subsection{Materials and methods}

\subsubsection{Materials}

The resins used in this work are Nuvia cPrime from Bio-Rad Laboratories (Hercules, CA, USA), which is based on the UNOsphere matrix discussed in the previous chapters of this dissertation, and Capto MMC from GE Healthcare (Piscataway, NJ, USA), which is agarosebased. Both resins are in spherical form with mean particle diameters, determined by optical microscopy, of 69 and $85 \mu \mathrm{m}$ for Nuvia cPrime and Capto MMC, respectively. The ligands in the two resins are shown in Fig. 5.1, as reported by the respective manufacturers. In both cases, the ligand contains a phenyl group, a peptide bond, and a carboxyl group but the arrangement of these moieties is different in the two ligands resulting in a different presentation of hydrophobic and charged groups to the adsorbate molecules. The cPrime ligand is tethered to the resin (R) via a secondary amine group while the MMC ligand is tethered via a thioether.

(a) Nuvia cPrime<smiles>[R]NCc1ccc(C(=O)NCC(=O)[O-])cc1</smiles>

(b) Capto MMC<smiles>[R]CSCCC(C(=O)[O-])N([TlH])C(=O)Cc1ccccc1</smiles>

Fig. 5.1. Multimodal ligands in (a) Nuvia cPrime and (b) Capto MMC according to the respective manufacturer 
The proteins used in this work are lysozyme (Lyo), with molar mass $\sim 15 \mathrm{kDa}$ and $\mathrm{pI} \sim 11$, obtained from Sigma-Aldrich (St. Louis, MO, USA), and a monoclonal antibody (mAb) with molar mass $\sim 150 \mathrm{kDa}$ and $\mathrm{pI} 8.2$, available in our laboratory. The hydrodynamic radii, $r_{h}$, of these two proteins are approximately 2 and $5 \mathrm{~nm}$, respectively, as determined from the StokesEinstein equation based on their respective aqueous diffusivities $D_{0}=1 \times 10^{-6}$ and $4 \times 10^{-7} \mathrm{~cm}^{2} / \mathrm{s}$ obtained from Tyn and Gusek [10]. Other chemicals were from Sigma-Aldrich (St. Louis, MO, USA) and Fisher Scientific (Pittsburg, PA, USA). Experiments at pH 5 or below were conducted in $20 \mathrm{mM}$ sodium acetate buffers while experiments at higher $\mathrm{pH}$ values were conducted in 20 $\mathrm{mM}$ sodium phosphate. All experiments were conducted at room temperature, $22 \pm 2{ }^{\circ} \mathrm{C}$.

\subsubsection{Methods}

\subsubsection{Resin physical and chemical properties}

Transmission electron microscopy (TEM) was used to determine each resin's backbone structure and inverse size exclusion chromatography (iSEC) was used to determine resin porosity and apparent pore size as previously described in Chapter 2. Resin samples for TEM were prepared by first saturating them with $1 \mathrm{mg} / \mathrm{mL}$ lysozyme at $\mathrm{pH} 5$ and fixing them with $2 \%$ glutaraldehyde, dehydrating them in an ethanol gradient from 0 to $100 \%$ anhydrous ethanol, and finally embedding them into LR-White resin (London Resin Company, London, UK) as described in by in Section 2.2.2.1 for the preparation of anion exchange resin samples saturated with BSA. After embedding, $80 \mathrm{~nm}$ slices were obtained using an ultramicrotome, stained with uranyl acetate and lead citrate, and viewed with a JEOL $100 \mathrm{CX}$ transmission electron microscope. As was observed for BSA, the bound lysozyme readily takes up the heavy metal stains, enhancing contrast and resolution compared to lysozyme-free samples. 
For iSEC, each resin was packed into a $6.6 \mathrm{~mm}$ x $140 \mathrm{~mm}$ Omnifit column (Diba Industries Inc., Danbury, CT, USA). Glucose and dextrans, obtained from Spectrum Chemical MFG Co. (Cardena, CA, USA), with molecular masses of 4, 10, 40, and $70 \mathrm{kD}$, and thyroglobulin, obtained from Sigma-Aldrich (St. Louis, MO, USA) with molecular mass of 700 $\mathrm{kDa}$, were used as size standards according to the procedure described in Stone and Carta [12] at $\mathrm{pH} 7.5$ for thyroglobulin and $\mathrm{pH} 6.5$ for other size standards. Thyroglobulin, which has a $\mathrm{pI}$ of 4.6 [13] was found to be un-adsorbed by either resin at $\mathrm{pH}$ 7.5. Pressure-flow curves, obtained under superficial velocities from 150 to $1000 \mathrm{~cm} / \mathrm{h}$, were linear for these columns and were used in conjunction with the Blake-Kozeny equation [14] (see Section 2.3.2) to determine the extraparticle porosity value of each column. The values were $0.36 \pm 0.03$ and $0.40 \pm 0.03$ for Nuvia cPrime and Capto MMC columns, respectively.

Potentiometric titrations were performed as described in ref. [15] to determine the $p K_{a}$ value of each ligand. For this purpose, each resin was first packed into a $5 \mathrm{~mm}$ x $50 \mathrm{~mm}$ Tricorn column (GE Healthcare, Piscataway, NJ, USA) and equilibrated with $10 \mathrm{mM} \mathrm{HCl}$ solutions (pH 2) containing 20,50, and $100 \mathrm{mM} \mathrm{NaCl}$. At this $\mathrm{pH}$, all carboxyl groups in either ligand are expected to be protonated. The resin samples were then extruded from the column into $25 \mathrm{~mL}$ of the equilibration solution and titrated with standardized sodium hydroxide while monitoring $\mathrm{pH}$ with a glass-combination electrode. Blank titrations without the resin were also conducted at each solution concentration and the results were subtracted from the resin titration curves.

\subsubsection{Equilibrium isotherms}

Equilibrium isotherms were obtained at $\mathrm{pH} 3,5$, and 7 for lysozyme and $\mathrm{pH} 4,5$, and 6 for the $\mathrm{mAb}$ over a range of $\mathrm{NaCl}$ concentrations. Higher $\mathrm{pH}$ values were not used for the $\mathrm{mAb}$ since little or no binding was observed at $\mathrm{pH}>6$, except at very low salt concentrations. For this 
purpose, resin samples were first equilibrated in the working buffer and then centrifuged at 5,000 rpm for $20 \mathrm{~min}$ in a microcentrifuge filter tube (Eppendorf MiniSpin Centrifuge 5702) to remove the extraparticle solution. Weighed amounts of each centrifuged resin were then added to plastic tubes containing $1.5 \mathrm{~mL}$ of solutions with different initial protein concentrations in the same buffer. The amount of resin added to each tube was estimated to provide a roughly $50 \%$ change in protein concentration at equilibrium. After rotating the tubes end-over-end at a few rpm for 24 h, the supernatant protein concentration was measured with a NanoVue spectrophotometer (GE Healthcare, Piscataway, NJ, USA) at $280 \mathrm{~nm}$ and the adsorbed protein concentration calculated by mass balance. Hydrated particle densities of $1.08 \mathrm{mg} / \mathrm{mL}$ for Nuvia cPrime and $1.13 \mathrm{mg} / \mathrm{mL}$ for Capto MMC, determined with a pycnometer, were used to express the protein bound in terms of adsorbed mass per unit volume of resin particle.

\subsubsection{Adsorption kinetics}

The protein adsorption kinetics was studied using batch uptake measurements, which provide information about the rates, and confocal laser scanning microscopy (CLSM), which also provides information about the dominant transport mechanism. Batch uptake measurements were conducted as described in ref. [16]. Briefly, a sample of centrifuged resin was added to a solution containing $1 \mathrm{mg} / \mathrm{mL}$ protein in a glass vessel agitated with a paddle stirrer while continuously recirculating the solution through a filter and a UV detector connected to a data acquisition system. The amount of resin added was again estimated to give a roughly $50 \%$ change in the supernatant protein concentration. The amount of protein bound as a function of time was obtained by material balance using the UV readings at $280 \mathrm{~nm}$.

CLSM imaging of mAb adsorption was conducted as described by Almodovar et al. $[11,17]$ and in Chapter 3. For this purpose, the $\mathrm{mAb}$ was conjugated with the amine-reactive 
fluorescent dye Rhodamine Green ${ }^{\mathrm{TM}}$, obtained from Invitrogen Corporation (Carlsbad, CA, USA) as described in ref. [18]. The experiments were conducted as follows. A sample of the resin was added to a plastic tube and mixed, by rotating the tube end-over-end at a few rpm, with $10 \mathrm{~mL}$ of a solution containing $1 \mathrm{mg} / \mathrm{mL}$ of the unlabeled protein admixed with the conjugated protein in a $1 / 40$ conjugated to unconjugated protein molar ratio. At periodic time intervals, a small amount of the suspension was pipetted out of the tube and rapidly processed in a microcentrifuge filter to separate the particles from solution. The Capto MMC particles, which are fairly transparent, were imaged by placing them in a drop of buffer on a microscope slide. The Nuvia cPrime particles, which are relatively opaque, were instead placed in a drop of buffered $50 \%(\mathrm{w} / \mathrm{w})$ sucrose as refractive index matching fluid [11,17]. All sample processing after the collection was done rapidly (less than $1 \mathrm{~min}$ ) in order to minimize any changes in the bound protein. A Zeiss LSM 510 confocal microscope equipped with a Plan-Apochromat 63X/1.4 NA oil objective (Carl Zeiss MicroImaging, LLC, Thornwood, NY, USA) was used to obtain equatorial image of the intraparticle fluorescence.

Column breakthrough experiments were conducted by packing each resin into a $5 \mathrm{~mm} \mathrm{x}$ $50 \mathrm{~mm}$ Tricorn column (GE Healthcare, Piscataway, NJ, USA) to a height of about $5 \mathrm{~cm}$ and providing a $1.9 \mathrm{mg} / \mathrm{mL}$ protein feed with an AKTA Explorer 10 unit. Based on pressure drop, the extraparticle porosities of these columns were $0.36 \pm 0.03$ and $0.40 \pm 0.03$ for Nuvia cPrime and Capto MMC columns, respectively. Flow rates were $1 \mathrm{~mL} / \mathrm{min}$, corresponding to a residence time of approximately $1 \mathrm{~min}$, for runs with lysozyme and $0.5 \mathrm{~mL} / \mathrm{min}$, corresponding to a residence time of approximately $2 \mathrm{~min}$, for runs with the $\mathrm{mAb}$. In each case, the effluent protein concentration was determined by UV at $280 \mathrm{~nm}$. 


\subsection{Results and discussion}

\subsubsection{Resin structure and chemistry}

Figure 5.2 shows representative TEM images of the two resins. For comparison purpose, the TEM image of UNO Q that was discussed in Chapter 2 is also included. All the three images shown correspond to areas near the outer edge of each particle, but similar features were also seen throughout each particle's interior. The lighter gray area is the embedding LRWhite resin, while the darker features are the resin matrix. As seen in Fig. 5.2a, Nuvia cPrime has a microgranular structure that defines a network of relatively large macropores, up to about 500 $\mathrm{nm}$ in size and similar to the structure reported for other UNOsphere matrices, such as UNO Q, Nuvia HR Q and Nuvia Q described in Chapter 2. The structure of Nuvia cPrime is essentially the same as UNO Q (Fig. 5.3c), indicating the ligand on Nuvia cPrime is also short. On the other hand, as seen in Fig. 5.2b, Capto MMC is very different from UNOsphere-based materials, characterized by fibrous structure typical of agarose matrices, which defines a network of smaller pores, most of which appear to be smaller than $100 \mathrm{~nm}$. 

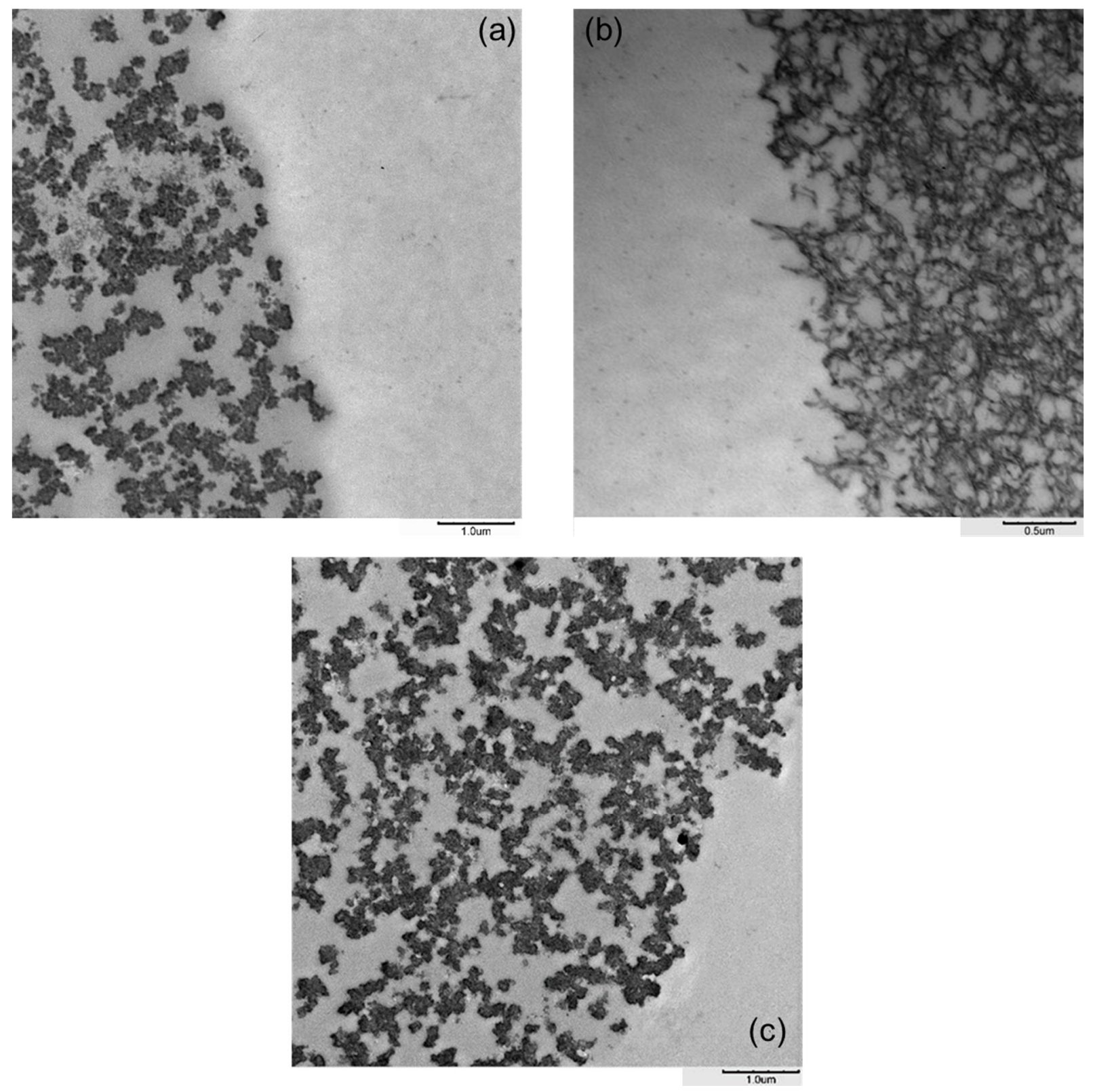

Fig. 5.2. TEM images of (a) Nuvia cPrime at 10k magnification, (b) Capto MMC at 20k magnification and (c) UNO Q at 10k magnification. Note the different scales for (b). 
Figure 5.3 shows the results of the iSEC experiments expressed as $K_{D}=(\overline{C V}-\varepsilon) /(1-\varepsilon)$ vs. the probe radius, $r_{h}$, where $\overline{C V}$ is the retention volume at the peak maximum (expressed as a function of the column volume) of each of the size standards. The Capto MMC data could be fitted using the following equation:

$$
K_{D}=\varepsilon_{p}\left(1-\frac{r_{h}}{r_{\text {pore }}}\right)^{2}
$$

where $\varepsilon_{p}$ is the intraparticle porosity and $r_{p o r e}$ is the pore radius, which assumes a monodispersed distribution of cylindrical pores [20]. The Nuvia cPrime data, on the other hand, which could not be described by Eq. 1, were fitted according to:

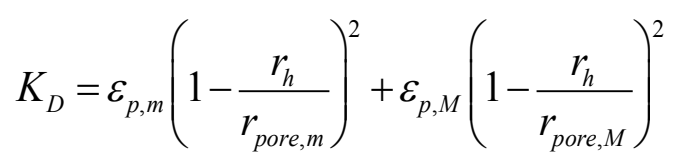

Which, as discussed in Chapter 2, assumes a bidispersed distribution of small cylindrical pore with radius $r_{p o r e, m}$, referred to as "micropores", and larger cylindrical pores with radius $r_{p o r e, ~}$, referred to as "macropores" [21,22]. In this equation, $\varepsilon_{p, m}$ and $\varepsilon_{p, M}$ are the intraparticle porosities associated with small and large pores, respectively; the total porosity is $\varepsilon_{p}=\varepsilon_{p, m}+\varepsilon_{p, M}$. The parameter values obtained by regressing these two equations to the data are summarized in Table 5.1. As seen from this table, while the total porosity is similar for the two materials, a large portion of the Nuvia cPrime porosity is associated with very large pores, while all the porosity in Capto MMC is associated with relatively small pores. 


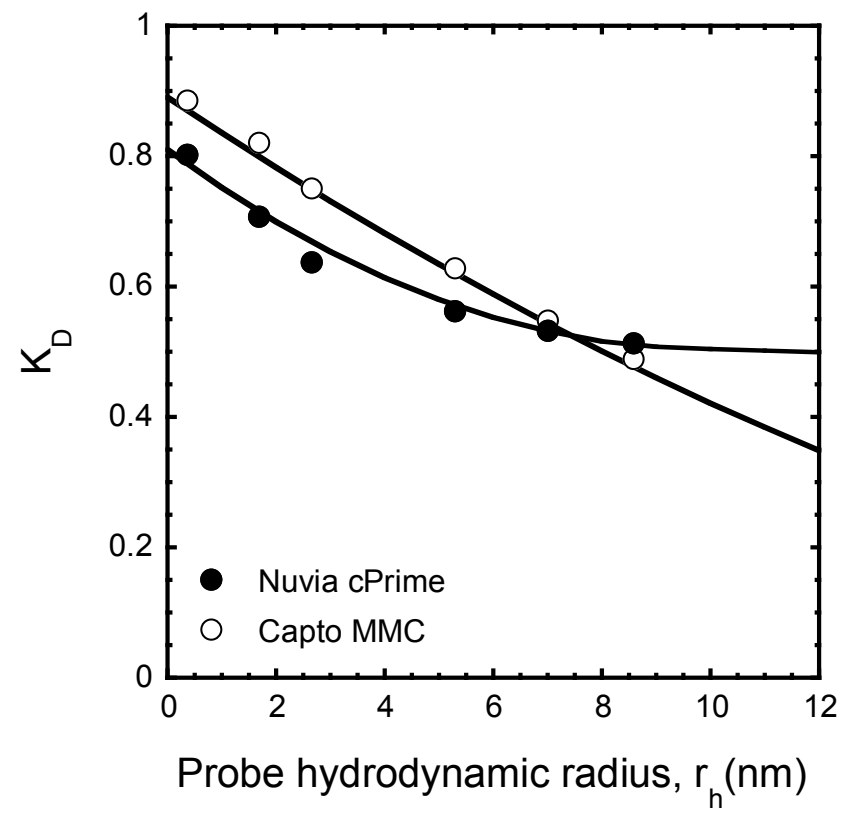

Fig. 5.3. iSEC results showing each probe $K_{D}$-values vs. its hydrodynamic radius. Lines are based on Eq. 12 for Capto MMC and Eq. 8 for Nuvia cPrime using the parameters in Table 5.1. 
Table 5.1 Physical and chemical properties of the resins used in this work.

\begin{tabular}{|l|l|l|}
\hline Property & Nuvia cPrime & Capto MMC \\
\hline Mean particle diameter $(\mu \mathrm{m})$ & 69 & 85 \\
\hline Extraparticle porosity $\varepsilon$ & 0.36 & 0.40 \\
\hline Total porosity, $\varepsilon_{p, t o t a l}$ & 0.80 & 0.89 \\
\hline Microporosity, $\varepsilon_{p, m}$ & 0.28 & - \\
\hline Macroporosity, $\varepsilon_{p, M}$ & 0.52 & 0.89 \\
\hline Micropore radius, $r_{p o r e, m}(\mathrm{~nm})$ & 10 & - \\
\hline Macropore radius, $r_{p o r e, M}(\mathrm{~nm})$ & $>400$ & 32 \\
\hline Ligand density, $q_{C}(\mathrm{mmol} / \mathrm{mL}$ & $0.151 \pm 0.010$ & $0.128 \pm 0.002$ \\
particle $)$ & & \\
\hline$p K_{a}$ of carboxyl group in ligand & $5.46 \pm 0.10$ & $5.64 \pm 0.06$ \\
\hline
\end{tabular}

Figure 5.4 shows the potentiometric titration curves at three different $\mathrm{NaCl}$

concentrations. Both resins have buffering capacity in the $\mathrm{pH}$ range between 4 and 7 because of the ligand's carboxyl group. At higher $\mathrm{pH}$ values, Capto MMC reaches a distinct plateau, corresponding to complete deprotonation of the carboxyl group (Fig. 5.4b). The behavior of Nuvia cPrime is similar to that of Capto MMC between $\mathrm{pH} 2$ and 7, however, the curves continue to rise, albeit slowly, at higher $\mathrm{pH}$ values. This continued increase is attributed to the presence of a small concentration of weak base groups, which, according to the resin manufacturer, are associated with the resin backbone. Based on the titration curves, the $\mathrm{pK}_{\mathrm{a}}$ of 

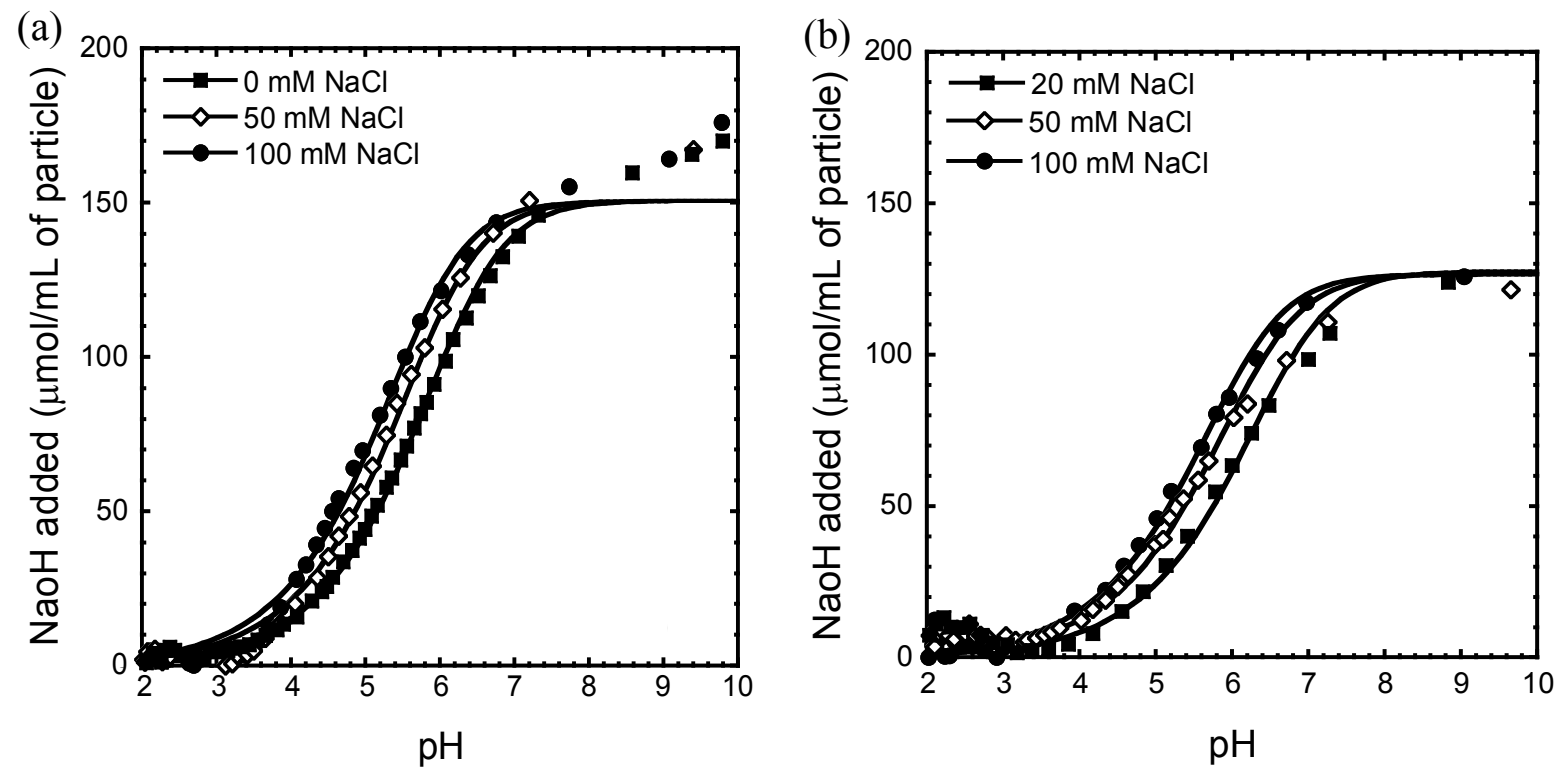

Fig. 5.4. Potentiometric titrations of (a) Nuvia cPrime and (b) Capto MMC with different concentrations of $\mathrm{NaCl}$. Lines are calculated from Eq. 5.3 with parameters in Table 5.1.

these groups is around 8 and their concentration is around $0.02 \mathrm{mmol} / \mathrm{mL}$ of particle. The following equation can be used to model the data in Figure 4 over the entire $\mathrm{pH}$ range for Capto MMC and for $\mathrm{pH}$ values up to about 7 for Nuvia cPrime [15]:

$$
q_{N a^{+}}^{\prime}=\frac{1}{2}\left[-\frac{K_{a} C_{N a^{+}}}{C_{H^{+}}}+\sqrt{\left(\frac{K_{a} C_{N a^{+}}}{C_{H^{+}}}\right)^{2}+4 q_{C}^{\prime} \frac{K_{a} C_{N a^{+}}}{C_{H^{+}}}}\right]
$$

where $q_{\mathrm{Na}^{+}}^{\prime}=q_{\mathrm{COO}^{-}}^{\prime}$ and $q_{\mathrm{C}}^{\prime}$ are the concentration of deprotonated carboxyl groups in the resin at a given $\mathrm{pH}$ and the total carboxyl group concentration, respectively, both expressed as mmol per $\mathrm{mL}$ of resin solid. The corresponding $q$-value expressed as $\mathrm{mmol}$ per $\mathrm{mL}$ of particle volume are found by dividing the $q^{\prime}$-values by the quantityl- $\varepsilon_{p}$, where $\varepsilon_{p}$ is the intraparticle porosity. As shown by Helfferich [23], this equation, which is based on Donnan equilibrium, allows a description of the effects on salt concentration on the titration curve with a single $\mathrm{pK}_{\mathrm{a}}$-value for 
the carboxyl groups. The parameter values obtained by fitting this equation to the data are given in Table 5.1, which shows that the $p K_{a}$-values of the two ligands are very similar. Nuvia cPrime has, however, a somewhat higher ligand density when expressed per unit particle volume.

\subsubsection{Adsorption isotherms}

Figures 5.5 and 5.6 show the adsorption isotherms for both resins obtained at different salt concentration and $\mathrm{pH}$ for lysozyme and the $\mathrm{mAb}$. Lines are based on the Langmuir isotherm, $q=q_{m} K C /(1+K C)$, with the regressed parameters summarized in Tables 5.2 and 5.3. As expected because of the multimodal nature of the ligands, both salt concentration and $\mathrm{pH}$ affect the adsorption isotherm. The trends are similar for both resins and for both proteins. At low $\mathrm{pH}$, the amount of protein bound is relatively insensitive to the salt concentration and actually increases somewhat as the salt concentration increases indicating that hydrophobic interactions are dominant. As shown in Fig. 5.4, at pH values between 2 and 4, both ligands are nearly completely protonated so that electrostatic interactions between protein and ligand are negligible. At the higher $\mathrm{pH}$ values ( $\mathrm{pH} 7$ for lysozyme and $\mathrm{pH} 6$ for the $\mathrm{mAb}$ ), protein binding becomes a strong function of salt concentration, decreasing rapidly as the $\mathrm{Na}^{+}$concentration increases. This effect is more pronounced for the mAb, which appears to be a weaker binder compared to lysozyme. At these higher $\mathrm{pH}$ values, electrostatic interactions between the protein molecules (which are positively charged) and both ligands, which are nearly completely deprotonated and, hence, negatively charged, are dominant. Even so, however, significant binding occurs for lysozyme even in $400 \mathrm{mM} \mathrm{NaCl}$ indicating that hydrophobic interactions between the protein and the ligand still contribute to binding. This effect, often referred to as "salt tolerance", is more pronounced for Capto MMC, which is consistent with the apparently more favorable presentation of the hydrophobic moiety of the ligand to the adsorbed protein molecules for Capto 
MMC compared to Nuvia cPrime. As seen in Fig. 5.6, however, the salt tolerance effect is protein dependent and is much less significant for the $\mathrm{mAb}$ at $\mathrm{pH} 6$. At the intermediate $\mathrm{pH}$ of 5 , when the both ligands are partially deprotonated (see Fig. 5.4), hydrophobic and electrostatic interactions appear to work cooperatively resulting in a relative high protein binding capacity and greater salt tolerance especially for lysozyme, for which the binding capacity is virtually independent of salt concentration, but also, although to a lesser extent, for the $\mathrm{mAb}$. At $\mathrm{pH} 7$, which is fairly close to the $\mathrm{pI}$ of the $\mathrm{mAb} 8.2$, little or no mAb adsorption was observed for Nuvia cPrime, while adsorption on Capto MMC was only observed without any added $\mathrm{NaCl}$ (data not shown for brevity). At this $\mathrm{pH}$, binding of this $\mathrm{mAb}$ is thus very weak despite the presence of the hydrophobic moiety in the Capto MMC ligand. 


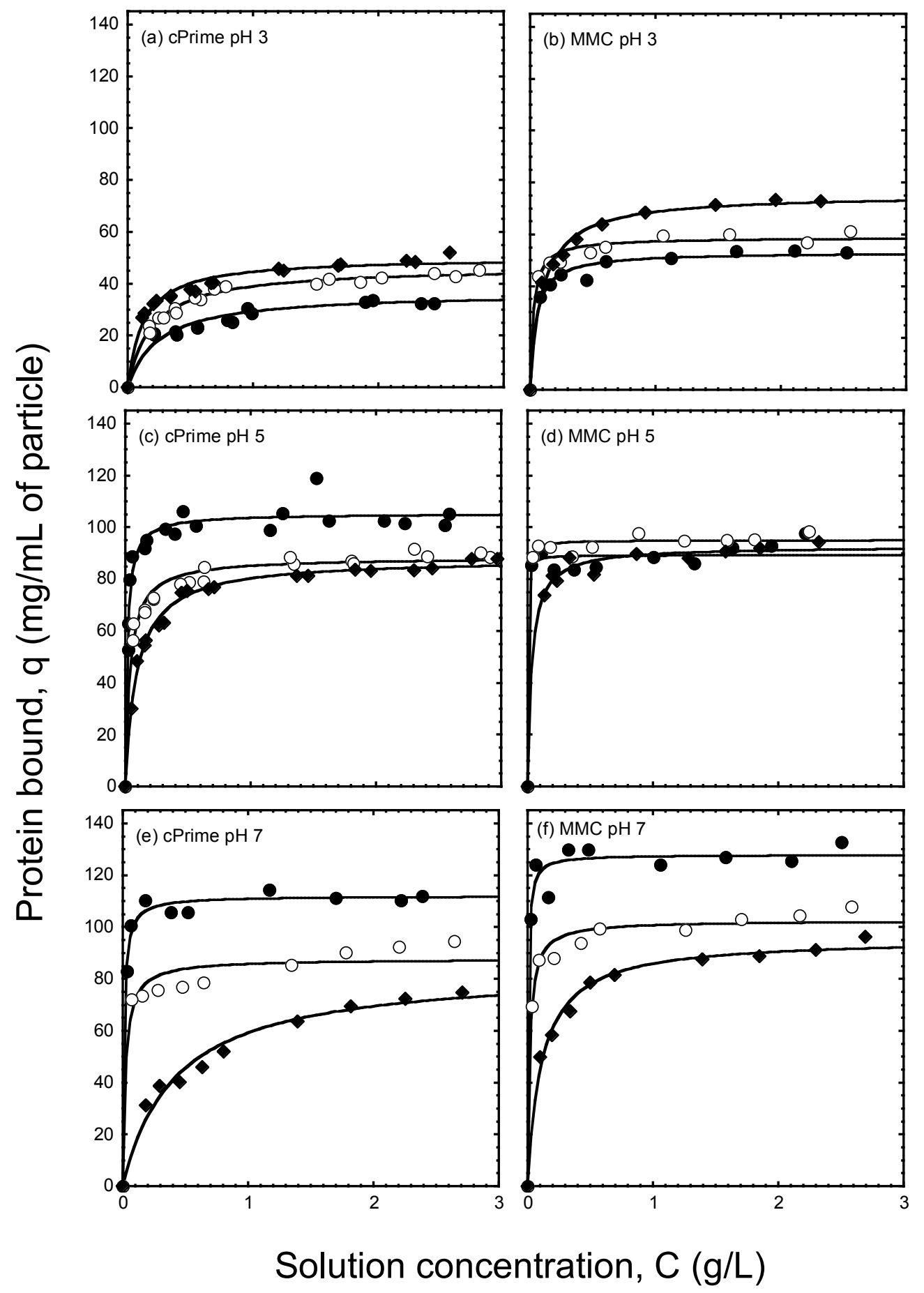

Fig. 5.5. Adsorption isotherms for lysozyme as a function of $\mathrm{pH}$ and $\mathrm{NaCl}$ concentration in buffers containing $20 \mathrm{mM} \mathrm{Na}^{+}$. $\mathrm{NaCl}$ concentration are: $0(\bullet), 200(0)$, and $400 \mathrm{mM}(\bullet)$. Lines are the Langmuir isotherm model with parameters in Table 5.2. 
Table 5.2 Langmuir isotherm parameters for lysozyme in buffers containing $20 \mathrm{mM} \mathrm{Na}$.

\begin{tabular}{|c|c|c|c|c|c|}
\hline & & \multicolumn{2}{|c|}{ Nuvia cPRime } & \multicolumn{2}{|l|}{ Capto MMC } \\
\hline & $\begin{array}{l}\text { Added } \mathrm{NaCl} \\
(\mathrm{mM})\end{array}$ & $q_{m}(\mathrm{mg} / \mathrm{mL})$ & $K(\mathrm{~mL} / \mathrm{mg})$ & $q_{m}(\mathrm{mg} / \mathrm{mL})$ & $K(\mathrm{~mL} / \mathrm{mg})$ \\
\hline \multirow{3}{*}{ pH 3} & 0 & $37 \pm 1$ & $5.0 \pm 0.6$ & $53 \pm 1$ & $22 \pm 4$ \\
\hline & 200 & $46 \pm 1$ & $5.2 \pm 0.3$ & $59 \pm 1$ & $38 \pm 8$ \\
\hline & 400 & $50 \pm 1$ & $8.0 \pm 0.8$ & $75 \pm 1$ & $10 \pm 1$ \\
\hline \multirow{3}{*}{ pH 5} & 0 & $110 \pm 2$ & $62 \pm 9$ & $89 \pm 2$ & $620 \pm 680$ \\
\hline & 200 & $88 \pm 1$ & $26 \pm 3$ & $95 \pm 1$ & $350 \pm 150$ \\
\hline & 400 & $89 \pm 1$ & $11 \pm 1$ & $93 \pm 1$ & $30 \pm 5$ \\
\hline \multirow{3}{*}{ pH 7} & 0 & $110 \pm 1$ & $100 \pm 20$ & $130 \pm 2$ & $180 \pm 60$ \\
\hline & 200 & $87 \pm 3$ & $44 \pm 16$ & $100 \pm 2$ & $58 \pm 10$ \\
\hline & 400 & $84 \pm 4$ & $2.4 \pm 0.4$ & $96 \pm 2$ & $8.8 \pm 0.9$ \\
\hline
\end{tabular}




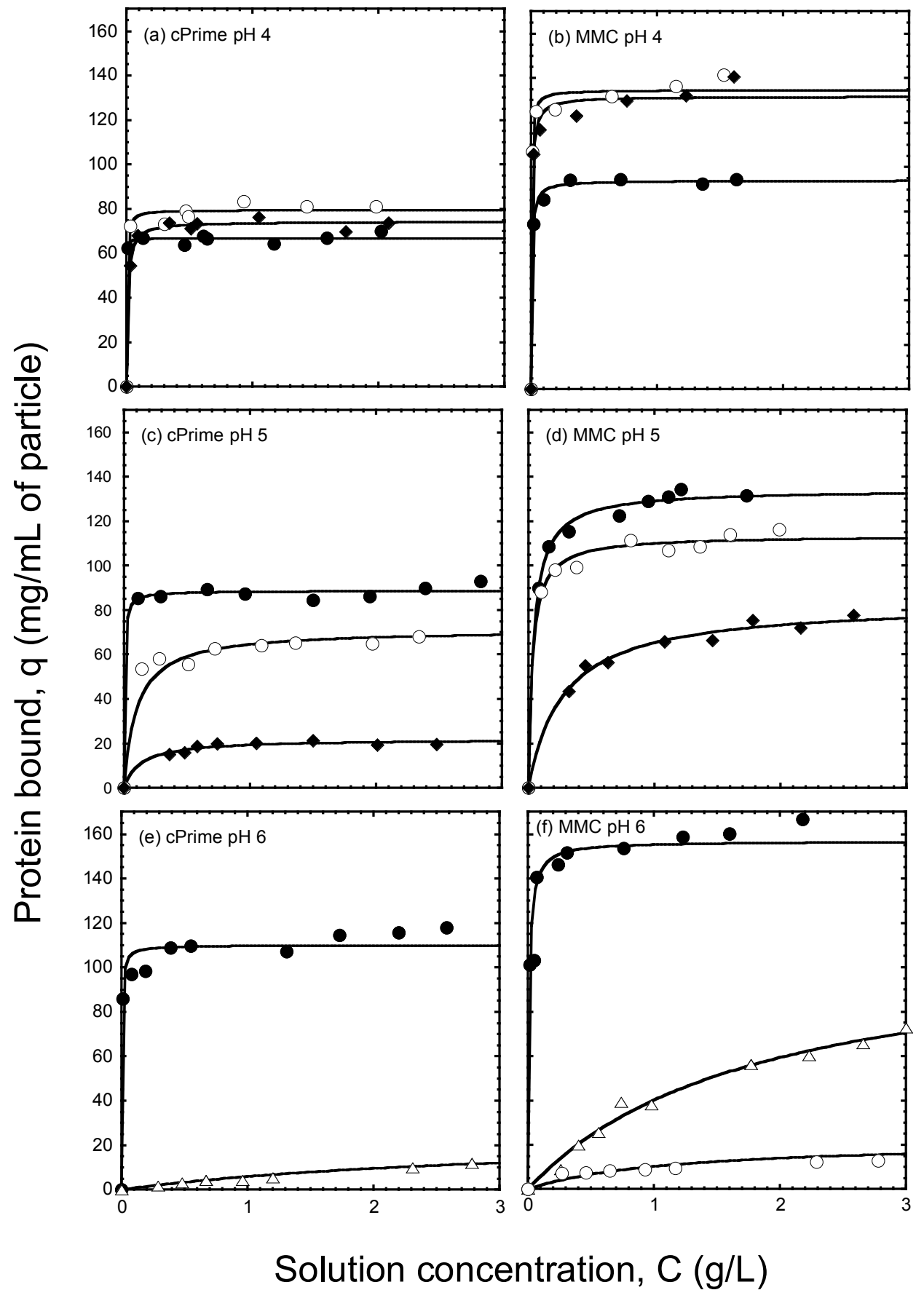

Fig. 5.6. Adsorption isotherms for the $\mathrm{mAb}$ as a function of $\mathrm{pH}$ and $\mathrm{NaCl}$ concentration in buffers containing $20 \mathrm{mM} \mathrm{Na}^{+}$. $\mathrm{NaCl}$ concentration are: $0(\bullet), 100(\triangle) 200(\bigcirc)$, and $400 \mathrm{mM}$ $(\bullet)$. Lines are the Langmuir isotherm model with parameters in Table 5.3. 
Table 5.3 Langmuir isotherm parameters for the $\mathrm{mAb}$ in buffers containing $20 \mathrm{mM} \mathrm{Na}$.

\begin{tabular}{|c|c|c|c|c|c|}
\hline & \multirow[b]{2}{*}{$\begin{array}{l}\text { Added } \mathrm{NaCl} \\
(\mathrm{mM})\end{array}$} & \multicolumn{2}{|c|}{ Nuvia cPrime } & \multicolumn{2}{|l|}{ Capto MMC } \\
\hline & & $q_{m}(\mathrm{mg} / \mathrm{mL})$ & $K(\mathrm{~mL} / \mathrm{mg})$ & $q_{m}(\mathrm{mg} / \mathrm{mL})$ & $K(\mathrm{~mL} / \mathrm{mg})$ \\
\hline \multirow{3}{*}{$\mathrm{pH} 4$} & 0 & $67 \pm 1$ & $1500 \pm 700$ & $110 \pm 2$ & $41 \pm 8$ \\
\hline & 200 & $80 \pm 1$ & $310 \pm 150$ & $130 \pm 2$ & $370 \pm 80$ \\
\hline & 400 & $74 \pm 1$ & $98 \pm 15$ & $130 \pm 3$ & $180 \pm 50$ \\
\hline \multirow{3}{*}{ pH 5} & 0 & $89 \pm 1$ & $210 \pm 170$ & $130 \pm 2$ & $25 \pm 2$ \\
\hline & 200 & $71 \pm 5$ & $9.7 \pm 5.3$ & $110 \pm 2$ & $32 \pm 6$ \\
\hline & 400 & $22 \pm 1$ & $7.4 \pm 2.3$ & $83 \pm 2$ & $3.6 \pm 0.5$ \\
\hline \multirow{3}{*}{ pH 6} & 0 & $110 \pm 2$ & $320 \pm 100$ & $160 \pm 5$ & $100 \pm 29$ \\
\hline & 100 & $25 \pm 5$ & $0.30 \pm 0.1$ & $110 \pm 10$ & $0.50 \pm 0.10$ \\
\hline & 200 & - & - & $22 \pm 4$ & $0.87 \pm 0.44$ \\
\hline
\end{tabular}

\subsubsection{Adsorption kinetics}

Figure 5.7 shows representative batch uptake results for lysozyme at $\mathrm{pH} 5$ (Fig. 5.7a) and for the $\mathrm{mAb}$ at $\mathrm{pH} 5$ and 6 (Fig. 5.7b), all with no added $\mathrm{NaCl}$. Additional results (not shown for brevity) were obtained at pH 5 with the addition of 200 and $400 \mathrm{mM} \mathrm{NaCl}$. An apparent effective pore diffusivity, $D_{e}$, was obtained in each case by fitting the analytical solution of the pore diffusion model for a rectangular isotherm taking into account the particle size distribution (Eqs. 33-34 in ref. [24]). The assumption of a rectangular isotherm is reasonable given the favorable nature of the adsorption isotherms. The fitted $D_{e}$-values are summarized in Table 5.4 along with the values $D_{e} / D_{0}$ normalized by each protein's aqueous diffusivity. In the case of lysozyme, the 
$D_{e}$-values are relatively independent of $\mathrm{NaCl}$ concentration and similar in magnitude for both resins. Different results are, however, obtained for the mAb. In the case of Nuvia cPrime, the $D_{e^{-}}$ value, although smaller than those obtained for lysozyme, are again relatively independent of conditions. Moreover, the $D_{e} / D_{0}$-values are comparable to the lysozyme values indicating that, despite their roughly 3 -fold difference in size, both proteins experience similar hindrance. This is a result of the large macropore size of Nuvia cPrime, which allows relatively unhindered diffusion of both proteins. The results for Capto MMC show a trend of increasing $D_{e}$ with increasing salt concentration at $\mathrm{pH} 5$ and with increasing $\mathrm{pH}$. With no added $\mathrm{NaCl}$, when $\mathrm{mAb}$ binding is strongest, the $D_{e}$-values are much smaller than the value obtained for Nuvia cPrime under the same conditions. This appears to be a result of the much smaller pore size of Capto MMC, which results in much greater diffusional hindrance for the larger mAb molecules. Diffusional hindrance increases in these small pores when more protein is bound, which, in turn, is likely to result in further reduction of the apparent pore size. At higher salt concentrations, when less protein is bound (see Fig. 5.6) the $D_{e}$-values for Capto MMC increase. This effect is likely due to less diffusional hindrance although surface diffusion, made possible by the lower protein binding strength and, hence, great surface diffusivity, can also be an additional contribution to transport for these conditions. 

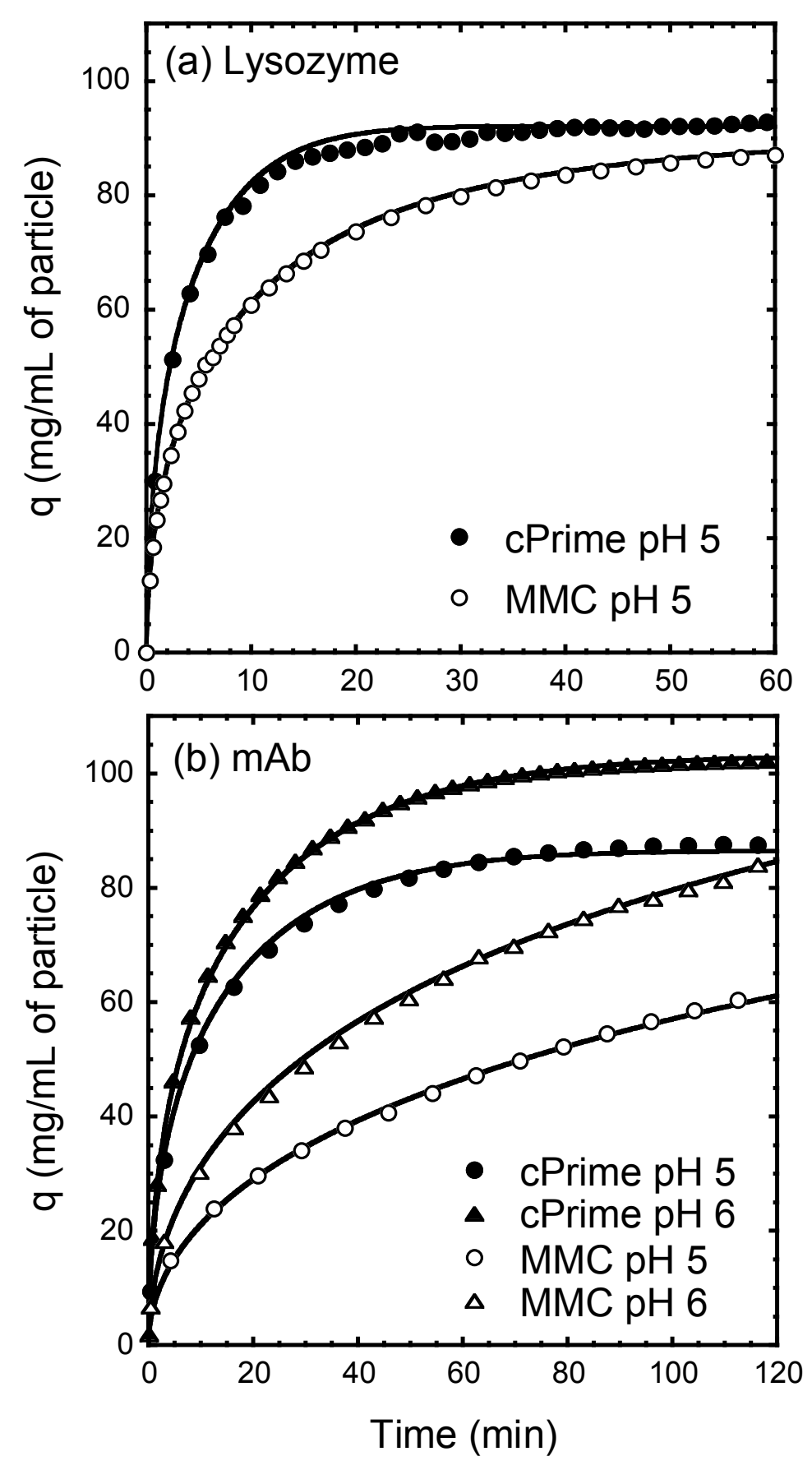

Fig. 5.7. Batch uptake curves for (a) lysozyme and (b) the mAb in buffers containing $20 \mathrm{mM}$ $\mathrm{Na}^{+}$. Lines are the pore diffusion model with $D_{e}$-values in Table 5. Note the different time scales in the two graphs. The initial protein concentration in solution was $1 \mathrm{mg} / \mathrm{mL}$ in all cases. 
Table 5.4 Effective pore diffusivities $D_{e}$ in $10^{-7} \mathrm{~cm}^{2} / \mathrm{s}$ in buffers containing $20 \mathrm{mM} \mathrm{Na}^{+}$.

\begin{tabular}{|c|c|c|c|c|c|c|c|c|c|}
\hline \multirow{2}{*}{$\begin{array}{l}\text { Protei } \\
\mathrm{n}\end{array}$} & \multirow{2}{*}{ Resin } & \multirow{2}{*}{$\mathrm{pH}$} & \multirow{2}{*}{$\begin{array}{l}\text { Added } \\
\mathrm{NaCl} \\
(\mathrm{mM})\end{array}$} & \multicolumn{2}{|c|}{ Batch $^{(a)}$} & \multicolumn{2}{|c|}{$\mathrm{CLSM}^{(\mathrm{b})}$} & \multicolumn{2}{|c|}{ Column ${ }^{(\mathrm{c})}$} \\
\hline & & & & $\mathrm{D}_{\mathrm{e}}$ & $\mathrm{D}_{\mathrm{e}} / \mathrm{D}_{0}$ & $D_{e}$ & $\mathrm{D}_{\mathrm{e}} / \mathrm{D}_{0}$ & $\mathrm{D}_{\mathrm{e}}$ & $\mathrm{D}_{\mathrm{e}} / \mathrm{D}_{0}$ \\
\hline \multirow{6}{*}{ Lyo } & \multirow{3}{*}{$\begin{array}{l}\text { Nuvia } \\
\text { cPrime }\end{array}$} & \multirow{3}{*}{5} & 0 & 2.6 & 0.24 & & & 2.1 & 0.19 \\
\hline & & & 200 & 3.4 & 0.31 & & & & \\
\hline & & & 400 & 2.9 & 0.26 & & & & \\
\hline & \multirow{3}{*}{$\begin{array}{l}\text { Capto } \\
\text { MMC }\end{array}$} & \multirow{3}{*}{5} & 0 & 1.6 & 0.14 & & & 1.3 & 0.12 \\
\hline & & & 200 & 3.2 & 0.29 & & & & \\
\hline & & & 400 & 3.7 & 0.33 & & & & \\
\hline \multirow{8}{*}{$\mathrm{mAb}$} & \multirow{4}{*}{$\begin{array}{l}\text { Nuvia } \\
\text { cPrime }\end{array}$} & \multirow{3}{*}{5} & 0 & 0.67 & 0.17 & 0.75 & 0.19 & 0.50 & 0.13 \\
\hline & & & 200 & 0.87 & 0.22 & & & & \\
\hline & & & 400 & 0.67 & 0.17 & & & & \\
\hline & & 6 & 0 & 0.96 & 0.25 & 1.12 & 0.29 & & \\
\hline & \multirow{4}{*}{$\begin{array}{l}\text { Capto } \\
\text { MMC }\end{array}$} & \multirow{3}{*}{5} & 0 & 0.08 & 0.02 & 0.06 & 0.02 & 0.07 & 0.02 \\
\hline & & & 200 & 0.33 & 0.08 & & & & \\
\hline & & & 400 & 0.82 & 0.21 & & & & \\
\hline & & 6 & 0 & 0.13 & 0.03 & 0.13 & 0.03 & & \\
\hline
\end{tabular}

(a) Determined by fitting batch uptake curves

(b) Determined by fitting adsorption front from confocal images

(c) Determined by fitting column breakthrough curves 
Figures 5.8 and 5.9 show representative CLSM images for the adsorption of the mAb on Nuvia cPrime and Capto $\mathrm{MMC}$, respectively, at different $\mathrm{pH}$ values without added $\mathrm{NaCl}$. At $\mathrm{pH}$ 5 and 6 , when protein binding is strongest, resin beads exhibit a very sharp adsorption front. The nature of this front is consistent with a pore diffusion mechanism with a rectangular isotherm and without kinetic resistance to binding. While the transport mechanism appears to be the same for both resins, the front moves much faster toward the center of the particles for Nuvia cPrime compared to Capto MMC (Fig. 5.9), consistent with the much higher effective pore diffusivity for Nuvia cPrime obtained from the batch uptake experiments.
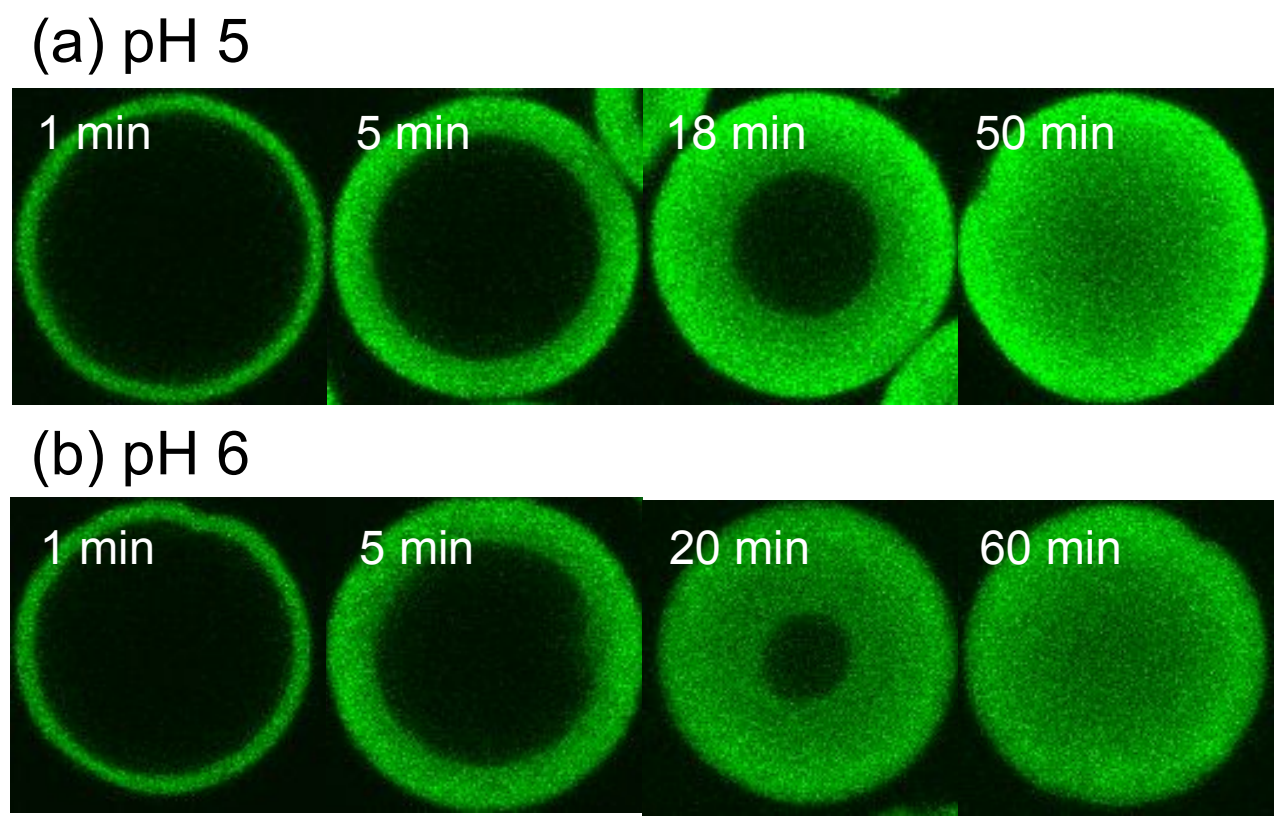

Fig. 5.8. CLSM images of $1 \mathrm{mg} / \mathrm{mL} \mathrm{mAb}$ adsorption on Nuvia cPrime particles in buffers containing $20 \mathrm{mM} \mathrm{Na}^{+}$at (a) $\mathrm{pH} 5$ and (b) $\mathrm{pH}$ 6. Actual particle diameters for the particles shown are $68 \pm 1 \mu \mathrm{m}$. 
(a) $\mathrm{pH} 5$

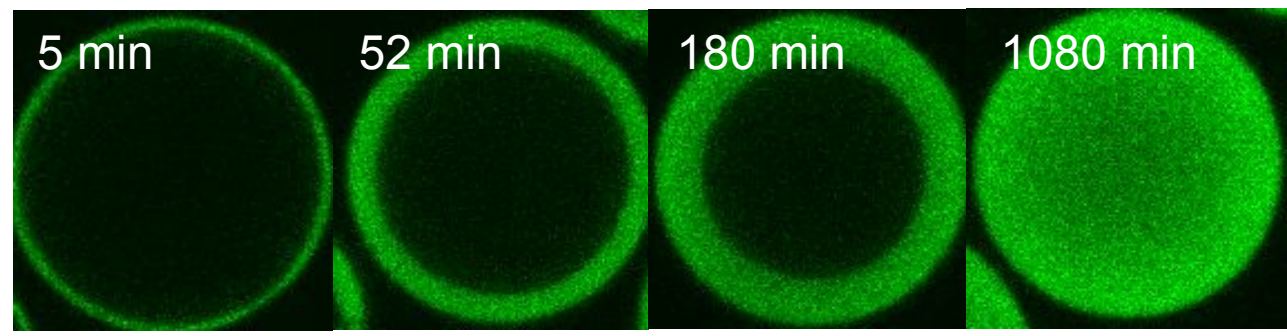

(b) $\mathrm{pH} 6$

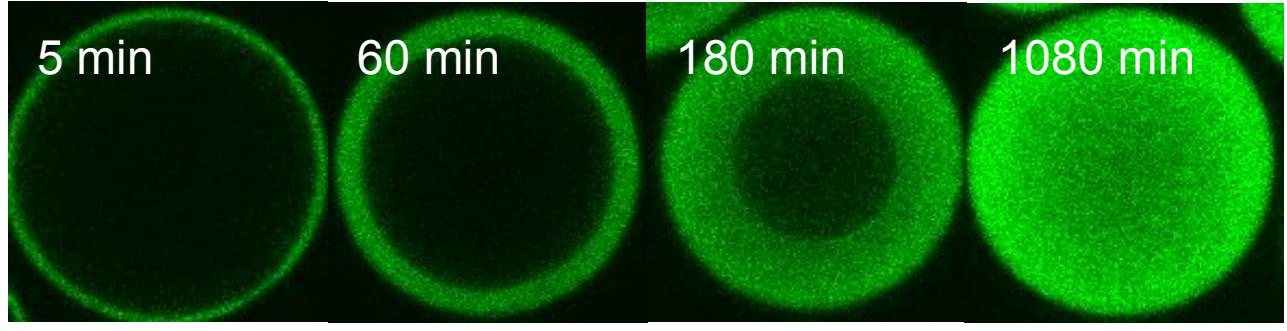

Fig. 5.9. CLSM images of $1 \mathrm{mg} / \mathrm{mL} \mathrm{mAb}$ adsorption on Capto MMC particles in buffers containing $20 \mathrm{mM} \mathrm{Na}^{+}$at (a) pH 5 and (b) pH 6. Actual particle diameters for the particles shown are $84 \pm 1 \mu \mathrm{m}$.

According to the classical shrinking core model, the position of the adsorption front in the particle is described by the following equation [25]:

$$
2 \rho_{s}^{3}-3 \rho_{s}^{2}+1=\frac{6 D_{0} C t}{q_{m} r_{p}^{2}} \frac{D_{e}}{D_{0}}
$$

where $\rho_{s}=r_{s} / r_{p}$ is the dimensionless position of the adsorption front. Figure 5.10 shows plots of this quantity obtained from graphical measurements of the position of the adsorption front for a large number of different particles collected at different times for both Nuvia cPrime and Capto MMC. The lines in both plots are based on Eq.5.4 fitted to the data. In the case of Nuvia cPrime, 
the data at both $\mathrm{pH} 5$ and 6 conform well to the model. The corresponding $D_{e}$-values, shown in Table 4, are in fact very similar to those obtained from the batch uptake experiments, with a
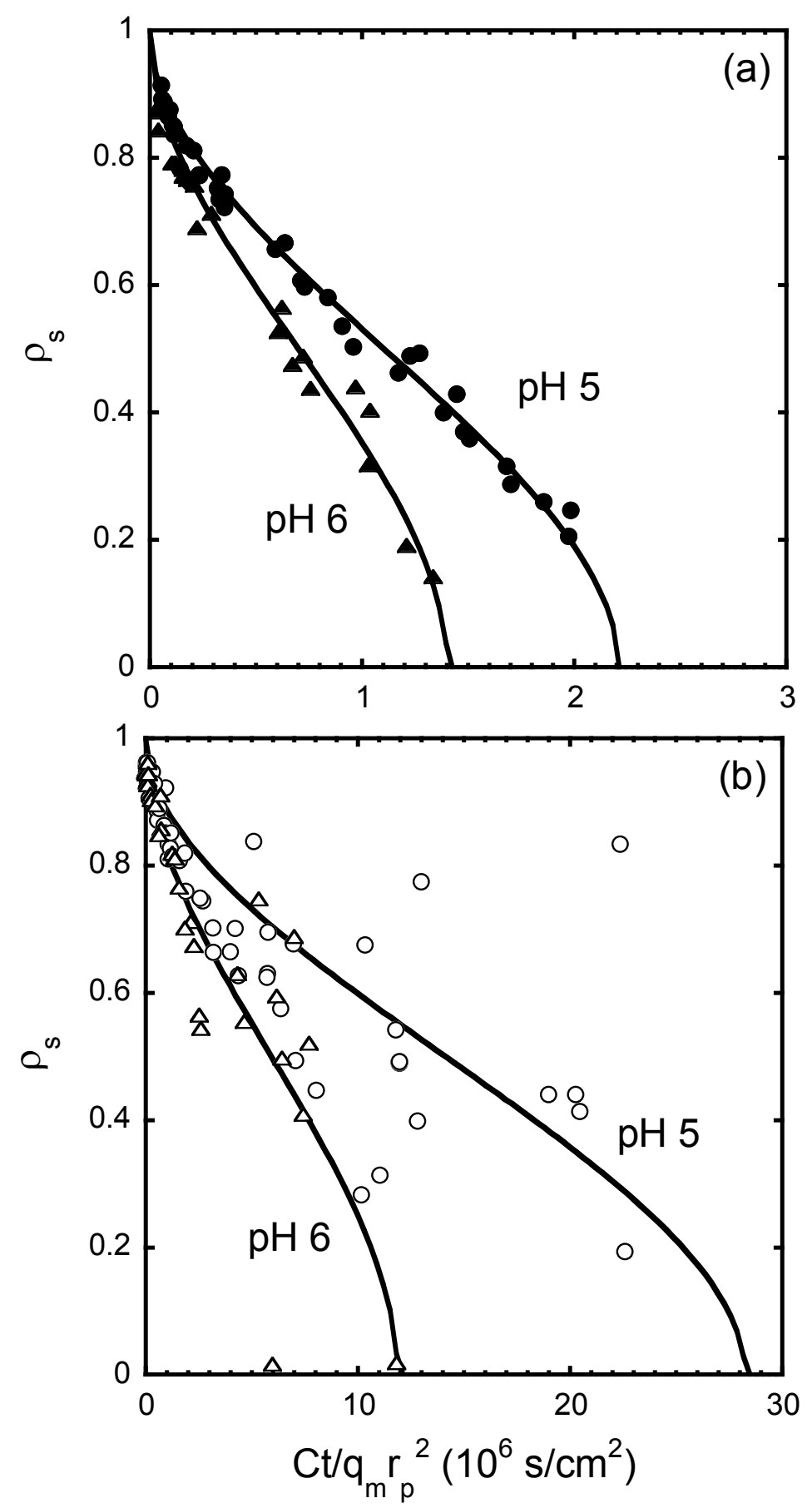

Fig. 5.10. Plots of dimensionless position of the adsorption front vs. reduced time based CLSM images for the adsorption of $1 \mathrm{mg} / \mathrm{mL} \mathrm{mAb}$ on (a) Nuvia cPrime and (b) Capto MMC particles in 
buffers containing $20 \mathrm{mM} \mathrm{Na}^{+}$. Note the different $\mathrm{x}$-axis scales in the two plots. Lines are calculated from Eq. 4 with $D_{e}$-values in Table 5.

maximum deviation of about $20 \%$, confirming the pore-diffusion limited kinetics. On the other hand, in the case of Capto MMC, we noted a substantial heterogeneity in the kinetic behavior of different particles from the same experiment, which resulted in a high degree of scatter in Fig. 5.10b, especially at $\mathrm{pH} 5$. In this case, while in some particles the adsorption front moved relatively quickly and reached the center of the beads, in others the adsorption front made only very modest headway into the particle even at long times. Figure 5.11 shows a few examples of this behavior, which appears to be related to either blocking of the pores by the bound protein or, perhaps, by a heterogeneous distribution of ligands within some beads. Due to the higher binding capacity and stronger binding at $\mathrm{pH} 5$, the diffusional hindrance and pore blockage caused by the bound protein are likely to be greater making the effect more pronounced than at $\mathrm{pH} 6$. This effect is also reflected in the greater scatter in Fig. $10 \mathrm{~b}$ at $\mathrm{pH} 5$ since each point represents a measurement for an individual particle and the heterogeneous distribution of adsorption kinetics seems broader at this $\mathrm{pH}$. On the average, however, as shown in Table 4, the $D_{e^{-} \text {-values }}$ determined by fitting Eq. 5.4 to the entire Capto MMC dataset including a large number of beads are in relatively good agreement with those obtained from the batch uptake experiments indicating that these values can be used as a practical description of protein binding kinetics in this resin. 


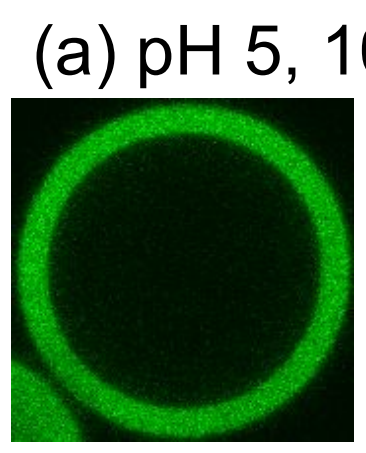

$080 \min$
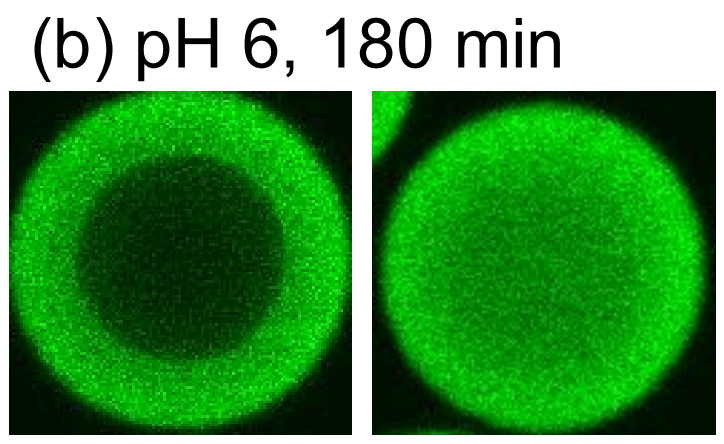

Fig. 5.11. CLSM images of $1 \mathrm{mg} / \mathrm{mL} \mathrm{mAb}$ adsorption on Capto MMC particles in buffers containing $20 \mathrm{mM} \mathrm{Na}^{+}$at (a) $\mathrm{pH} 5$ and (b) $\mathrm{pH}$ 6, illustrating different adsorption rates for different particles in the same experiment. Actual particle diameters for the particles shown are $100 \pm 1 \mu \mathrm{m}(\mathrm{a})$ and $66 \pm 1 \mu \mathrm{m}$ in (b).

Figures 5.12a and 5.12b compare the breakthrough curves obtained for Nuvia cPrime and Capto MMC for lysozyme and the mAb at residence times of 1 and $2 \mathrm{~min}$, respectively. All data are at $\mathrm{pH} 5$ with no added $\mathrm{NaCl}$. For these conditions, in the case of lysozyme both equilibrium and dynamic binding capacities (DBC) are similar. Very different results are obtained, however, for the mAb. While the equilibrium binding is somewhat higher for Capto MMC compared to Nuvia cPrime, (see Figs. 5c and 5d), the adsorption kinetics are much faster in Nuvia cPrime resulting in a much sharper breakthrough curve and in a substantial DBC at $10 \%$ of 

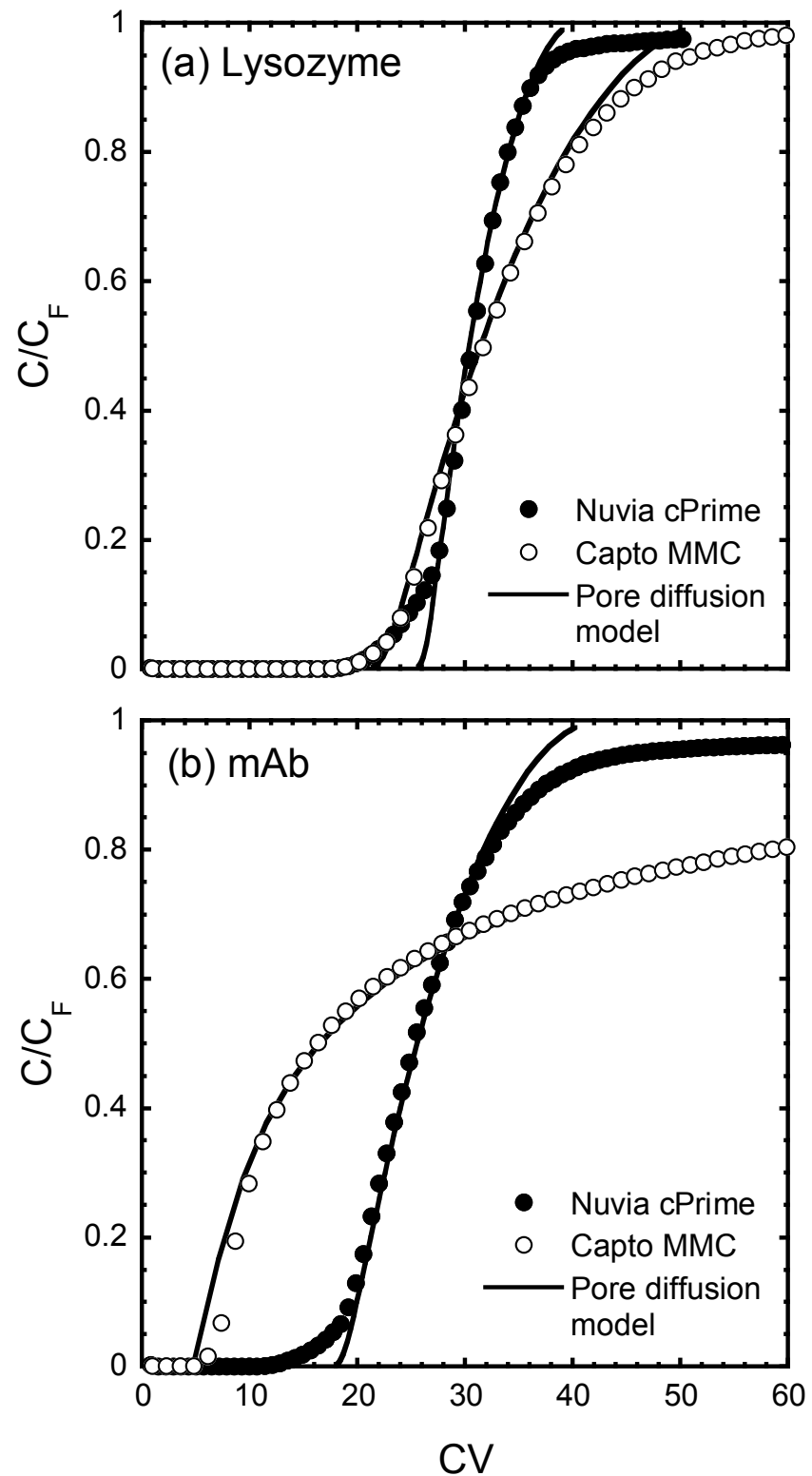

Fig. 5.12. Breakthrough curves for (a) lysozyme at 1 min residence and (b) the mAb at 2 min residence time at $\mathrm{pH} 5$ in $20 \mathrm{mM}$ sodium acetate. The protein feed concentration was $C_{F}=$ $1.9 \pm 0.1 \mathrm{mg} / \mathrm{mL}$. Actual column lengths were $5.8 \mathrm{~cm}$ for Nuvia cPrime and $5.3 \mathrm{~cm}$ for Capto MMC. Flow rates were 1 and $0.5 \mathrm{~mL} / \mathrm{min}$ for lysozyme and the $\mathrm{mAb}$, respectively. Lines are the pore diffusion model with $D_{e}$-values in Table 5. 
breakthrough. In the case of Capto MMC, mass transfer is very slow as a result of the large diffusional hindrance. The net effect is that, in this case, the breakthrough curve is very shallow with early breakthrough. The lines shown in Fig. 5.12 are calculated according to the analytical solutions of the pore diffusion model with a rectangular isotherm, neglecting boundary layer resistance and axial dispersion, which are given by ref. [26]. For both lysozyme and the mAb on Nuvia cPrime and for lysozyme on Capto MMC, mass transfer is sufficiently fast that at the residence times used, the mass transfer is fully developed and, thus, the simpler constant pattern solution (Eq. 24 in ref. [26]) could be used to predict the breakthrough curve. On the other hand, for the mAb on Capto MMC mass transfer is too slow to attain a constant pattern with a twominute residence time, which required use of the general, non-constant pattern solution (Eqs. 10, 20 , and 27 in ref. [26]) to predict the breakthrough curve. In either case, the analytical solution was fitted to the experimental breakthrough curves by adjusting the $D_{e}$-value and the best-fit

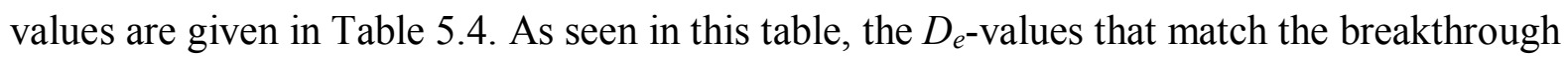
curves are consistent with those obtained from the batch uptake and confocal experiments confirming the validity of the model assumptions and the ability to predict column behavior.

\subsection{Conclusions}

The two multimodal cation exchangers considered in this work have different physical structures and ligands but they exhibit similar trends with regards to the effects of $\mathrm{pH}$ and salt concentration on protein binding. Seemingly because of the different presentation of the hydrophobic group in the Capto MMC ligand, this resin appears to be more hydrophobic exhibiting greater salt tolerance across a range of $\mathrm{pH}$ values for both lysozyme and the $\mathrm{mAb}$ considered in this work compared to Nuvia cPrime. At $\mathrm{pH} \mathrm{5,} \mathrm{which} \mathrm{corresponds} \mathrm{approximately}$ to the $p K_{a}$ of the ligand carboxyl group, binding capacities for the two resins are similar for 
lysozyme, but the capacity drops off more rapidly for the mAb in Nuvia cPrime as salt is added. In general, for both resins the adsorption behavior appears to be dominated by hydrophobic interactions at low $\mathrm{pH}$ values and by electrostatic interactions at $\mathrm{pH} 6$ or higher.

The adsorption rate mechanism controlling protein binding kinetics is also similar in the two materials, apparently dictated largely by pore diffusion. The main difference is, however, the rate of adsorption of the larger $\mathrm{mAb}$. This large difference in rates is attributed to the much larger macropore size of Nuvia cPrime, which allows transport even at very high protein loads with relatively small diffusional hindrance. Another difference between the two materials observed by CLSM, is that at $\mathrm{pH} 5$ the adsorption kinetics in Capto MMC appears to be heterogeneous resulting in a distribution of particles that are either completely saturated, partially saturated, or barely saturated with protein even after a long time. We attribute these differences to pore blockage caused by the bound protein in Capto MMC and to subtle variations in structural properties from bead to bead. It is likely that these effects are not seen for Nuvia cPrime since its larger pore size allows diffusion with relatively small hindrance in a manner that is more tolerant of modest variations in structure. In either case, the faster kinetics observed in batch uptake and confocal microscopy experiments results in sharper breakthrough curves and higher dynamic binding capacities for Nuvia cPrime compared to Capto MMC even at short residence times. This provides yet another cautionary note to the extrapolation of dynamic behavior from static uptake studies. For the downstream processing of relatively large protein molecules, such as $\mathrm{mAb}$, pore size may be more critical than the static binding capacity, especially for preparative purpose when high dynamic binding capacity is desired.

\subsection{List of symbols}

C protein concentration in solution $(\mathrm{mg} / \mathrm{mL})$ 
$C_{\mathrm{Na}^{+}}$concentration of sodium ion in solution phase during titration $(\mathrm{mmol} / \mathrm{mL})$

$C_{H^{+}} \quad$ concentration of proton in solution phase during titration $(\mathrm{mmol} / \mathrm{mL})$

$D_{e} \quad$ effective pore diffusivity $\left(\mathrm{cm}^{2} / \mathrm{s}\right)$

$D_{0} \quad$ free solution diffusivity $\left(\mathrm{cm}^{2} / \mathrm{s}\right)$

$K_{a} \quad$ dissociation constant of carboxyl group in resin phase

$K_{D} \quad$ partition coefficient in SEC

$K \quad$ parameter in Langmuir isotherm $(\mathrm{mL} / \mathrm{mg})$

$q \quad$ bound protein concentration $(\mathrm{mg} / \mathrm{mL})$

$q_{C}^{\prime} \quad$ total carboxyl group concentration in the resin $(\mathrm{mmol} / \mathrm{mL}$ resin solid)

$q_{\text {COO }}^{\prime}$ concentration of deprotonated carboxyl groups in the resin $(\mathrm{mmol} / \mathrm{mL}$ resin solid)

$q_{N a^{+}}^{\prime} \quad$ concentration of sodium ion in the resin ( $\mathrm{mmol} / \mathrm{mL}$ resin solid)

$q_{m} \quad$ parameter in Langmuir isotherm $(\mathrm{mg} / \mathrm{mL})$

$r_{h} \quad$ hydrodynamic radius of size standards $(\mathrm{nm})$

$r_{p} \quad$ particle radius $(\mathrm{cm})$

$r_{\text {pore }}$ pore radius $(\mathrm{nm})$

$r_{p o r e, m}$ radius of small pores $(\mathrm{nm})$

$r_{p o r e, M}$ radius of large pores (nm)

$r_{s} \quad$ radius of adsorption front in CLSM image

$V_{R} \quad$ retention volume at peak maximum of size standards

$V_{C} \quad$ column volume

$\varepsilon \quad$ extraparticle column porosity

$\varepsilon_{p} \quad$ intraparticle porosity 
$\varepsilon_{p, m} \quad$ intraparticle porosity associated with small pores

$\varepsilon_{p, M} \quad$ intraparticle porosity associated with large pores

$\rho_{s} \quad r_{s} / r_{p}$, the dimensionless position of the adsorption front

\subsection{Reference}

[1] W.S. Hancock, J.T. Sparrow, Use of mixed-mode, high-performance liquid chromatography for the separation of peptide and protein mixtures, J. Chromatogr. 206 (1981) 71-82.

[2] L. Kennedy, W. Kopaciewicz, F. Regnier, Multimodal liquid chromatography columns for the separation of proteins in either the anion-exchange or hydrophobic-interaction mode, J. Chromatogr. A. 359 (1986) 73-84.

[3] W.K. Chung, A.S. Freed, M. a Holstein, S. a McCallum, S.M. Cramer, Evaluation of protein adsorption and preferred binding regions in multimodal chromatography using NMR., Proc. Natl. Acad. Sci. U. S. A. 107 (2010) 16811-6.

[4] Y. Hou, S.M. Cramer, Evaluation of selectivity in multimodal anion exchange systems: a priori prediction of protein retention and examination of mobile phase modifier effects., $\mathrm{J}$. Chromatogr. A. 1218 (2011) 7813-20.

[5] K. Kallberg, K. Becker, L. Bülow, Application of a $\mathrm{pH}$ responsive multimodal hydrophobic interaction chromatography medium for the analysis of glycosylated proteins, $\mathrm{J}$. Chromatogr. A. 1218 (2011) 678-683.

[6] A. Hirano, T. Arakawa, T. Kameda, Interaction of arginine with Capto MMC in multimodal chromatography., J. Chromatogr. A. 1338 (2014) 58-66.

[7] D. Gao, D.-Q. Lin, S.-J. Yao, Mechanistic analysis on the effects of salt concentration and $\mathrm{pH}$ on protein adsorption onto a mixed-mode adsorbent with cation ligand., J. Chromatogr. B. Analyt. Technol. Biomed. Life Sci. 859 (2007) 16-23. 
[8] K. a Kaleas, M. Tripodi, S. Revelli, V. Sharma, S. a Pizarro, Evaluation of a multimodal resin for selective capture of CHO-derived monoclonal antibodies directly from harvested cell culture fluid., J. Chromatogr. B. 969 (2014) 256-63.

[9] J. Pezzini, G. Joucla, R. Gantier, M. Toueille, A.-M. Lomenech, C. Le Sénéchal, et al., Antibody capture by mixed-mode chromatography: a comprehensive study from determination of optimal purification conditions to identification of contaminating host cell proteins., J. Chromatogr. A. 1218 (2011) 8197-208.

[10] M.T. Tyn, T.W. Gusek, Prediction of diffusion coefficients of proteins, Biotechnol. Bioeng. 35 (1990) 327-338.

[11] E.X. Pérez Almodóvar, Y. Tao, G. Carta, Protein adsorption and transport in cation exchangers with a rigid backbone matrix with and without polymeric surface extenders., Biotechnol. Prog. 27 (2011) 1264-72.

[12] M.C. Stone, G. Carta, Protein adsorption and transport in agarose and dextran-grafted agarose media for ion exchange chromatography., J. Chromatogr. A. 1146 (2007) 202-15.

[13] M. Heidelberger, K.O. Pedersen, THE MOLECULAR WEIGHT AND ISOELECTRIC POINT OF THYROGLOBULIN., J. Gen. Physiol. 19 (1935) 95-108.

[14] R.B. Bird, W.E. Stewart, E.N. Lightfoot, Transport Phenomena, John Wiley \& Sons, 1960.

[15] T.M. Pabst, G. Carta, $\mathrm{pH}$ transitions in cation exchange chromatographic columns containing weak acid groups., J. Chromatogr. A. 1142 (2007) 19-31.

[16] G. Carta, A.R. Ubiera, T.M. Pabst, Protein mass transfer kinetics in ion exchange media: Measurements and interpretations, Chem. Eng. Technol. 28 (2005) 1252-1264. 
[17] E.X. Perez-Almodovar, Y. Wu, G. Carta, Multicomponent adsorption of monoclonal antibodies on macroporous and polymer grafted cation exchangers., J. Chromatogr. A. 1264 (2012) 48-56.

[18] M. Zhu, G. Carta, Adsorption of polyethylene-glycolated bovine serum albumin on macroporous and polymer-grafted anion exchangers., J. Chromatogr. A. 1326 (2014) 29-38. [19] J.M. Reck, T.M. Pabst, A.K. Hunter, X. Wang, G. Carta, Adsorption equilibrium and kinetics of monomer-dimer monoclonal antibody mixtures on a cation exchange resin., J. Chromatogr. A. 1402 (2015) 46-59.

[20] L. Hagel, M. Östberg, T. Andersson, Apparent pore size distributions of chromatography media, J. Chromatogr. A. 743 (1996) 33-42.

[21] P. DePhillips, A.M. Lenhoff, Pore size distributions of cation-exchange adsorbents determined by inverse size-exclusion chromatography, J. Chromatogr. A. 883 (2000) 39-54. [22] Y. Wu, J. Simons, S. Hooson, D. Abraham, G. Carta, Protein and virus-like particle adsorption on perfusion chromatography media, J. Chromatogr. A. 1297 (2013) 96-105.

[23] F.G. Helfferich, Ion Exchange, Courier Corporation, 1962.

[24] G. Carta, A. Ubiera, Particle-size distribution effects in batch adsorption, AIChE J. 49 (2003) 3066-3073.

[25] D.M. Ruthven, Principles of Adsorption and Adsorption Processes, John Wiley \& Sons, 1984.

[26] R.S. Cooper, D.A. Liberman, Fixed-Bed Adsorption Kinetics with Pore Diffusion Control, Ind. Eng. Chem. Fundam. 9 (1970) 620-623. 


\section{Chapter 6}

\section{Concluding Remarks}

\subsection{Conclusions}

This study has examined the physical and functional properties of a series of new and improved stationary phases for protein chromatography based on a relatively rigid macroporous matrix formed by acrylamide and vinyl copolymers and known as UNOsphere. Two kinds of interaction chemistries have been studied: anion exchangers with a range of grafted polymeric surface extender and a multimodal cation exchanger.

The polymer grafted anion exchanger with moderate grafted polymer content, Nuvia HR Q, and with high grafted polymer content, Nuvia Q, contain smaller pore volumes compared to the macroporous anion exchanger, UNO Q, characterized by neutral macromolecules probes and TEM. However, enhanced chromatographic retention, adsorption capacity, and adsorption kinetics are found for both native BSA and PEGylated BSA on Nuvia HR Q and Nuvia Q, as a result of interactions with the grafted polymers. Images of intraparticle bound protein concentration profiles obtained by confocal scanning laser microscopy show that the transport mechanisms are very different in macroporous resin and polymer-grafted resin. The protein binding kinetics are dominated by ordinary pore diffusion and are essentially independent of the direction of transport for UNO Q as a result of its large pore size. On the other hand, the protein binding kinetics in polymer-grafted resin are consistent with a solid diffusion mechanism driven by the bound protein concentration. For these materials, protein transport is very fast for one component adsorption of BSA and PEGylated BSA. Different multicomponent behavior are found for Nuvia HR Q and Nuvia Q, due to the difference in the grafted polymer content and the 
correlated pore size. For Nuvia HR Q, BSA and 10 KD PEG-BSA can counter diffuse freely similar as in UNO Q but for Nuvia Q the counter diffusion is highly hindered by the long grafted polymer. The last part of this work studied an unexpected adsorption behavior of thyroglobulin, a very large protein whose size is comparable to the length of the grafted polymer in Nuvia HR Q. Lower binding capacities and slow transport kinetics are found for the thyroglobulin adsorption in Nuvia HR Q under strong binding condition, attributing to the very small mobility of bound thyroglobulin molecules in the relatively short grafted polymers. Higher ionic strength is found to enhance the transport rate as well as increase the binding capacity by reducing the interaction strength of bound protein molecules and the charged ligand on the grafted polymers.

Protein adsorption equilibrium and kinetics for the multimodal cation exchange resins, Nuvia cPrime, have been studied and compared with another multimodal resin Capto MMC, which is based on an agarose matrix. In both resins, the ligand contains a phenyl group, a carboxyl group, and peptide group but with a different arrangement. TEM and inverse size exclusion chromatography indicate a bimodal distribution of pores in Nuvia cPrime, including small pores with $10 \mathrm{~nm}$ radius and pores larger than $400 \mathrm{~nm}$, similar to $\mathrm{UNO}$ Q, and a monodispersed distribution of pores in Capto MMC, averaging $32 \mathrm{~nm}$ in radius. Potentiometric titration curves show similar buffering ranges and $p K_{a}$ values for the ligand in both resins and a slightly higher ligand density for Nuvia cPrime. Both resins also have a similar trend of equilibrium binding capacities with regard to effects of $\mathrm{pH}$ and salt concentration for lysozyme and a monoclonal antibody $(\mathrm{mAb})$. Capto MMC shows greater salt tolerance across a range of $\mathrm{pH}$ as a result of the more easily accessible phenyl group in the ligand. The transport mechanisms are pore diffusion controlling for both resins elucidated by confocal results. However, binding kinetics of the $\mathrm{mAb}$, which is larger of the two proteins studies, is very different on these two resins. The rate of mass 
transfer is much smaller in Capto MMC at $\mathrm{pH}$ values of 5 or 6 because of the smaller pores. As a result, much smaller column dynamic binding capacities are obtained for this resin.

In general, this study helps to design better stationary phases and chromatographic processes. Chromatographic process is always an optimization between many factors such as capacity, transport rate, and scalability. A better understanding of the properties of stationary phase, as well as protein adsorption and transport on the representative stationary phase type, is important in the rational design of chromatographic process and will lead to more effective optimization process. Research on anion exchangers showed that polymer grafted material can be used for capture steps where high adsorption capacities and kinetics are needed. However, proper grafted polymer content and buffer condition are required according to the protein properties during implementation. Research on multimodal resin proposed a model that described the ligand charge response to $\mathrm{pH}$, which is useful in the prediction of $\mathrm{pH}$ gradient elution using similar materials. The study also showed pore size may be more critical than static binding capacity during the downstream processing of relatively large protein molecules.

\subsection{Recommendations}

\subsubsection{Polymer grafted anion exchangers}

Based on the results of the polymer grafted anion exchangers, following recommendations can be made for the future work.

A more comprehensive understanding of the effect of ionic strength can be obtained by studying both BSA and thyroglobulin adsorption equilibrium and kinetics at a wider range of ionic strength. An optimized ionic strength should exist for both small and large protein molecules which may vary with the grafted polymer content. 
The measurement of dynamic binding capacities of thyroglobulin on polymer grafted anion exchangers at different ionic strength via breakthrough experiments is useful. The results can be compared with batch uptake results and confocal microscopy results, to better understand the transport mechanisms. Also from a practical viewpoint, the dynamic binding capacity is crucial in the protein chromatography for industrial production and is worth to look into.

The multicomponent binding behavior of thyroglobulin along with a small molecule (say BSA) is also interesting to look at since in the purification step a combination of different sized proteins is usually present. All these studies could provide further information to improve the performance of the polymer grafted materials in the purification of large biomolecules.

Another recommendation for the future work is to study the adsorption behavior of nuclei acid on these materials. Under neutral $\mathrm{pH}$, nucleic acid molecules are negatively charged. They usually bind strongly to the anion exchangers. The transport mechanisms of linear shaped nucleic acid molecules in polymer grafted materials is not known. How would they compete with the protein binding is also not clear. This study could provide further information for the application of polymer grafted materials in DNA/RNA removal process.

\subsubsection{Multimodal cation exchanger}

Based on the results of the multimodal cation exchangers, following recommendations can be made for the future work.

Adsorption equilibrium studies in this work showed that the protein adsorption behaviors under different $\mathrm{pH}$ values were very different for the multimodal resins. Hence, implementation of $\mathrm{pH}$ gradient elution using these resins could be efficient in the separation of biomolecules that are often difficult to purify, for example, the charge variants of monoclonal antibody. The gradient can be either introduced by the buffer gradient outside the column or induced $\mathrm{pH}$ 
gradient generated by the weak cation group in the ligand. Elution on HIC resins and cation exchange resins containing same chemical moieties could be served as comparisons for the resolution.

It is also useful to incorporate Nuvia Cprime with grafted polymer for a higher binding capacity as well as a faster transport rate. The influence of grafted polymer on multimodal resin can be tricky since the binding strength of protein and the multimodal ligand can be very strong. The mobility in the grafted polymer is then slow resulting in slow transport rate instead. Hence the careful design of the stationary phase in regards to the ligand density and the polymer content is important and the effects of salt and $\mathrm{pH}$ should be understood to find proper binding and eluting conditions. 